University of Redlands

\title{
Translating Monsoon Event Precipitation into Rainfall Estimates for Joshua Tree National Park
}

A Major Individual Project submitted in partial satisfaction of the requirements

for the degree of Master of Science in Geographic Information Systems

$$
\text { by }
$$

Abigail Lynn Gleason

Ruijin Ma, Ph.D., Committee Chair

Mark Kumler, Ph.D.

August 2013 
Translating Monsoon Event Precipitation into Rainfall Estimates for Joshua Tree National Park

Copyright (C) 2013

by

Abigail Lynn Gleason 
The report of Abigail Lynn Gleason is approved.

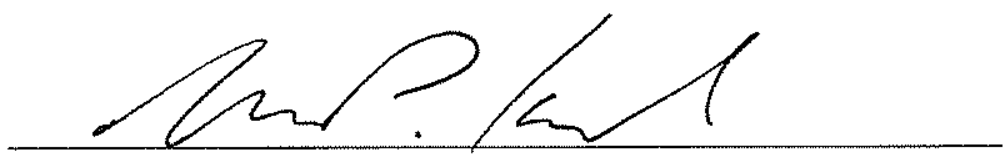

Mark Kumler, Ph.D.

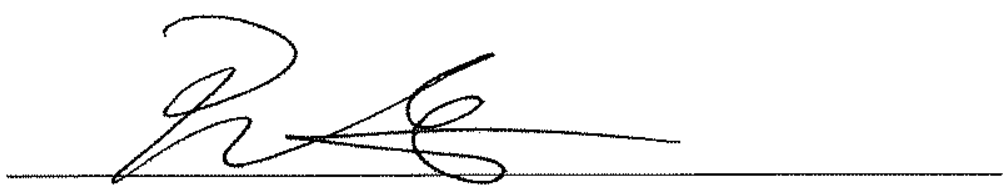

Ruijin Ma, Ph.D., Committee Chair

August 2013 



\section{Acknowledgements}

So many people helped me get through this program! First I need to thank NGA, who gave me the opportunity to expand my education. This was a truly amazing experience, and I'm very grateful to have been given the chance. I also need to thank my coworkers, who encouraged me along the way.

I would like to thank my advisor, Dr. Ruijin Ma, for keeping me on track, being patient, and helping me work out many issues. I would also like to thank the entire MS GIS faculty for their support and willingness to answer any questions. And special thanks to Debbie Riley for making sure this program ran smoothly, for listening when I just needed a break to talk, and for stocking the candy jar.

I'm grateful to the entire adjunct faculty, who taught some wonderful and unique courses. Specifically, I would like to thank Mark Stewart, Pinde Fu, Dean Djokic, and Nate Strout for all of their help. I would also like to thank my client, Mr. Sean Murphy, and Joshua Tree National Park for providing data, guidance and the opportunity.

I would like to thank my family. Through geography, this program has allowed me to live closer to my family than I have in several years, and their support has been immeasurable. My parents' love and encouragement have always been there no matter what path I find myself on, and I will always be so grateful to have them. I also want to specifically thank my grandfather, who passed away this year, for teaching me so much and always believing in me.

Finally, I'm thankful to Cohort 22. The Cohort of Awesomeness! We worked through this program together and really supported each other. These people became great friends and I'm grateful to have been with them throughout this year. 


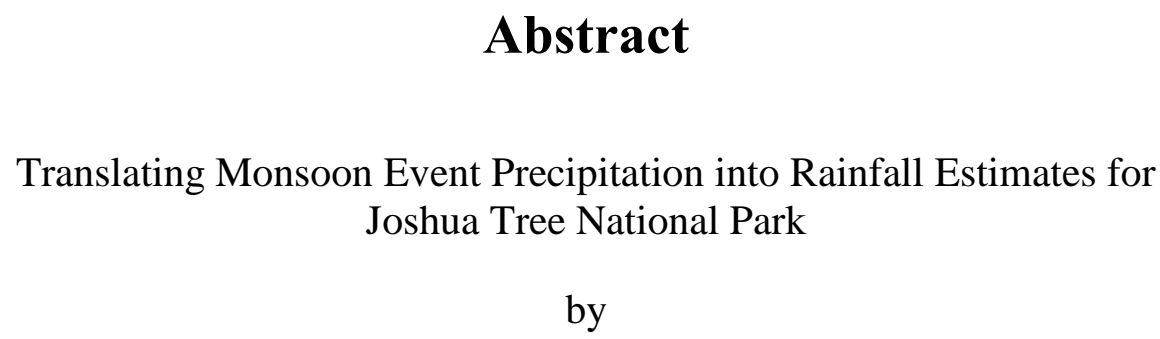

Abigail Lynn Gleason

Due to the remote nature of Joshua Tree National Park, few direct measurements of precipitation exist. This is especially true of summer monsoon events, which are localized and discrete yet provide all of the summer rainfall for the region. These events have an impact on wildlife, vegetation, and infrastructure. This project incorporated NEXRAD WSR-88D Level II data into a GIS environment to process rainfall events in order to enhance the park's monitoring capability. An empirical relationship was derived to produce rainfall estimates from radar reflectivity data more accurately for the region. A toolset was developed within ArcGIS to automatically reformat and process NEXRAD datasets to produce precipitation data for monsoon events, with rainfall locations and amounts. This toolset also included methods to provide information on the amount of runoff, infiltrated water, and accumulated water volume produced from a precipitation event. These products can be fully integrated with vegetation information, facilities, and infrastructure locations for vegetation habitat modeling and infrastructure management. 



\section{Table of Contents}

Chapter 1 - Introduction ......................................................................................... 1

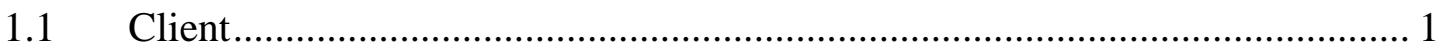

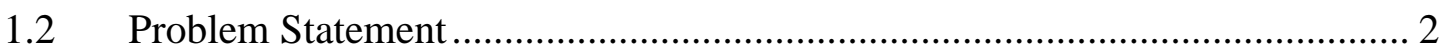

1.3 Proposed Solution ……………………………….................................. 3

1.3.1 Goals and Objectives ............................................................................... 4

1.3.2 Scope

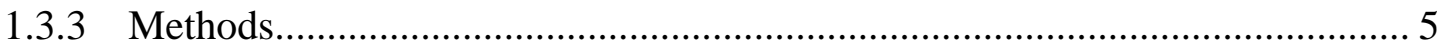

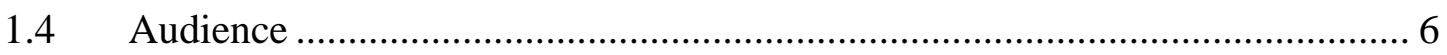

1.5 Overview of the Rest of This Report .......................................................

Chapter 2 - Background and Literature Review ............................................................... 9

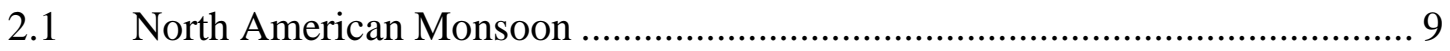

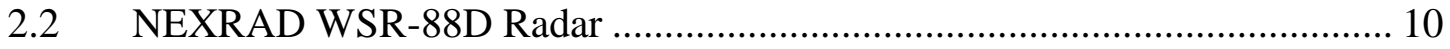

2.2.1 NEXRAD Precipitation Estimation ............................................................. 13

2.2.2 NEXRAD and GIS - Previous Work...................................................... 17

2.3 Precipitation - Runoff Models ................................................................ 19

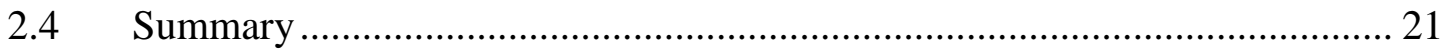

Chapter 3 - Systems Analysis and Design......................................................................... 23

3.1 Problem Statement ................................................................................... 23

3.2 Requirements Analysis ........................................................................... 23

3.3 System Design ............................................................................... 25

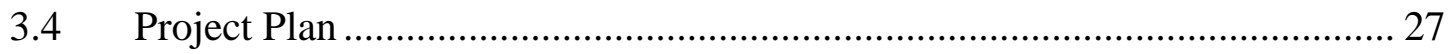

3.5 Summary ………………………......................Error! Bookmark not defined. 
Chapter 4 - Database Design...................................................................................................... 31

4.1 Conceptual Data Model ............................................................................ 31

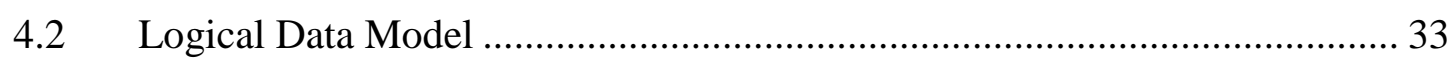

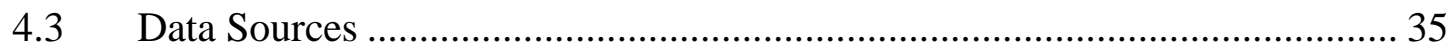

4.4 Data Scrubbing and Loading ………………………............................... 38

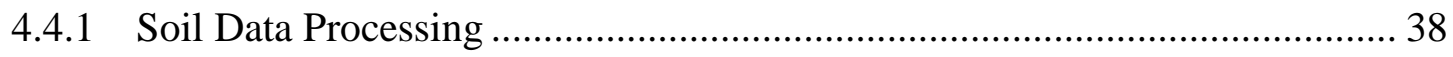

4.4.2 Land Cover Processing ............................................................................ 39

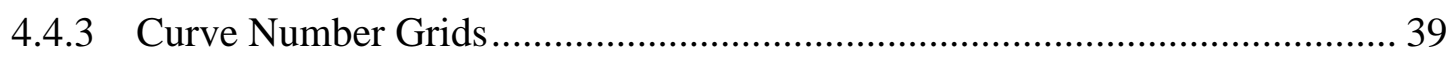

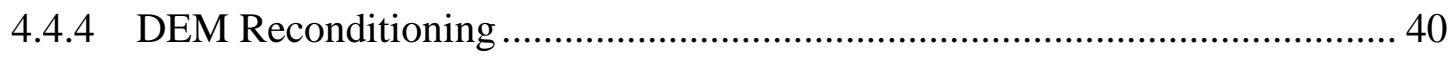

4.4.5 NEXRAD Radar Data Reformatting ……………........................................ 42

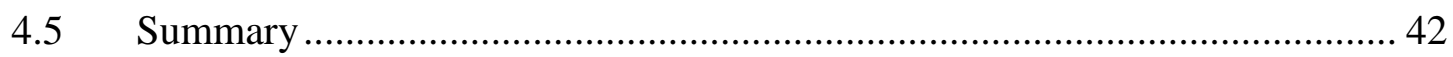

Chapter 5 - Implementation................................................................................................... 43

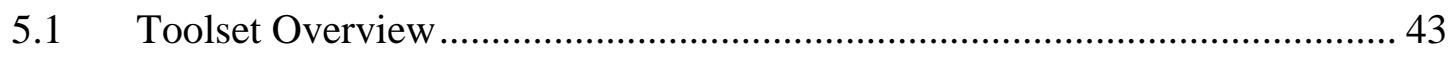

5.2 NEXRAD Level II Conversion Tool ............................................................. 46

5.3 National Weather Service Precipitation Tool ……………………………..... 51

$5.4 \quad$ Runoff-Water Infiltration Tool ................................................................... 54

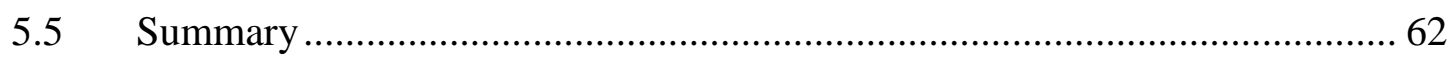

Chapter 6 - Results and Analysis.......................................................................................... 63

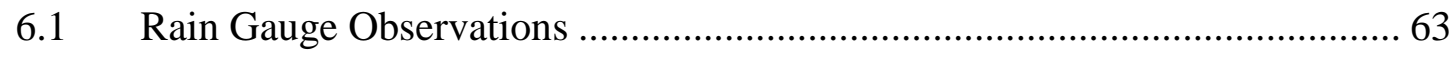

6.2 National Weather Service Precipitation Data ……………............................... 65

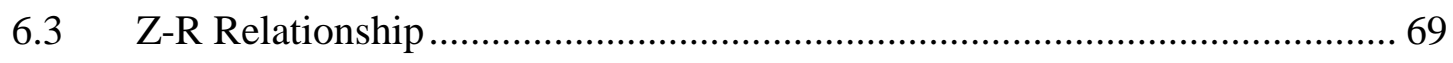

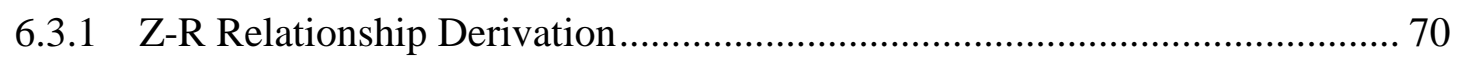

6.3.2 Regional Z-R Relationship for Joshua Tree National Park ........................... 70 


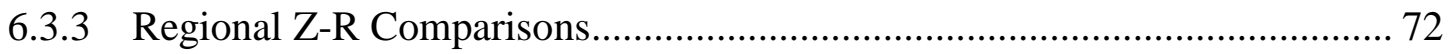

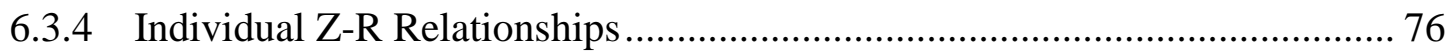

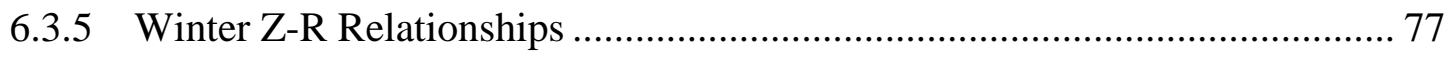

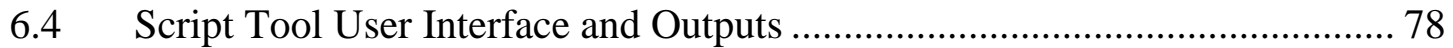

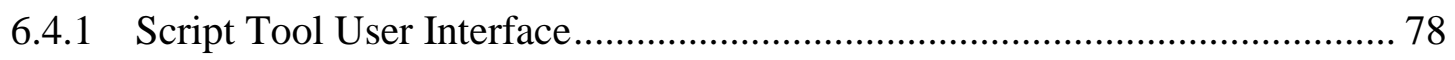

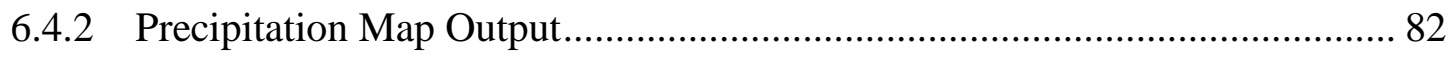

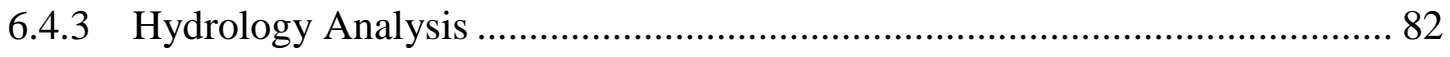

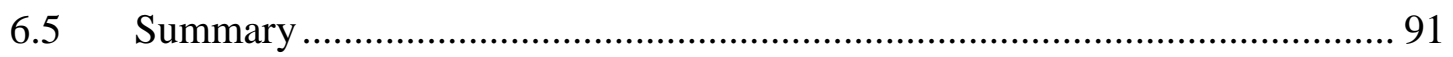

Chapter 7 - Conclusions and Future Work ............................................................93

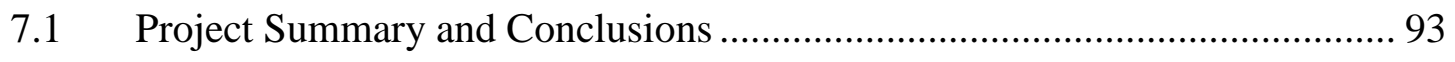

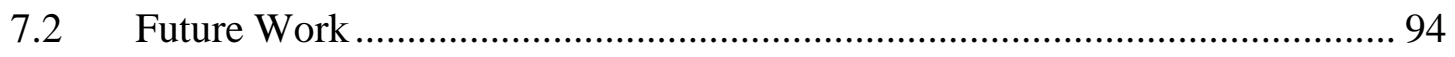

Works Cited

Appendix A. Geodatabase Schema.................................................................. 101

Appendix B. Rainfall Comparison Tables............................................................... 102

Appendix C. Python Scripts...................................................................................... 109 



\section{Table of Figures}

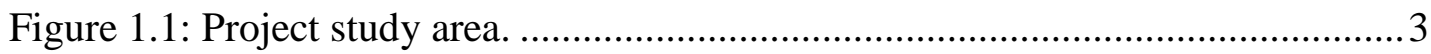

Figure 3.1: System Design..............................................26

Figure 3.2: Original project timeframe and schedule ........................................27

Figure 4.1: Conceptual model UML diagram ................................................... 32

Figure 4.2: Logical model and geodatabase architecture.........................................34

Figure 4.3: Example collection capabilities at nearby radar sites ............................. 36

Figure 4.4: CN grid generated from ARC II values.......................................... 40

Figure 5.1: Overview of the toolset workflow .................................................... 44

Figure 5.2: NEXRAD Level II Conversion tool process and workflow...................47

Figure 5.3: Example NEXRAD Level II Conversion tool output ...........................50

Figure 5.4: Processing workflow for the NWS Precipitation tool................52

Figure 5.5: Example output product from the NWS Precipitation tool .....................54

Figure 5.6: Runoff and Infiltration process workflow......................56

Figure 5.7: Potential runoff generated from NEXRAD Level II data .......................58

Figure 5.8: Infiltrated water output from NEXRAD Level II data ..........................59

Figure 5.9: Accumulated runoff output from NEXRAD Level II data......................61

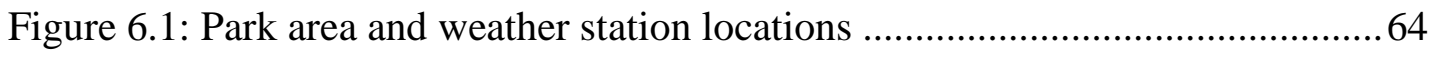

Figure 6.2: Comparison between precipitation datasests.....................................6 68

Figure 6.3: Fitting NEXRAD Level II reflectivity data to rain gauge data ..............72

Figure 6.4: Comparison between regional Z-R estimates..................................... 75

Figure 6.5: NEXRAD Level II conversion tool graphical user interface ................. 79

Figure 6.6: NWS Precipitation Conversion tool graphical user interface .................80 
Figure 6.7: User interface for the runoff and infiltration calculation tool.

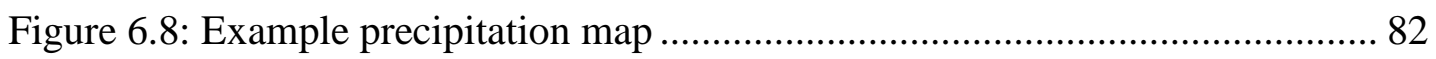

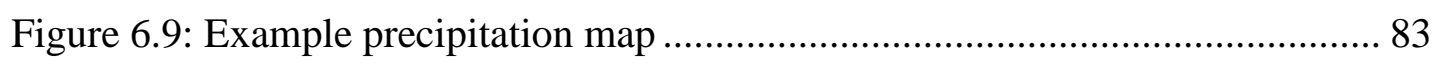

Figure 6.10: Example of maximum potential water infiltration output ................... 84

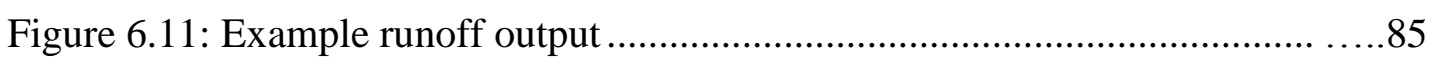

Figure 6.12: Runoff discrepancies between two soil datasets...................86

Figure 6.13: Example of a precipitation map for September 13, $2011 \ldots \ldots \ldots \ldots \ldots . . .87$

Figure 6.14: Northern road damage....................................... 88

Figure $6.15:$ Southern road damage....................................... 89

Figure 6.16: Example accumulated runoff output $\ldots \ldots \ldots \ldots \ldots \ldots \ldots \ldots \ldots \ldots \ldots$ 


\section{List of Tables}

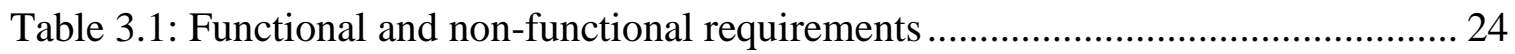

Table 4.1: Dataset sources and format information................................ 37

Table 6.1: Example monsoon event rain gauge totals............................65

Table 6.2: Example NWS precipitation data compared to rain gauge observations......66

Table 6.3: Comparison between rain gauge observations and estimates.................71

Table 6.4: Estimates from regional Z-R relationships...........................73

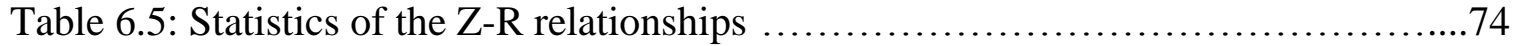

Table 6.6: Individual station Z-R relationships...............................76

Table 6.7: Comparing park-wide Z-R relationships to local relationships...............77

Table A-1: Rain gauge observations.......................................... 98

Table A-2: Rain gauge observations compared to regional Z-R relationship............99

Table A-3: Rain Gauge observations compared multiple regional Z-R relationships....101 



\title{
List of Acronyms and Definitions
}

\author{
ARC - Antecedent Rainfall Condition \\ $\mathrm{CN}$ - Curve Number \\ DEM - Digital Elevation Model \\ GIF - Graphics Interchange Format \\ GIS - Geographic Information System \\ GOES - Geostationary
}

GUI - Graphical User Interface

HEC-HMS - Hydrologic Engineering Center Hydrologic Modeling System

HRAP - Hydrologic Rainfall Analysis Project

JTNP - Joshua Tree National Park

NAD 83 - North American Datum 1983

NCDC - National Climatic Data Center

NEXRAD- NEXt generation RADar

NIDS - NEXRAD Information Dissemination Service

NLCD - National Land Cover Database

NRCS - Natural Resources Conservation Service

NWS - National Weather Service

SCS - Soil Conservation Service

SSURGO - Soil SURvey GeOgraphic Database

STATSGO - STATe Soil GeOgrahic Database

TIFF - Tagged Image File Format

USDA - United States Department of Agriculture 
USGS - United States Geological Survey

UTM - Universal Transverse Mercator

WCT - Weather and Climate Toolkit

WSR 88D - Weather Surveillance Radar 1988 Doppler 


\section{Chapter 1 - Introduction}

Precipitation is vital for all ecological systems, but it is especially vital for desert regions where rain events can be particularly sparse and dramatic. This is true for Joshua Tree National Park, which experiences short lived yet intense monsoon events in the summer. This project focused on developing methods, models, and tools for determining the amount of precipitation associated with desert monsoon events over the various regions

of park. Weather radar data were employed to develop reflectivity and precipitation into rainfall totals. The tools developed through this project were given to Joshua Tree National Park for use by park biologists to help model the impact of these storms on the environment, as well as to park management to help address potential damage after storm events occur.

\subsection{Client}

The client for this project was Joshua Tree National Park (JTNP). Mr. Sean Murphy, a GIS Specialist at JTNP, served as the main point of contact for the project and provided several primary datasets that aided in the completion of this project. In particular, he provided rain gauge data for the park and a Digital Elevation Model (DEM). The client also provided several secondary datasets that were included in a geodatabase to be used in conjunction with precipitation maps. The client also helped lay out the final requirements for the project's success and completion. 


\subsection{Problem Statement}

Desert monsoon events are often dramatic, lasting only minutes but potentially producing several inches of rain at a time, and occur over small, localized areas. Estimating precipitation amounts for these storms is challenging and often no direct precipitation amounts can be modeled from these short lived events. This is especially true for JTNP, as it currently has only three widely dispersed rain gauges within the park's nearly 800,000 acres (see Figure 1) (S. Murphy, personal communication, Oct. 11, 2012). Park biologists wanted to understand how monsoon events affect the local plant environment and wildlife. Park management also needed to know where rain events had occurred in the park, as these events sometimes lead to flash flooding, which can have damaging effects on roads and infrastructure (S. Murphy, personal communication, Oct. 11, 2012). At the beginning of this project, however, there was no accurate way of locating rain events within the park. Therefore, a tool was needed to generate precipitation maps, as well as a tool that could estimate the potential impact to the park. 


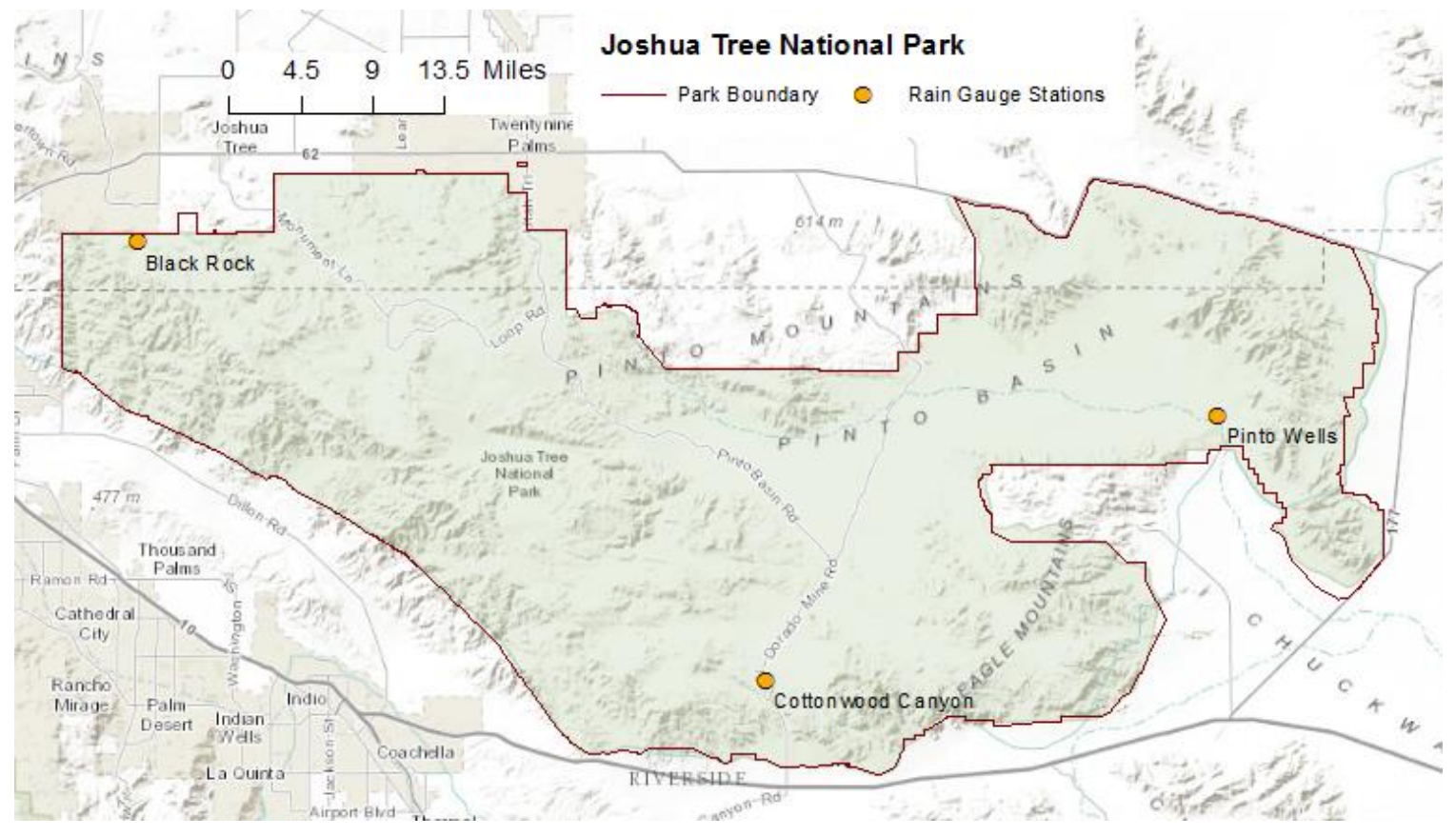

Figure 1.1: Joshua Tree National Park, the study area for this project. The three rain gauge stations with rain gauges are also shown.

\subsection{Proposed Solution}

Since monsoon precipitation patterns within JTNP are unknown, the ecological systems that depend on these processes are not well understood. To help address this problem, this project focused on developing a precipitation toolset that processes Weather Surveillance Radar 1988 Doppler (WSR-88D) data, more commonly known as NEXRAD (for NEXt Generation RADar), and produces precipitation maps. The toolset is accessed by a Graphical User Interfaces (GUI) in ArcMap 10.1, which facilitates the use by JTNP employees. This project also developed a simple hydrological model which, used in conjunction with the precipitation products, gives an estimation of the runoff and volume of surface water produced by a storm event. 


\subsubsection{Goals and Objectives}

The primary goal of this project was to produce precipitation maps that give the location and amount of rainfall for each monsoon event within the park. Specifically, the goal was to design and build a set of scripts and models that could decode and process NEXRAD products automatically. These scripts would also reformat, georeference, reproject, and clip the radar datasets to the boundaries of JTNP. The resultant precipitation maps would be produced as stand-alone products, but could also serve as an input for a simple hydrologic model, as well as be capable of interfacing with any of the map products produced by park employees.

For ease of usability, a major objective was to design the scripts and models to be accessed through a GUI in ArcMap 10.1. This would facilitate the use and interpretability of the precipitation toolset by park employees with cursory GIS knowledge and other primary responsibilities. It was an objective to deliver a geodatabase as well, to serve as a solution for organizing the precipitation products and information and to serve as a template database for future weather monitoring.

\subsubsection{Scope}

The requirements for this project were to produce an automated processing tool that generates precipitation maps with an estimate of or where precipitation has occurred within the park. In order to achieve these basic requirements, the major components generated for this project were a script that converts the NEXRAD data into a usable format as well as clips and projects the data to the area of interest and provides an easyto-use graphical user interface. The outputs of these components are the precipitation maps. Other components that were considered to meet these basic requirements were 
multiple types of NEXRAD data and the options for using other precipitation sources, such as data from the Parameter-Elevation Regressions on Independent Slopes Model (PRISM). In order to produce the most accurate precipitation estimates for JTNP, an analysis portion of this project was developed to compare rain gauge observations from within the park to NEXRAD derived precipitation estimates. At the completion of this project, two tools were delivered to produce precipitation maps: the NEXRAD Level II conversion tool and a National Weather Service (NWS) precipitation tool.

For ecological modeling, the users needed to know where surface water collected and travelled after a monsoon event. Therefore, development of a simple hydrological model also fell within the scope of this project. This model was developed using a $5 \mathrm{~m}$ DEM, soil data, and the precipitation maps as input.

\subsubsection{Methods}

In order to develop the precipitation map scripts, two NEXRAD datasets were collected and utilized: Level II reflectivity data, and NWS precipitation data. These datasets were downloaded from National Climatic Data Center (NCDC) NEXRAD Data Inventory Search or the Advanced Hydrologic Prediction Service. These datasets were delivered in a NEXRAD Information Dissemination Service (NIDS) binary format or a Hydrologic Rainfall Analysis Project (HRAP) format and had to be converted to a vector or gridded format in order to be incorporated into ArcMap 10.1. A conversion tool was developed by NOAA, in the form of an executable .bat file. This tool was incorporated into the precipitation map script for this project in order to automatically perform the conversion. This script also converts reflectivity units to rainfall rates, using the Z-R relationship 
developed from the analysis performed for this project described below. The script then sums the rainfall totals, clips, and re-projects the resulting map.

The analysis for this project compared precipitation totals observed from rain gauge data within the park to NEXRAD reflectivity data and NEXRAD precipitation data. This was to ensure the results from the precipitation map script were accurate and customized to JTNP's region. To determine the best fitting relationship to convert reflectivity data to rainfall rate, a curve estimation technique was utilized. The data were also analyzed based on the season and location to determine if this relationship changes, remains constant, or varies.

The output from the precipitation map script produced the input for the hydrologic model. This model also utilized a 5m DEM (provided by the primary contact at the park), soil component data, and derived rain-runoff coefficients for soil types within the park. These inputs were used to develop flow direction and volume estimates.

\subsection{Audience}

The primary audience for this project is the end users - the employees at Joshua Tree National Park who utilize the tools and capabilities produced and delivered as a result of this project. These employees encompass two groups of users with two interests: park biologists who are interested in where monsoon rain is occurring and how it is affecting those ecosystems, and if those ecosystems are changing in response; and facility management and GIS personnel who are interested in whether flash floods after monsoon events damage roads and infrastructure. 
That being said, there is a secondary audience for this project: other GIS

professionals who are interested in precipitation data and about the methods and data collection techniques presented in this project.

\subsection{Overview of the Rest of This Report}

The rest of this report is broken into six chapters that address the components of this project in more detail. Chapter Two is concerned with the literature review that was completed in order to fully understand and address the problem. Monsoon rain events, the use and errors of radar data for precipitation derivation, and hydrologic modeling are examined. Chapter Three outlines the system and design, relating the project requirements and how the problem was approached and solutions were developed.

Chapter Four outlines the conceptual and logical models, as well as the development of the database design and how the input data and resulting processed data were organized for the client. Chapter Five describes the project implementation. Chapter Six describes the analysis, methods, and results for this project. Finally, Chapter Seven summarizes the work completed and discusses potential future directions and endeavors to further this work. 



\section{Chapter 2 - Background and Literature Review}

This project focused on determining where and how much precipitation falls over Joshua Tree National Park, particularly during the Monsoon season. To put this work into a broader context, this chapter begins with a discussion of the North American Monsoon. From the onset of this project, the tools have been developed with NEXRAD data as they have the highest available resolution, can be downloaded in near real time, and cover the entire park. Given this decision, it was important to understand how radar remote sensing works, how NEXRAD data is collected and processed, and some of the limitations and challenges involved. This chapter discusses these topics and gives an overview of how NEXRAD data is used to estimate precipitation. Several studies that investigated the use and performance of NEXRAD precipitation estimates are presented. The hydrologic impact of each storm was also of concern for this project; therefore, the topic of hydrologic modeling is also discussed and studies that incorporate NEXRAD data in hydrologic models are presented.

\subsection{North American Monsoon}

The storm events that this project concentrated on were the "monsoon" events that occur each summer. These events are associated with a larger seasonal climatic process known as the North American Monsoon. While a detailed overview of the processes involved is beyond the scope of this review, a general summary that places the area of interest, Joshua Tree National Park (JTNP), in the larger context of this phenomenon is applicable. A comprehensive examination of the North American Monsoon is given by Adams and Comrie (1997). During the summer months of June to mid-September, a 
pressure contrast moves cooler air masses above the Gulfs of California and Mexico over the heated surfaces above northwestern Mexico and the southwestern U.S., driving a moisture surge in the lower and upper troposphere. The precipitation from this moisture is mainly concentrated over northern Mexico and becomes more variable over the southwestern U.S. Even so, much of the summer rainfall in this region is attributed to this monsoon pattern. Tubbs (1972) described summer rainfall events in southern California as humid air masses from the southeast that result in thunderstorms over the mountainous regions. These events begin abruptly in July and gradually diminish in September, but have a similar frequency to monsoon events in Arizona, where the phenomenon is more widely known.

\subsection{NEXRAD WSR-88D Radar}

While monsoon events over JTNP are the primary motivation for this project, the data used to analyze these events and their impacts were derived from weather radar. A brief review of radar characteristics and how rainfall is derived from radar is therefore appropriate for this discussion.

Radar (Radio Detection and Ranging) is an active remote sensing system that transmits microwave radiation at a certain wavelength and receives the returned signal. Weather radar measures the amount of returned energy from precipitation particles in the air, given the supposition that rain particles are uniquely subject to Rayleigh scattering at the wavelength of the radar signal (Muller, n.d.; Hunter, 2009). The returned power of the signal is measured by the radar equation:

$$
P_{r}=\frac{\pi^{3} P_{t} g^{2} \theta \varphi c t|K|^{2} l z}{1024 \ln (2) \lambda^{2} r^{2}}
$$

where $P_{r}=$ the returned energy of the signal 


$$
\begin{aligned}
& P_{t}=\text { the amount of transmitted energy } \\
& G=\text { the gain of the particular radar } \\
& \theta=\text { the horizontal beam width } \\
& \varphi=\text { the vertical beam width } \\
& \mathrm{c}=\text { the speed of light } \\
& \mathrm{t}=\text { time of pulse duration } \\
& \mathrm{K}=\text { the dielectric constant of water } \\
& \mathrm{l}=\text { the loss factor for attenuation, assumed to be } 1 \\
& \lambda=\text { the wavelength of transmitted signal } \\
& \mathrm{r}=\text { the range, or distance to the target } \\
& \mathrm{z}=\text { the reflectivity, or echoes, of the targets, measured in } \mathrm{mm}^{6} / \mathrm{m}^{3}
\end{aligned}
$$

Most of these parameters are known for the particular instrument, or have assumed values, such as the dielectric constant and the loss factor. Therefore this equation can be solved for $\mathrm{z}$ and reduced to:

$$
z=C_{1} P_{r} r^{2}
$$

where $\mathrm{C}_{1}$ encompasses the constants and assumed values of equation 1 (Muller, n.d.). Reflectivity has been shown to depend on sixth power of the diameter of a raindrop, such that within a unit volume of sampled air, $\mathrm{z}$ will be a measure of the summed diameters, each to the sixth power, of the raindrops. More simply stated $\mathrm{z}$ is a measure of the raindrop size distribution (Muller, n.d.; Hunter 2009). Given the assumption of a uniform size distribution, the returned reflectivity can then be used to estimate the rate of rainfall within the sampled airspace. This relationship will be explored and discussed further in section 2.2.1. 
The NEXRAD, or Weather Surveillance Radar -1988 (WSR-88D) Doppler system, is currently used to monitor weather over the United States. This system provides continuous and nearly complete radar coverage over the contiguous U.S. using an S-band transmitter and receiver (10-11.1 cm wavelength). The system continuously scans the environment in $360^{\circ}$ azimuthal sweeps at predefined tilt angles. A complete sequence of sweeps at every tilt angle is called a "volume scan" and takes about 5 minutes to complete while actively tracking storm systems. The system can directly measure reflectivity, mean radial velocity, and spectrum width (the variability in radial velocities within the sample volume) from storm particles and air masses, as described by the methods in the preceding paragraph. Reflectivity can be measured from a distance of $230 \mathrm{~km}$ with a resolution of $1 \mathrm{~km}$, and to a distance of $460 \mathrm{~km}$ with a resolution of $\sim 4 \mathrm{~km}$, whereas radial velocity measurements can be made at a distance of $230 \mathrm{~km}$ and a resolution of $0.25 \mathrm{~km}$ (Crum \& Alberty, 1993).

Although reflectivity, velocity, and spectrum width are the three measurable quantities at the level II processing level, as many as 39 derived products can be generated through the level III radar product generator (Klazura and Imy, 1993). Of primary concern for this project are the level II reflectivity products and National Weather Service precipitation products, or Stage III precipitation products. The level II reflectivity data was used in this project to take advantage of the higher resolution, as monsoon storms are often small in scale and localized. The Stage III precipitation products provide a daily total accumulation at a resolution of $4 \mathrm{~km} \mathrm{x} 4 \mathrm{~km}$ and result from additional processing that undergoes more extensive calibration and quality control 
(Klazura and Imy, 1993; Fulton, Briedenback, Miller, \& O'Bannon, 1998). This process will be described in more detail in section 2.2.1.

\subsubsection{NEXRAD Precipitation Estimation}

The derivation of rainfall rate, and therefore the total amount of precipitation, has been a primary concern of many researchers for flood analysis and forecasting (Hunter 2009), and is a primary concern for this project. A discussion of how rainfall rate is derived from reflectivity is presented in this section. In addition to this, how standard precipitation products are generated is addressed, as well as potential errors, issues, and observations that have been made within the literature.

Reflectivity, $\mathrm{z}$, is dependent on the raindrop size distribution. Rainfall rate is dependent on the number and volume of the particles present, as well as their velocity Because reflectivity and rainfall rate are dependent on similar physical characteristics, the two variables are related through the Z-R relationship (Smith and Krawjewski, 1993).

This relationship is expressed as

$$
z=a R^{b}
$$

where $\mathrm{z}$ is reflectivity in unit of $\mathrm{mm}^{6} / \mathrm{m}^{3}, \mathrm{R}$ is rainfall rate in units of $\mathrm{mm} / \mathrm{h}$ and "a" and "b" are empirically derived constants (Morin, Krajewski, Goodrich, Gao, \& Sorooshian, 2003; Hunter 2009). Hundreds of Z-R relationships have been derived or proposed, each describing different precipitation conditions (Fulton, Briedenback, Miller, \& O'Bannon, 1998). It is important to note that because the measured reflectivity encompasses a wide range of particle diameters, from fog to hail, a scaling factor of

$$
Z=10 \log (z)
$$


is used to generate radar products. Using this scaling factor gives reflectivity products a unit in decibels, or dBZ. Given this, the Z-R relationship has to be rearranged in order to relate the reflectivity values found in level II products to rainfall rate (Muller, n.d.). This results in the equation:

$$
R=10^{\frac{-\log * a}{b}} * 10^{\frac{\log * Z}{b}}
$$

Currently, the default Z-R relationship used over the continental U.S. for convective systems is $Z=300 R^{1.4}$, developed by the National Weather Service for use with the WSR-88D system (Fournier, 1999). Fulton et al. (1998) gave a comprehensive review of the Precipitation Processing System (PPS). Rainfall rates are calculated using this expression based on the $1 \mathrm{~km} \times 1^{\circ}$ grids from the reflectivity measurements, although averaging with adjacent cells reduces the resolution. Once the rainfall rates for each volume scan are derived, the accumulation algorithm simply integrates the totals using a linear average rainfall from each cell. This same accumulation method is used for all precipitation products. These products can be optionally adjusted with the introduction of rain gauge data, which effectively tweaks the "a" parameter in the Z-R relationship to produce a more robust rainfall estimate for each local event (Fulton et al., 1998). Zhang and Srinivasan (2010) updated this to add that data from the Geostationary Operational Environmental Satellites (more commonly known as GOES) is now used in conjunction with local rain gauge data to adjust the Z-R relationship. The updated algorithm produces the Digital Precipitation Array products, at a resolution of $4 \mathrm{~km} \times 4 \mathrm{~km}$. This product is the input for additional processing, at different processing "stages." Stage III data is corrected for biases and mosaicked from multiple radars, if coverage permits. 
It is important to note the limitations and potential errors in the precipitation estimation process. Hunter, 2009, provided a review of these limitations. The first potential error noted was radar calibration. Each radar was calibrated to precision of $1 \mathrm{~dB}$, which corresponds to a potential error of $17 \%$ in rainfall rate. Another potential error was reflection off of melting snow and hail. These particles are much larger than raindrops and consequently reflect more energy, inflating the reflectivity measurement. Currently, a hail threshold (53 dBZ) is employed in precipitation processing, but hail and snow present at lower dBZ values is still possible. "Beam overshoot" was another potential issue resulting from the radar beam becoming more elevated at far ranges from the radar. The result was an incomplete vertical profile of the storm and subsequently an underestimation of the amount of precipitation. Other potential radar errors included beam blockage, primarily from topography surrounding the radar site, attenuation and anomalous propagation resulting from non-standard atmospheric conditions. All of the potential errors noted thus far relate to errors in radar measurement; but there is potential for error in the precipitation estimation itself. The most critical source of error is the choice of Z-R relationship. As Hunter (2009) noted, this relationship likely changes regionally, seasonally, and even daily. As such, much research has gone into refining the Z-R relationship choice for specific conditions and geographic locations. For example, linear regression type analyses were investigated to derive specific Z-R relationships from radar and rain gauge data for Northern Italy and Tripoli (Alfieri, Claps and Laio, 2010; Ali and Said, 2009). Smith and Krawjewski (1993) used rainfall cameras to estimate specific characteristics of rain drop size distributions in order to derive equations for determining the Z-R relationship for several broad regions across the U.S., with 
specific emphasis on North Carolina. They found that the Z-R relationship was dependent on the raindrop size distribution and velocity. These studies showed that the relationships derived were general, and were subject to error based on different conditions.

Rain gauge observations are considered "ground truth", as they estimate the amount of rainfall at the ground surface. However, since the implementation of the WSR88D system, many researchers have noted the discrepancy between NEXRAD precipitation estimations and rain gauge observations (Hunter, 2009). There are several potential causes for the discrepancy. The first is that for NEXRAD products, estimates are made over a large area, whereas rain gauges are point measurements. Another is potential vertical displacement of precipitation, or that the precipitation measured at storm elevation may not fall where the rain gauge is stationed (Morin et al., 2003). A third potential cause for the discrepancy is the initial use of the incorrect Z-R relationship, which has been the focus of most studies have concentrated on (Neary, Habib, and Fleming, 2004). Some studies have found the rainfall rates to be underestimated (Gad and Tsanis, 2003) while others have found that rainfall rates were either overestimated or underestimated, depending on the season and time scale studied (Xie, et al., 2006). Klazura, Thomale, Kelly, and Jendrowski (1999) noted that precipitation may be overestimated in cases of high-reflectivity gradient storms, and drastically underestimated in cases of low-reflectivity gradient storms. This study also noted a dependency between precipitation estimation and range (distance) to the storm. Hardegree, Van Vactor, Levinson and Winstral (2008) described a situation where precipitation estimates underestimated rain gauge observations over Idaho prior to an 
update to the radar processing system in 2002, and overestimated the true precipitation after the update. As a result of these discrepancies, several studies have been conducted to try to calibrate the Z-R relationship using rain gauge data in a local area. Morin, Maddox, Goodrich, and Sorooshian (2005) conducted a specific study on the Z-R relationship for summer monsoon events in Arizona. They cite that in the case of intense convective systems, such as those that occur during monsoon season, the standard Z-R relationship used by the National Weather Service often overestimated rainfall accumulations. Based on comparisons to rain gauge data, they suggested a relationship of $Z=655 R^{1.4}$. Their modified Z-R relationship is recommended for more accurate rainfall estimates over the southwestern U.S.

Calibration between rain gauge observations and NEXRAD estimations have been investigated in order to further enhance data accuracy. Several calibration methods have been used in previous work. Zhang and Srinivasan (2010) described a simple bias adjustment method that multiplies the NEXRAD precipitation value by a ratio of the observed rain gauge value and the NEXRAD value. An averaged ratio of rain gauge observation to NEXRAD derived precipitation was also applied to the NEXRAD products in the PPS during the rain gauge adjustment (Hunter, 2009).

\subsubsection{NEXRAD and GIS - Previous Work}

GIS is a natural solution for viewing NEXRAD products, as well as producing flood inundation maps or performing forecast modeling. To this end, several studies have examined the use of radar data in a GIS environment, and discovered several common issues that needed to be addressed before radar data could be applied within a GIS.

Rainfall data are typically derived using a polar stereographic projection and produced in 
a compressed binary format. Therefore, the data need to be uncompressed, reformatted, georeferenced, re-projected, scaled, and clipped to the appropriate study area (Abdella \& Alfredsen, 2010; Xie H., Zhou, Vivoni, Hendrickx, \& Small, 2005; and Zhang \& Srinivasan, 2010). Since most studies used data over a large time frame, automation and batch processing greatly expedite these operations. Xie et al. (2005) developed an Arc Macro Language script in a UNIX operating system to automatically ingest WSR-88D Stage III data and produce precipitation maps. These maps were used to explore the potential for GIS-based radar data in hydrology models as well as to study monsoon rainfall patterns over the Rio Grande River. The methodologies implemented, however, were designed for more advanced users. Zhang and Srinivasan (2010) developed a more user friendly GIS interface for ingesting WSR-88D Stage III data for use with rain gauge data in order to calibrate Z-R relationships. Ultimately, the calibration of NEXRAD data to rain gauge observations facilitates the use of the data in hydrology modeling applications. Vivoni and Sheehan (2001) and Knebl, Yang, Hutchinson, and Maidement (2005) presented studies using NEXRAD data in conjunction with hydrology models. The hydrology application will be discussed further in section 2.3.

To facilitate the use of NEXRAD products in a GIS visualization environment, the National Weather Service developed the Weather and Climate Toolkit in 2009. This software allows users to view NEXRAD level II and III products as well as GOES products, connect to web mapping services, and export data in a wide range of formats (Ansari, Hutchins, Del Greco, Stroumentova, \& Phillips, 2009). The command-line batch export capability developed as a component of the Weather and Climate Toolkit was utilized in this project. 


\subsection{Precipitation - Runoff Models}

Runoff from rainfall is extremely important for understanding hydrological processes, as it impacts everything from water management to floodplain analysis and stream recharge (Hammouri and El-Naqa, 2007; McGee, 2009). For the purposes of this study, it is important to know where rainfall over Joshua Tree National Park is impacting the environment as well as where runoff may occur after monsoon events. In order to accomplish this, simple hydrologic modeling was employed using Arc-Hydro and HECgeoHMS software.

Currently, the most widely used method for calculating runoff from rainfall is the Soil Conservation Service (SCS) Curve Number method (Bhadra, Bandyopadhyay, Singh, \& Raghuwanshi, 2010). Runoff is modeled as:

$$
Q=\frac{\left(P-I_{a}\right)^{2}}{\left(\left(P-I_{a}\right)+S\right)}
$$

where: $\mathrm{Q}=$ runoff in inches

$$
\begin{aligned}
& \mathrm{P}=\text { rainfall in inches } \\
& \mathrm{I}_{\mathrm{a}}=\text { initial abstraction (water initially soaked into the ground) } \\
& \mathrm{S}=\text { potential maximum retention }
\end{aligned}
$$

Surface runoff is further calculated as:

$$
Q_{s r}=\frac{A * Q}{1000}
$$

where $\mathrm{A}$ is area of the basin. $\mathrm{S}$ is dependent on the Curve Number for the soil type. The equation for $\mathrm{S}$ is:

$$
S=\frac{1000}{C N}-10
$$

for the U.S. customary units of measure (HEC, 2000). The Curve Number, or CN, is dependent on the soil type, and more specifically, the hydrologic soils group. Each soil 
type is assigned a value of $\mathrm{A}, \mathrm{B}, \mathrm{C}$, or $\mathrm{D}$, depending on how much water that soil can retain, where A retains the most and D retains the least (McGee, 2009; HEC 2000). Standard lookup tables for different environments and hydrologic soil groups have been developed and are available. It's important to note that the $\mathrm{CN}$ does change depending on how saturated the ground is from previous precipitation, or if the ground is frozen. Given this, lookup tables list the average Antecedent Runoff Condition (ARC II) for average saturation; however ARC I and ARC III values can be derived for dry and completely saturated conditions respectively (HEC, 2000). One of the reasons the Curve Number method is widely used is because it needs relatively few inputs. The model requires precipitation, soil data, landcover data and a CN lookup table. Additional datasets such as impervious areas (such as buildings) and topography can be added in a GIS environment (McGee, 2009; Knebl et al., 2005)

In order to model rainfall-runoff, the HEC-HMS model is often used in studies. HEC-HMS was developed by the Army Corps of Engineers to model runoff in dendritic systems (Knebl et al., 2005; Martin, LeBoeuf, Dobbins, Daniel, and Abkowitz, 2005; Neary et al., 2004). The software offers many capabilities, including modeling runoff volume, direct runoff, and several routing models to choose from. In order to use NEXRAD data with HEC-HMS, the data should be in HRAP format (Stage III precipitation data) or the software's hydrologic grid format. The radar data should also be calibrated by rain gauge observations prior to use in the model (HEC, 2000).

Several studies have used NEXRAD precipitation data in conjunction with either a simple CN method and DEM routing technique (Vivoni and Sheehan, 2001) or as a direct input into HEC-HMS to model rainfall runoff (Knebl et al., 2005). Neary, Habib, 
and Fleming (2004) examined the use of NEXRAD data in comparison to the more traditional rain gauge measurements in HEC-HMS. The goal was to see if the higher spatial coverage of NEXRAD data could compare with the relatively poorer spatial coverage of a ground truth dataset. The authors noted that the average density of rain gauges over the U.S. was 0.0013 gauges $/ \mathrm{km}^{2}$, compared to 0.0625 observations $/ \mathrm{km}^{2}$ for NEXRAD data (based on the $4 \mathrm{~km} \times 4 \mathrm{~km}$ resolution of Stage III data). Ultimately, the researchers found that the NEXRAD data underestimated the rainfall in the study area, though it should be noted that the study time frame took place in a time frame (19972001) prior to the adjustments applied to the radar processing algorithm (Hardegree, Van Vactor, \& Levinson, 2008). Despite the limitations, researchers have found NEXRAD precipitation data to be a useful input for the HEC-HMS process and hydrology modeling in general.

\subsection{Summary}

Throughout this chapter, the topics researched for this project have been presented. This background laid the foundation for how this project took shape, as well as described the challenges and issues that needed to be addressed. Throughout the remainder of this report, the background presented in this chapter will be referenced regarding the workflows established and the decisions made for this project. In particular, several of the characteristics of NEXRAD data and the specific requirements of the project had to be taken into consideration while developing the system design. These considerations and the final system design are presented in the next chapter. 



\section{Chapter 3 - Systems Analysis and Design}

This chapter considers the planning and design phase of this project and discusses the requirements and system design. The requirements for the project are presented in Section 3.2, as well as how each requirement was developed for the success of the project. The system design is outlined in Section 3.3, describing the system components and the system environment at the client's site. Finally, a review of the project plan is described in Section 3.4, both as how the project was initially planned and how the project took shape throughout its duration.

\subsection{Problem Statement}

Prior to the undertaking of this project, officials at Joshua Tree National Park did not have accurate measurements of rainfall over the majority of the park. They also had difficulty tracking and understanding the impact of monsoon storm events. This project aimed to find a solution to these problems by providing a set of tools implemented in ArcGIS to produce precipitation and hydrology maps using NEXRAD datasets. In order to develop this toolset, several requirements had to be taken into consideration for the system design. These requirements are described in the next section.

\subsection{Requirements Analysis}

The overarching requirement for this project was to develop a tool that would automatically produce a precipitation map of Joshua Tree National Park after storm events. This broad requirement broke down into several smaller functional and nonfunctional requirements. These requirements are summarized in Table 3.1. The table has 
a description of each requirement, as well as its status as a functional or non-functional requirement.

Table 3.1: Functional and non-functional requirements

\begin{tabular}{|c|l|l|}
\hline Type & Description & Constraints \\
\hline \multicolumn{1}{|c|}{ Functional } & $\begin{array}{l}\text { Toolset will produce precipitation and } \\
\text { hydrology maps }\end{array}$ & $\begin{array}{l}\text { Data must be } \\
\text { converted to } \\
\text { readable format }\end{array}$ \\
\cline { 2 - 3 } & $\begin{array}{l}\text { Tool will convert NEXRAD data to } \\
\text { GeoTIFF format }\end{array}$ & $\begin{array}{l}\text { Decoding software } \\
\text { must be installed } \\
\text { on Client's system }\end{array}$ \\
\cline { 2 - 3 } & $\begin{array}{l}\text { Tool will output products as a raster } \\
\text { type, GeoTIFF or Esri grid }\end{array}$ & \\
\cline { 2 - 3 } & $\begin{array}{l}\text { Tool will project output to NAD 83 UTM } \\
\text { zone 11N }\end{array}$ & $\begin{array}{l}\text { Tool will clip products to the park } \\
\text { boundary }\end{array}$ \\
\cline { 2 - 3 } & $\begin{array}{l}\text { Solution will use ArcGIS software 10.1 } \\
\text { suite }\end{array}$ & $\begin{array}{l}\text { Proper software } \\
\text { versions delivered } \\
\text { via DVD }\end{array}$ \\
\cline { 2 - 3 } & Provide tool help/training & $\begin{array}{l}\text { Java and WCT software to be delivered } \\
\text { and installed on client's operating } \\
\text { systems }\end{array}$ \\
\cline { 2 - 3 } Non-functional &
\end{tabular}

Using ArcGIS software was a specific requirement from the client. ArcGIS software version 10.1 was the GIS software the park was using; therefore the developed tools needed to work in this software environment. The client also required that the output products from the toolset be in raster format and in the same projection that standard park products are in. The products from the toolset would potentially serve as input for additional processes, and therefore needed to be compatible with the park's other workflows. The precipitation and radar products initially covered a large area; therefore an additional requirement was that the output products be clipped to the park's area of 
interest. As the hydrology products could also be subject to use in additional processes and workflows, the same requirements listed above applied to the hydrology toolset.

An initial non-functional requirement was to produce documentation for the toolset. Some of the potential users at the park are not well versed in the ArcGIS software suite, and therefore help and training documentation needed to be made available. The last requirement listed in Table 3.1 describes the need to install Java software and the Weather and Climate Toolkit batch command line software. These software packages were necessary to the project design and will be explained further in section 3.4. The client agreed that these software packages could be added to their operating systems and requested that they be included in the deliverables.

\subsection{System Design}

As mentioned previously, the data utilized for this project was NEXRAD radar data, specifically reflectivity level II and derived National Weather Service precipitation (Stage III) products. These products were delivered in a NEXRAD Information Dissemination Service (NIDS) binary format, which could not be read by ArcGIS, or Hydrologic Rainfall Analysis Projection (HRAP) format, and therefore had to be converted to a readable format before processing. This conversion process made up the first component of the system design. To avoid deriving the binary conversion from scratch, the Weather and Climate Toolkit command line functionality was implemented in a Python script. This required the toolkit, as well as Java, to be installed on the operating systems. The Python script formed another component of the system, which integrated into the ArcGIS software as a script tool. The tool and interface were implemented in ArcGIS 10.1. The 
hydrology tools were also developed from a Python script, and similarly are accessed through the software. The output products can be viewed and analyzed in ArcGIS, as well as stored in mosaic datasets within the geodatabase developed for this project. The basic system design is illustrated in Figure 3.1.

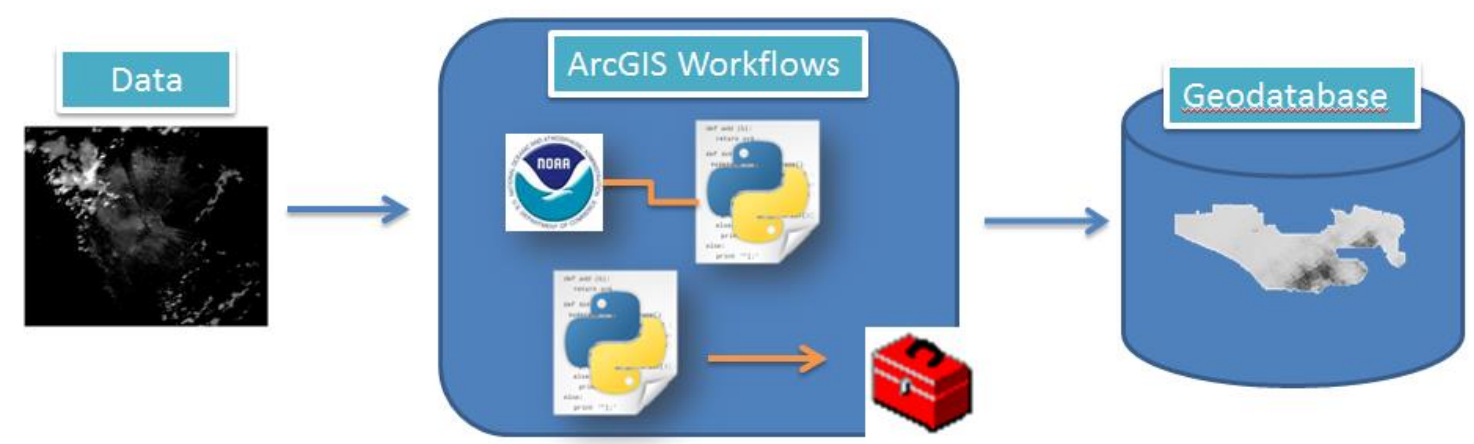

Figure 3.1: System Design

There are two primary users of the tools developed for this project: a GIS Specialist and the Vegetation Branch Chief. Both users are located at the Joshua Tree National Park office. The toolsets were loaded locally at the park location at each user's workstation, with the option to load the tools to the park's GIS server. No additional network, web application, or security requirements were considered for the project, as it was designed for the personal desktop environment described above. The desktop workstations at the park operate with 32- and 64-bit Windows 7 operating systems. This was compatible with the development environment and therefore did not require any additional considerations. 


\subsection{Project Plan}

The primary goal of this project was to develop a tool that would ingest weather data and produce a rain accumulation maps over Joshua Tree National Park. This map could then serve as input in a simple hydrologic runoff model. Even though the goals of the project remained the same throughout, the plan of how those goals would be accomplished changed as the project developed. The original timeline for the project is shown in Figure 3.2 as a Gantt chart.

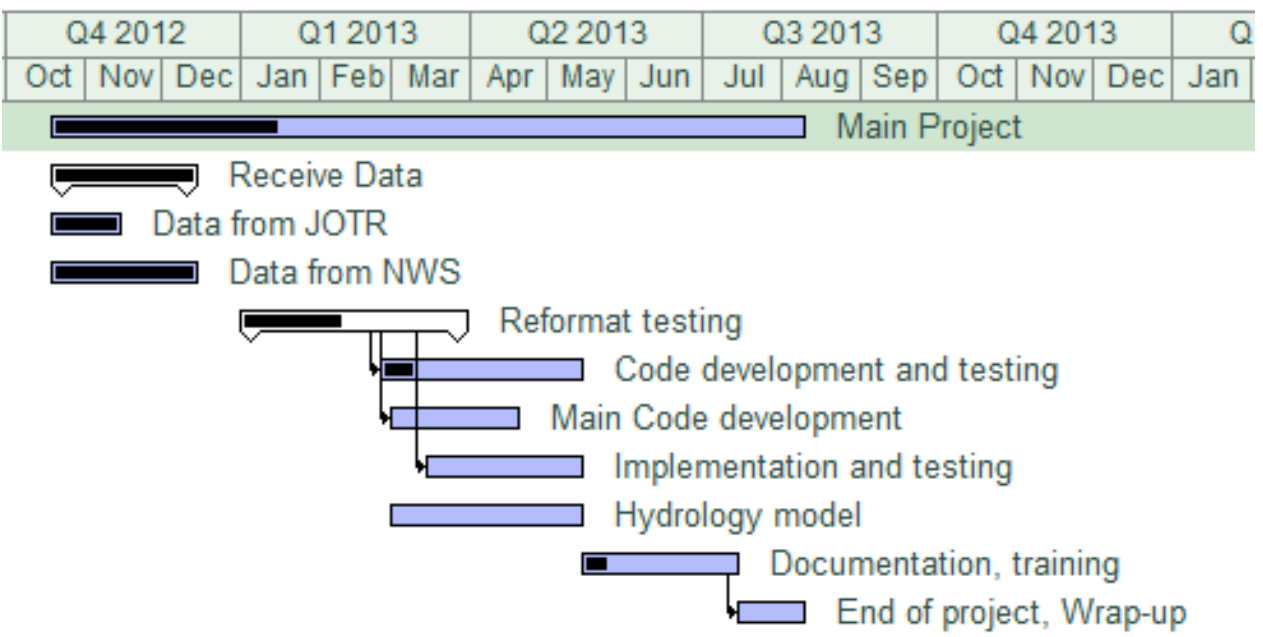

\section{Figure 3.2: Original project timeframe and schedule}

NEXRAD radar data were settled upon from the start. Originally, however, the plan was to use freely available source code and adapt it for the Python language in order to decode and convert the data. The decoding of the data was identified as the first major task, and consumed the majority of the resources for the early stages of the project, as all other tasks depended on this. The level III reflectivity products would be used in order to take advantage of their higher resolution. In order to estimate precipitation from the reflectivity products, a standard Z-R relationship would be applied, and the rainfall totals 
summed up over the duration of the storm in a python script. This task would be implemented in a Python script, and together with the script developed in the first task to decode the data, would represent the second major task. Most of the resources were allocated here since the other tasks were dependent on this process. The hydrology process would be developed after the completion of the previous tasks. A geodatabase was planned, but only for the organizational purposes of this project. This decision, as with the other decisions discussed here, altered over time.

A great deal of time and effort went into learning how to convert the data from the native binary NIDS format into a readable format that could be ingested into ArcGIS. The initial plan was to adapt existing code that utilized the decoders for radar data. The source code for the Weather and Climate Toolkit (WCT) is freely available from the National Climatic Data Center (NCDC). The decoders are indeed embedded in this code, but it proved challenging to extract them because the whole source code was written with interwoven modules that were designed primarily for viewing the data in a Java viewer application.

Once it was determined that adapting the source code would take up too many resources the plan was altered. It was discovered that command line programs could be called upon externally by a Python script. After contacting the developer of the WCT at the NCDC for additional information, it was discovered that there was a standalone WCT command line export tool. This solution was implemented.

Another aspect of the project that did not go quite as expected is the data itself. Despite doing a literature review prior to undertaking the project, there were some characteristics of the NWS precipitation data that were unexpected. These products 
undergo calibration and post-processing. Even so, more research indicated that even these products could have several errors, and some events were not present in the dataset. The NWS precipitation data are easily accessible, however, and the decision was made to provide the option to use these data and develop a tool for them. It was decided that this would not be the primary dataset used, however. Instead, NEXRAD Level II data was used because the resolution of the reflectivity values was $0.5 \mathrm{dBZ}$, as opposed to $5 \mathrm{dBZ}$ for Level III products, and the spatial resolution overall was higher. It was decided that an analysis to derive the correct Z-R relationship for the area would be done.

The plan for the hydrology tool also altered over time. More robust hydrologic modeling is generally done with the assistance of external models or programs, such as HEC-HMS and HEC-RAS, developed by the U.S. Army Corps of Engineers. For the purposes of this project it was important to make the workflow contained within ArcGIS and relatively simple to follow, as the users will likely not be GIS experts or personnel may change over time. The overall motivations for the project were considered, and a tool modeling for runoff and in-situ water was developed to calculate runoff depth, accumulated runoff volume, and maximum potential water infiltration. This reduced the original plan for the hydrologic modeling, but delivered some key capabilities and allowed resources to be devoted to analysis.

The original plan was to develop a geodatabase for internal use only, but as the project continued, it became apparent that the best solution for the client was to deliver a formalized geodatabase with the capability to store the raster products as mosaic datasets. This was only a minor change. Overall, it is fair to say that the overarching plan 
remained intact; however each detail therein experienced some redesigning. Solutions were ultimately found for each issue, aided by outside expertise, research, or creativity.

\subsection{Summary}

This chapter presented an overview of the project requirements, the system design, and the overall project plan as it evolved. This discussion leads to the next chapter, in which the requirements and design elements described here were used to develop the conceptual and logical designs for the project. The next chapter will also describe the geodatabase that was designed, as well as the data that went into the project. 


\section{Chapter 4 - Database Design}

This chapter outlines the conceptual and logical models designed for this project. These models were developed to understand the relationships between datasets and how those datasets were used to derive the overall solution. Ultimately, the conceptual and logical models developed determined the final database design and the datasets that were included.

Section 4.1 discusses the conceptual model developed for this project, introducing the primary entities involved and the relationships between them. Section 4.2 discusses the logical model developed. The overall database architecture is also presented in this section. Since this chapter focuses on the datasets used for this project, Section 4.3 discusses the sources of those datasets and Section 4.4 describes how the datasets were prepared before implementation and incorporation into the database.

\subsection{Conceptual Data Model}

The conceptual model considers the problem that needs to be addressed and the real world entities that formulate each aspect of that problem. The conceptual model for this project was fairly simple; the largest concern being addressed was how much rainfall occurred over the park for any given storm event. The spatial component of this project was introduced when the relationship between the rainfall and the terrain was considered. This relationship addressed the question "Where did it rain?" Two additional components were added to the conceptual model in order to address the question of what happened to the rainfall after it had reached the terrain surface. These components were surface 
runoff, which occurs once the precipitation had accumulated to a certain threshold, and infiltration. Infiltration, for the purpose of this project, considers the proportion of rainfall that remains in situ. This water is available for vegetation, may pool in small surface depressions, or infiltrate directly into the ground surface. Together, these four broad classes - rainfall, terrain, surface runoff, and infiltration - model the overall system the project was concerned with. These entities and their relationships are diagramed in Figure 4.1.

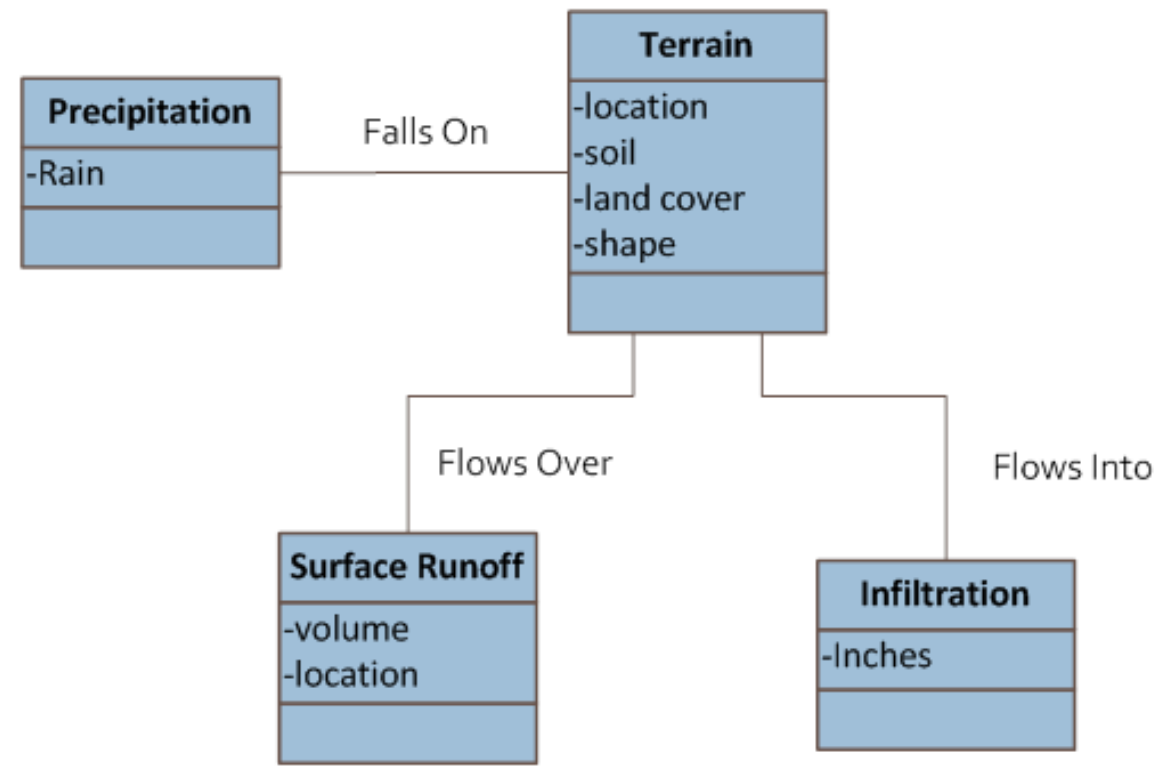

Figure 4.1: Conceptual model UML diagram 


\subsection{Logical Data Model}

The conceptual model described in the previous section outlines processes and relationships that are reconstructed during each storm event. Therefore, the challenge for the logical database model was to find a way to contain all of the toolsets and supporting datasets needed to rebuild the relationships for each storm considered. A database solution that could organize the output datasets and facilitate analysis was also needed. Since the primary products for this project were toolsets designed to be used within the ArcGIS environment, an ArcGIS File Geodatabase solution was implemented.

NEXRAD radar data were chosen to model the rain events due to their high spatial and temporal resolution. Despite the design and use of a geodatabase, the original NEXRAD radar data were all stored outside of the geodatabase in a file folder structure arranged by event date. This organization style was implemented for several reasons, the first being that each time the toolsets within the geodatabase were used they would operate on different raw datasets. Additionally, the NEXRAD radar data (in particular, the Level II data) are delivered in a binary format that is not accessible to ArcGIS software. Besides this, the NEXRAD data is converted to a TIFF format, which cannot be stored within the geodatabase. The radar data needed to be either converted into a rainfall estimate or calibrated to produce precipitation datasets, and would then be organized both within the original file system and within the geodatabase after these processes are completed. These products are organized as mosaic datasets within the geodatabase. By implementing this solution, the outputs from each storm event process could be accessed, compared, and viewed directly from the ArcGIS environment. The output products will be inserted into the respective mosaic dataset depending on whether it is a result from the 
precipitation process or hydrologic process. An overall diagram of the logical database design and architecture are presented in Figure 4.2.

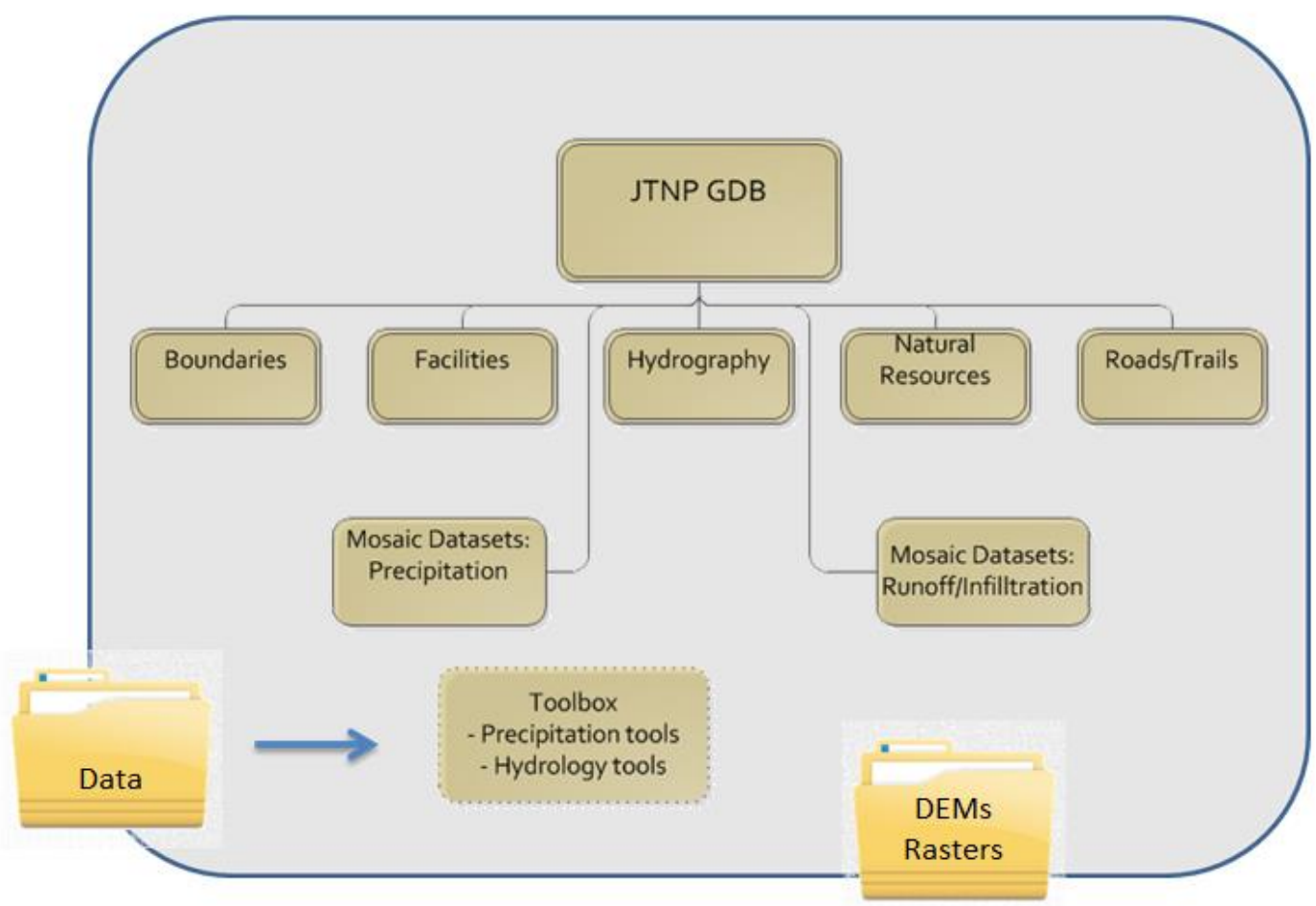

\section{Figure 4.2: Logical model and geodatabase architecture}

The toolsets are stored within the geodatabase. Several additional rasters, which are needed during processing, are stored in a TIFF format just outside the geodatabase. These rasters are labeled as "DEMs and Rasters" in Figure 4.1, and include the Curve Number grids, hydrologically reinforced DEM, and Flow Direction Grid. The process by which these datasets were tailored and prepared for the geodatabase is discussed in Section 4.4. Also incorporated in the final geodatabase are several feature classes organized into five feature datasets. These feature datasets are: Facilities, Boundaries, Natural Resources, Roads and Trails, and Hydrography which contains vector data provided by the client. 
These data were included for ease-of-access to support analysis and management decisions. The relevant attributes for each dataset and feature class within the database are listed in Appendix A.

\subsection{Data Sources}

The primary data used for developing the toolsets for this project are NEXRAD Level II and Stage III data. The NEXRAD Level II data are delivered in NIDS binary format representing approximately five minutes of radar data. The data were available from the National Climatic Data Center (NCDC) via a file transfer protocol. The NEXRAD Stage III data is a mosaicked product over the continental United States; however the NEXRAD Level II data were collected from the Yuma, Arizona radar site. Despite its

further distance from the park, the Yuma site was chosen to collect the NEXRAD data for this project. This is because the two closest sites -- Santa Ana and San Diego -- are both partially blocked by topography and therefore cannot collect reflectivity data over Joshua Tree National Park consistently. Figure 4.3 shows an example of a storm event from the perspective of each radar site. Slight differences occur due to small variations between the time of collection, but it is clear that the Santa Ana and San Diego radars do not have full coverage over the park. 


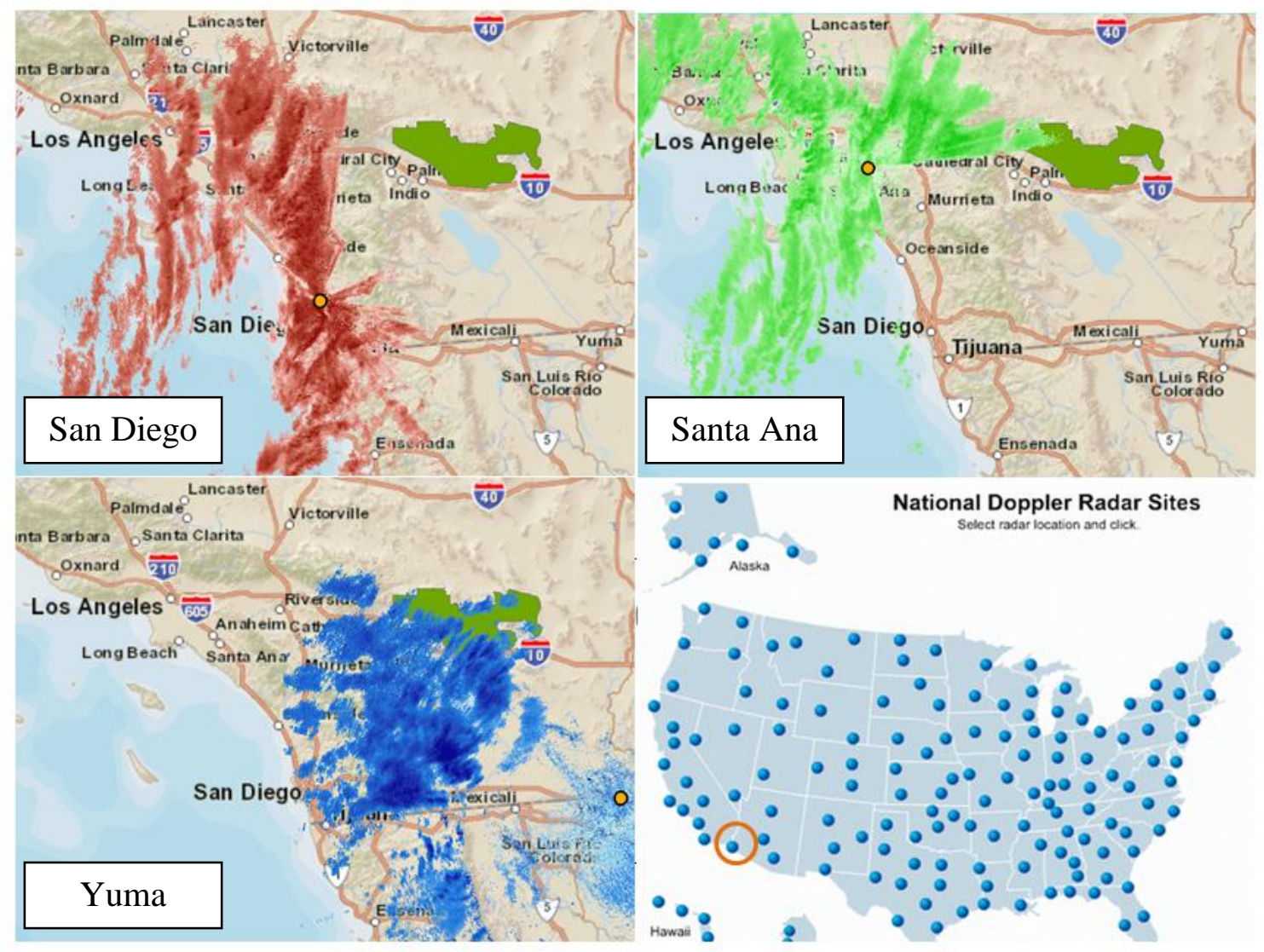

Figure 4.3: Example radar site collection capabilities for the three closest radars to JTNP during a storm event. Circled in orange is the Yuma station on the National Doppler Radar Sites graphic

The NWS precipitation data were available from the National Weather Service as a shape file representing a cumulative daily product over the entire continental U.S. and were delivered in the Hydrologic Rainfall Analysis Project (HRAP) format. The development of the tools and the analysis performed for this project were also facilitated by the rain gauge data provided by the client. These data were provided in Excel spreadsheets.

The hydrology toolsets utilized several datasets, all of which were maintained and 
made accessible through the geodatabase. The first of these was $5 \mathrm{~m}$ Digital Elevation Model (DEM) of the park, provided by the client. The Soil SURvey GeOgraphic Database (SSURGO) soil and land cover data were both utilized to generate the Curve Number grids (see Section 4.4) which were used to create the water runoff and infiltration maps. The SSURGO data is a National Resources Conservation Service (NRCS) product and was downloaded through the United States Department of Agriculture (USDA) Geospatial Gateway. The land cover data were provided by the National Land Cover Database (NLCD) and retrieved through the United States Geological Survey (USGS) National Map Viewer application. The data, their formats, and sources are summarized in Table 4.1 below.

Table 4.1: Dataset sources and format information

\begin{tabular}{|l|l|l|}
\hline Dataset & Format & Source \\
\hline NEXRAD Level II & NIDS Binary & NCDC \\
\hline NEXRAD Stage III & HRAP Grid & NWS \\
\hline Rain Gauge data & Microsoft Excel spreadsheet & Client \\
\hline DEM & Raster, .img & Client \\
\hline SSURGO soil data & Vector, Access Database & NRCS/USDA \\
\hline STATSGO soil data & Vector, Access Database & Client \\
\hline Land cover & Raster & NLCD/USGS \\
\hline Streams & Vector & Client \\
\hline
\end{tabular}




\subsection{Data Scrubbing and Loading}

All the datasets used for this project needed to be reconditioned in some fashion. Reprojection and clipping were needed in each case, but several other operations were also necessary before the data could be loaded into the geodatabase. This section discusses the pre-processing performed in order to derive the correct attributes and features from each dataset.

\subsubsection{Soil Data Processing}

Soil data, combined with land cover data, were used to derive Curve Number $(\mathrm{CN})$ grids, which were necessary for calculating potential runoff. The primary soil data used in this project were SSURGO Database soil data. Data retrieved from the NRCS were in an Access database format, including multiple relational database tables with various types of data and a shape file with location information. The data tables provided were related to the shape file through a series of primary database keys and foreign database keys. The SSURGO 2.2 Data Model Diagram 1 was used to understand the Access database and relationships therein. The specific soil attribute needed to derive the curve numbers was the "hydrologic group", a letter classification of A, B, C or D describing the soil's ability to retain moisture. The table with the hydrologic group classification was located in the Component table, related to the Mapunit Table by the map unit key, or "mukey". These tables were joined in ArcGIS and a new feature class was exported containing the hydrologic group information for each soil polygon.

The SSURGO soil dataset was used due to its higher level of detail and currency, whereas the STATe Soil GOegraphic database (STATSGO) datasets provided by the 
client were more appropriate for a regional scale (Pennsylvania State University, 2009). However, a few gaps within the hydrologic component classification were noted in the SSURGO data. The STATSGO dataset was consulted and was added to complement the SSURGO dataset.

\subsubsection{Land Cover Processing}

Land cover data were a prerequisite input for deriving the $\mathrm{CN}$ grids, along with the soil data discussed in the previous section. The land cover data used was a NLCD product derived from Landsat Thematic Mapper landcover classification techniques and was subsequently provided in a $30 \mathrm{~m}$ spatial resolution raster format. The data was classified into 20 broad land cover categories. Both the soil and land cover datasets were used as input into the Generate CN Grid tool provided by the HEC-geoHMS add-in toolbar that accompanied Arc Hydro toolset. In order to be combined with the soil data in the $\mathrm{CN}$ Grid tool, the land cover data was converted from raster format to polygon format.

\subsubsection{Curve Number Grids}

Another input into the CN Grid tool was a curve number table, which was manually generated by consulting the land cover, soil hydrologic group information, and a NRCS look-up table. Three different values were actually possible as input into the curve number table for each land cover and soil hydrologic group combination, given the Antecedent Rainfall Condition, or ARC. In general, ARC II values are listed in the NRCS table and other available look-up tables, which describe an average soil moisture condition prior to a rainfall event. ARC I values describe dry conditions, and ARC III values describe much wetter conditions. The choice between these values affects the 
runoff calculated, therefore three separate curve number tables were generated from the three ARC values for this project. These tables were combined with the land cover vector data and the soil hydrologic group data using the Generate CN Grid tool from HEC-geoHMS. This resulted in three separate $\mathrm{CN}$ grids developed by the $\mathrm{CN}$ Grid tool. The choice of which grid to use was left to the user, and will be further described in Chapter 5 for the implementation of this choice. The CN Grid generated from ARC II values is shown in Figure 4.4 as an example from the CN Grid tool.

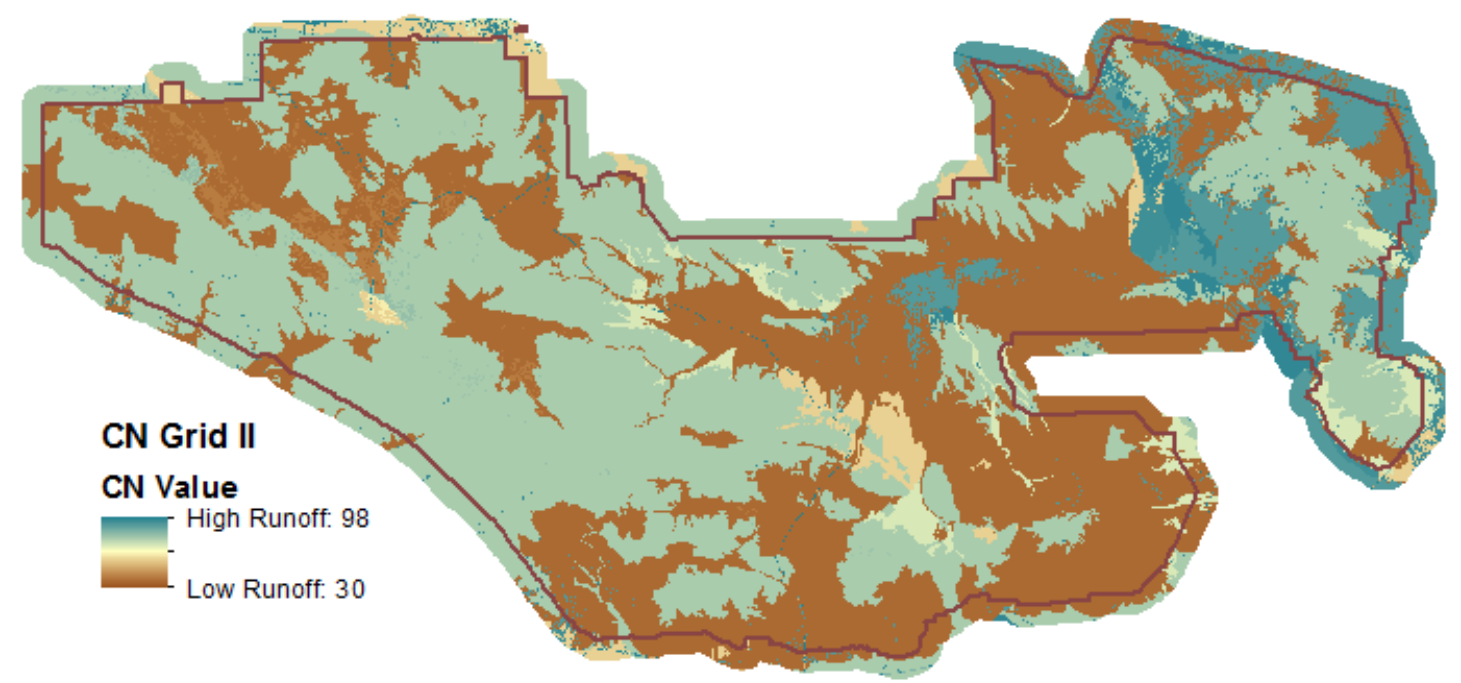

Figure 4.4: CN grid generated from ARC II values. This grid is one of three choices the user has when creating a runoff product

\subsubsection{DEM Reconditioning}

A $5 \mathrm{~m}$ DEM provided by the client was used to generate a flow direction grid. Before the flow direction could be generated, however, the DEM had to be reconditioned and hydrologically reinforced. This involved using Arc Hydro tools to fill any sinks and using the raster calculator to "burn" the existing streams and washes into the DEM. The stream 
dataset used to perform the burn was provided by the client in a vector format, but was converted to a raster prior to the burn operation. The Whitebox GAT Decay Coefficient algorithm was used to burn the streams into the DEM and produce hydrologic DEM that more accurately portrayed the correct stream flow through the park. A flow direction grid was generated from the reconditioned DEM using the Flow Direction tool in Arc Hydro. This raster describes the direction of flow from every cell in the DEM. The use of this grid to find runoff accumulation along precipitation impacted streams is described in Chapter 5.

All of the pre-processed datasets described in this section, along with the derived products such as the $\mathrm{CN}$ grids and the flow direction grid, were entered into the geodatabase. The pre-processing logical model and data-scrubbing diagram are illustrated in Figure 4.5.

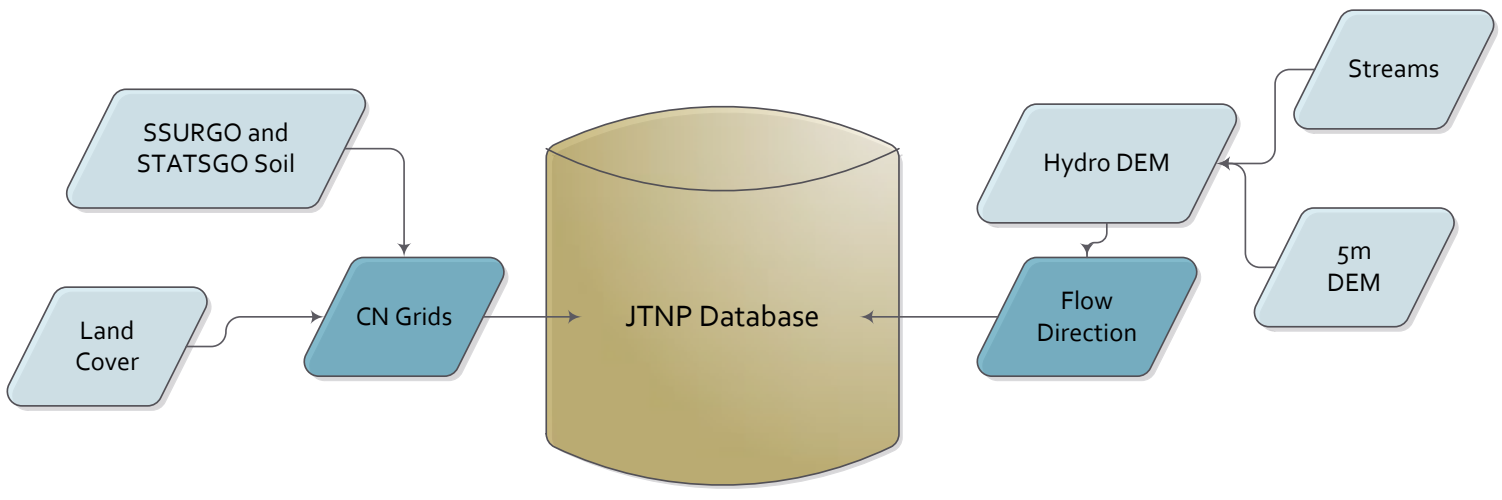

Figure 4.5: Data scrubbing diagram for inputting DEMs and ancillary rasters in the geodatabase. 


\subsubsection{NEXRAD Radar Data Reformatting}

The NEXRAD radar data had to be reformatted in order to be used in the processing workflow. This was accomplished for the NEXRAD Level II data by integrating the Weather and Climate Toolkit Java command line tool into a Python script to convert the data to a TIFF format. The NWS Precipitation data were delivered as a shape file that contained daily rainfall totals over the entire continental United States. These data were also delivered in HRAP grid projection, a polar stereographic projection true at $60^{\circ} \mathrm{N}$ and $105^{\circ} \mathrm{W}$. Therefore both the extent of the dataset and the projection needed to be altered. More detail on these operations will be discussed in Chapter 5.

\subsection{Summary}

The conceptual model developed for this project identified the primary entities that played a role in the solution as being rain, terrain, surface runoff, and infiltrated water. From there, a logical model was designed to describe the interaction and processing workflow between these key entities. The datasets chosen to represent the key entities were NEXRAD Level II data, NWS precipitation data, soil and land cover data, a DEM, and stream data provided by the client. Chapter 5 next describes how these datasets, once processed and conditioned, played a role in the project implementation. 


\section{Chapter 5 - Implementation}

This chapter describes the methodology, workflow, modules, and outputs that make up the toolsets developed for this project. Section 5.1 gives an overview of the tools developed and how they work together to produce a workflow. Sections 5.2, 5.3, and 5.4 describe the NEXRAD Level II conversion tool, the National Weather Service (NWS) precipitation tool, and the runoff-water infiltration tool, respectively.

\subsection{Toolset Overview}

The toolset design and workflow are illustrated in a flow diagram shown in Figure 5.1, which describes three tools: the NEXRAD Level II conversion tool, the NWS precipitation tool, and the runoff-water infiltration tool. The processing operations within each tool are denoted in the green boxes in Figure 5.1. In the subsequent sections, each process will be described in greater detail. 


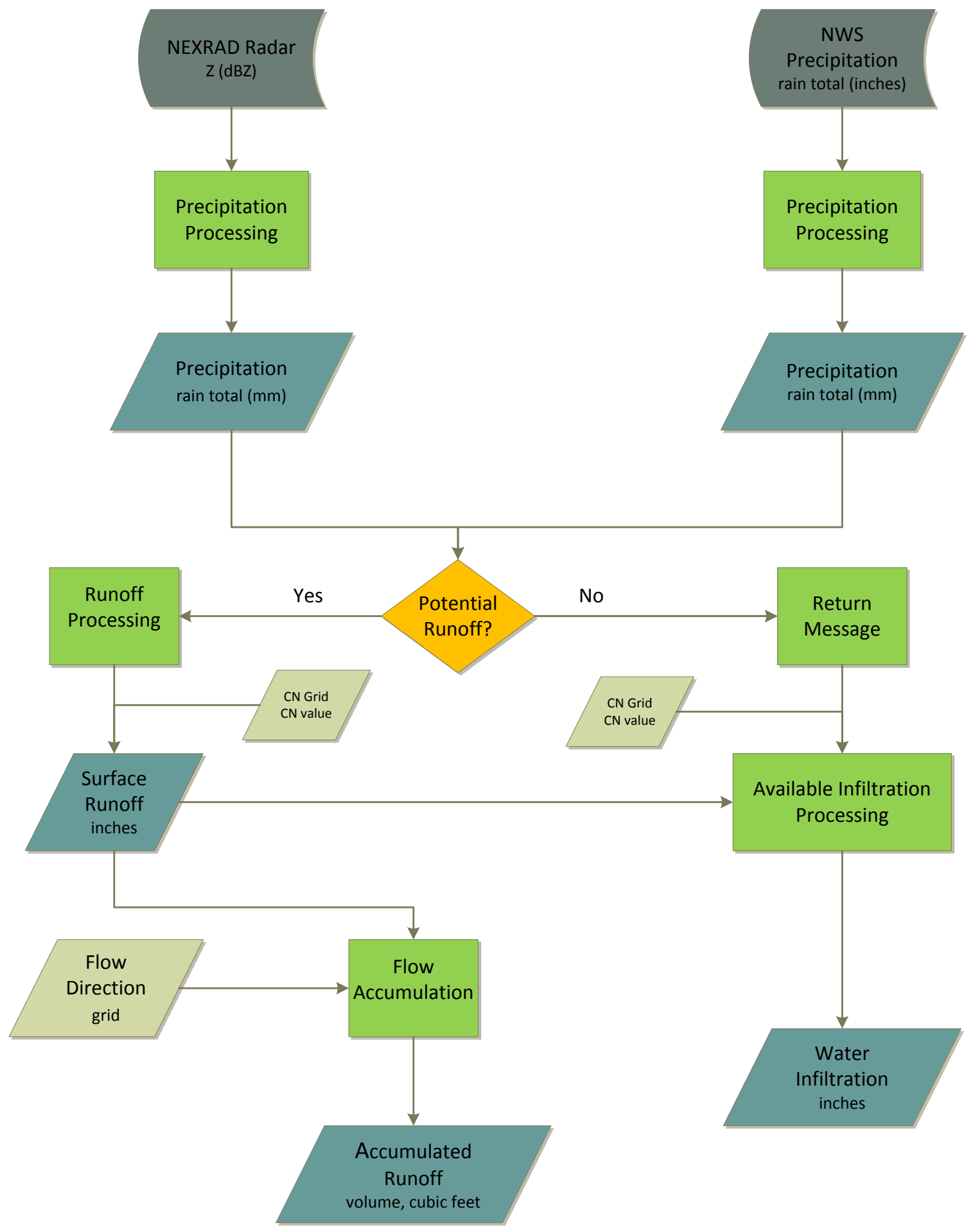

Figure 5.1: Overview of the toolset workflow 
The NEXRAD Level II tool utilizes input from the National Climatic Data Center and the NWS precipitation tool utilizes input from the National Weather Service, as described in Chapter 4. These two tools were designed to act independently of each other, as illustrated in Figure 5.1 by the parallel branches in the flow diagram. The necessary conversions are applied to each data source in a separate script. Designed in this way, the source of data for each storm event could be chosen based on availability, convenience, or preference. Output from either tool could then be used as an independent product or serve as input into the runoff-water infiltration script.

The runoff-water infiltration tool utilizes an additional input, labeled "CN Grid" in the flow diagram. The precipitation input, either derived through the NEXRAD Level II tool or from the NWS precipitation tool, along with the CN grid, are used to process the maximum potential water infiltrated after each storm event. From this point, the script evaluates the conditions for potential runoff to be generated. If the condition evaluates as true, a runoff map is generated. If a runoff map is generated, the process uses an additional input called "Flow Direction" to produce an accumulated runoff volume map. Otherwise, the water infiltration map is the only output from this process.

Python scripts were written for all three tools. While ArcGIS Modelbuilder models could have been invoked and substituted in the place of Arcpy module operations within each process, third-party open source libraries were also used in addition to the Arcpy library. 


\subsection{NEXRAD Level II Conversion Tool}

The input data for the NEXRAD Level II Conversion Tool was retrieved from the NCDC archive. For each storm event, a collection of files, each representing approximately four to five minutes of radar volume scans, were downloaded to cover the duration of the event. The files for each event were then stored locally in a separate folder, organized by event date. These raw radar files were then ready to be input into the Level II tool process. Figure 5.2 focuses on the NEXRAD Level II Conversion tool and illustrates the processing workflow in more detail. 


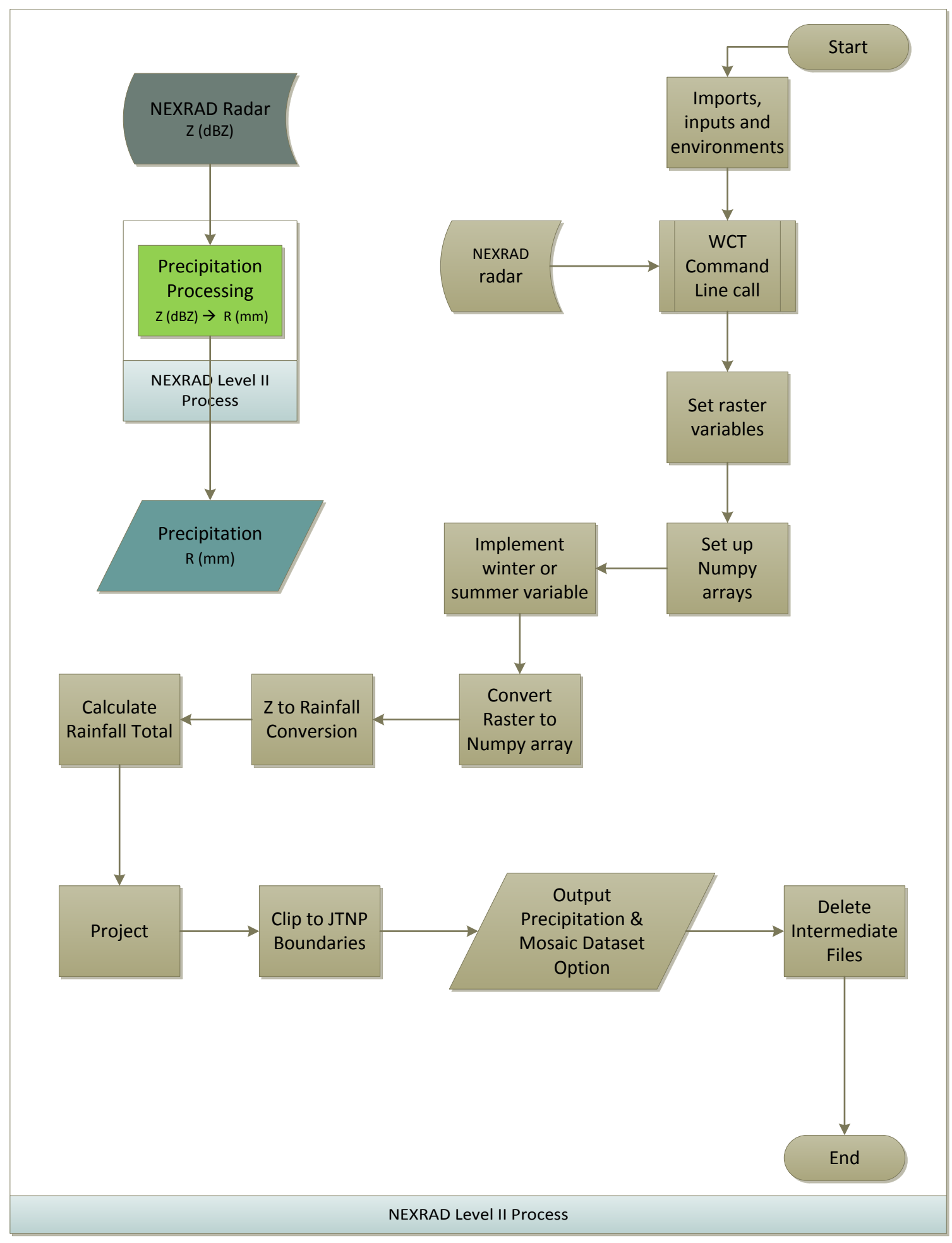

Figure 5.2: NEXRAD Level II Conversion tool process and workflow 
The Level II tool script begins with importing the necessary modules that are needed throughout the process. These include Arcpy, the ArcGIS module, numpy, and subprocess. The user-provided parameters are also set in variables at the beginning of the script. The parameters needed from a user include the input directory where the raw Level II files are stored, the desired output directory, the desired output file name, and the season as either winter or summer.

The first process decodes the files and reformats them from their original binary format into a TIFF format. The Weather and Climate Toolkit (WCT) was developed by the National Climatic Data Center specifically for decoding, viewing, and exporting NEXRAD radar files. While the WCT viewer does offer many capabilities, the companion command line function was implemented in order to make the format conversion automatic and seamless a GIS user. The imported subprocess module uses a single command to call a Java .jar file stored locally and implements the line of code through the command line as a background process. The command line function uses several parameters: the location of the .jar file, the input file directory where the NEXRAD files are located, the desired output location, the desired output format, and the location of an xml configuration file that stores additional conversion parameters. Both the input directory and the output directory are parameters given by the user, though they can be the same directory. The original WCT command line file allows for several output format options, including ESRI grid file, netCDF file, ASCII file, and TIFF file. The decision was made to use the TIFF format option because this format is a common file format used across software packages. The xml file, named wctbatchconfig.xml, stores format conversion parameters such as the radar product to generate from the raw data, the 
radar elevation angle to use, and grid spacing. The radar product generated for this project was reflectivity. The lowest radar elevation angle was used since this angle captures the targets closest to the ground and represents the rainfall closest to the ground. The default grid spacing of $1000 \mathrm{~m}$ was used in the configuration file, as this most closely matches the original resolution of the radar data.

Once the WCT command operation is complete, the resulting reformatted files reside in the same directory. This directory needs to be devoid of other image data, as the script reads the number of images and processes each image from this file. The original Level II data are not considered images by the process, however, and therefore can remain in the same file. The next operation utilizes the user-provided season parameter to choose between a winter and summer set of variables to use in the reflectivity to rainfall rate conversion process. This parameter determines the constants used to convert the reflectivity data to a rainfall rate. The proper choice of the winter or summer variable implements different constants for each condition and improves the accuracy of the overall rainfall total calculation.

The reflectivity to rainfall rate conversion utilizes the RasterToNumPy module to convert each TIFF image to a numpy array, and then computes the conversion for each cell. Once this conversion is complete, the image is treated as a layer in a larger numpy array. This is possible because the WCT command line operation produces images with the same row and column number dimensions, allowing for the creation of a numpy array multiple layers. Each layer represents five minutes of rainfall over each cell. By averaging the rainfall rate for each cell, a total rainfall estimate for that cell can be calculated. The result from this operation is a single numpy array. 
The remaining operations within the script were implemented using the Arcpy module, and could therefore be handled in a Modlebuilder model if further customization is needed. The numpy array is converted to a raster image which is then re-projected to the NAD 83 UTM Zone 11 projection. The raster is then clipped to the park boundaries and converted to a new TIFF image. While the output products are physically stored as TIFF images, a mosaic dataset layer can be created allowing the user organize the final output through ArcMap. If this option is set to "yes" in the user interface, the Arcpy module will complete the mosaic dataset operation at this point in the script. After all operations are complete, intermediate files are deleted from the work directory and the script is exited. An example output precipitation map is shown in Figure 5.3. It should be noted that the precipitation units are in millimeters, as this compares directly with rain gauge measurements.

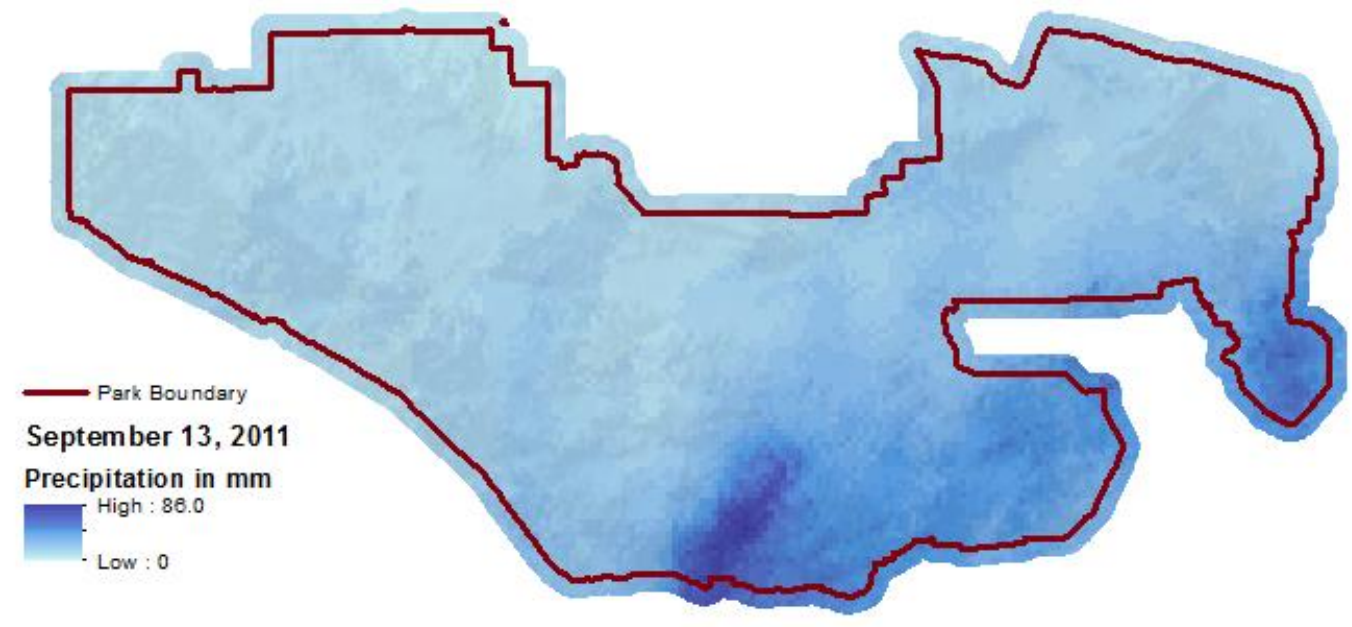

Figure 5.3: Example precipitation map product output from the NEXRAD Level II Conversion tool script process. 


\subsection{National Weather Service Precipitation Tool}

The National Weather Service (NWS) precipitation products can be downloaded from the NWS. The data from the NWS are derived from the original NEXRAD Level II data in that a standard Z-R relationship is applied and precipitation is calculated. This data then undergoes a calibration process comparing the calculated totals to rain gauge totals over the radar collection area. A large processing extent is usually used to conduct the calibration resulting in a lower spatial resolution of roughly 4 by $4 \mathrm{~km}$. Despite the lower resolution, these data are convenient as the product represents a calibrated and accumulated daily rainfall total. The data can be downloaded in either shape file or netCDF format. The shape file option was utilized for this project as it can be recognized and viewed within ArcGIS software. Figure 5.4 depicts on the NWS Precipitation tool and expands into greater detail on the processes behind the production of the NWS precipitation products. 


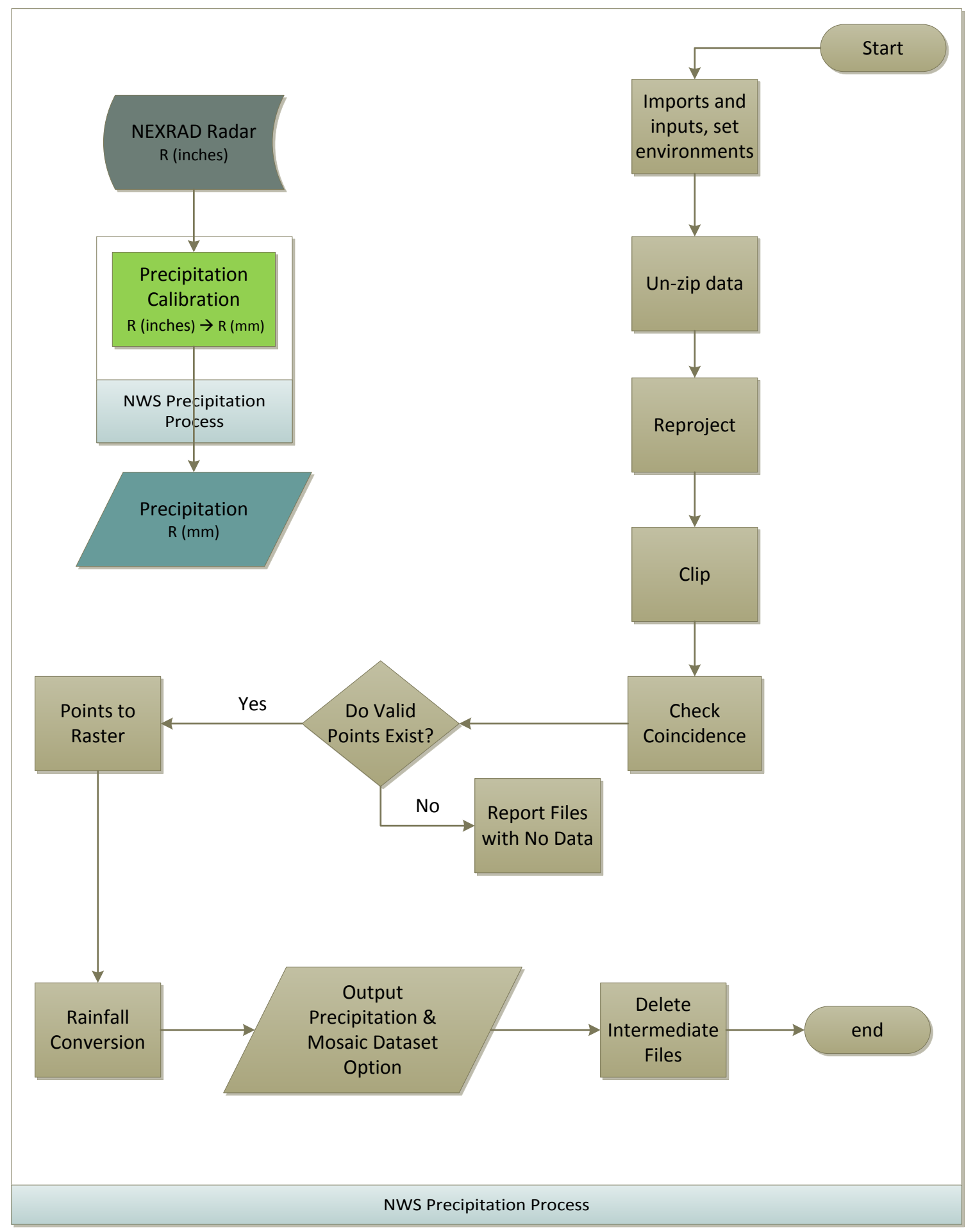

Figure 5.4: Processing workflow for the NWS Precipitation tool 
The NWS Precipitation tool begins with importing three modules: the tarfile, the os module, and the Arcpy module. The data are downloaded in a compressed gz format, for gzip. One of the goals for this project was to make the operations as seamless as possible, therefore the module tarfile was used to decompress the files and store them to the local hard drive. The os module guarantees the uncompressed files are saved to the original file directory. The user-provided parameters are the input file directory, output file location, and the option to add the output to the mosaic dataset. The script can process either a single file or multiple files, but the input directory should contain only the files that need to be processed, as the script will try to process all raster type files under the specified folder.

It was noted early in the project that a discrepancy among the NWS precipitation data and the NEXRAD Level II data and the rain gauge data can exist. Due to this discrepancy, an internal check for valid data over the study region is performed within the script. Data were re-projected into the NAD 83 UTM Zone 11 projection and then clipped using a shape file of the area of interest. The number of points that exist in this intermediate file is returned. If the count is zero, the file name is logged in a list as well as returned to the processing window to alert the user. Otherwise, the data are converted to a raster format using a spatial resolution of $4500 \mathrm{~m}$. The data are then clipped to a buffered extent around the park boundaries to ensure all points within the boundary are retained.

The precipitation data provided by the NWS had already been converted to a rainfall estimate; however, the data were originally reported in inches. This value was 
converted within the script to millimeters in order to compare directly to the rain gauge measurements.

The data were converted to a TIFF file at this point in the process. All intermediate files were deleted from the workspace. If the script is processing several files at once and any of the files failed to have valid rainfall data over the area of interest, the list of failed files will be returned and the program is exited. Figure 5.5 shows an example output file from the NWS Precipitation tool.

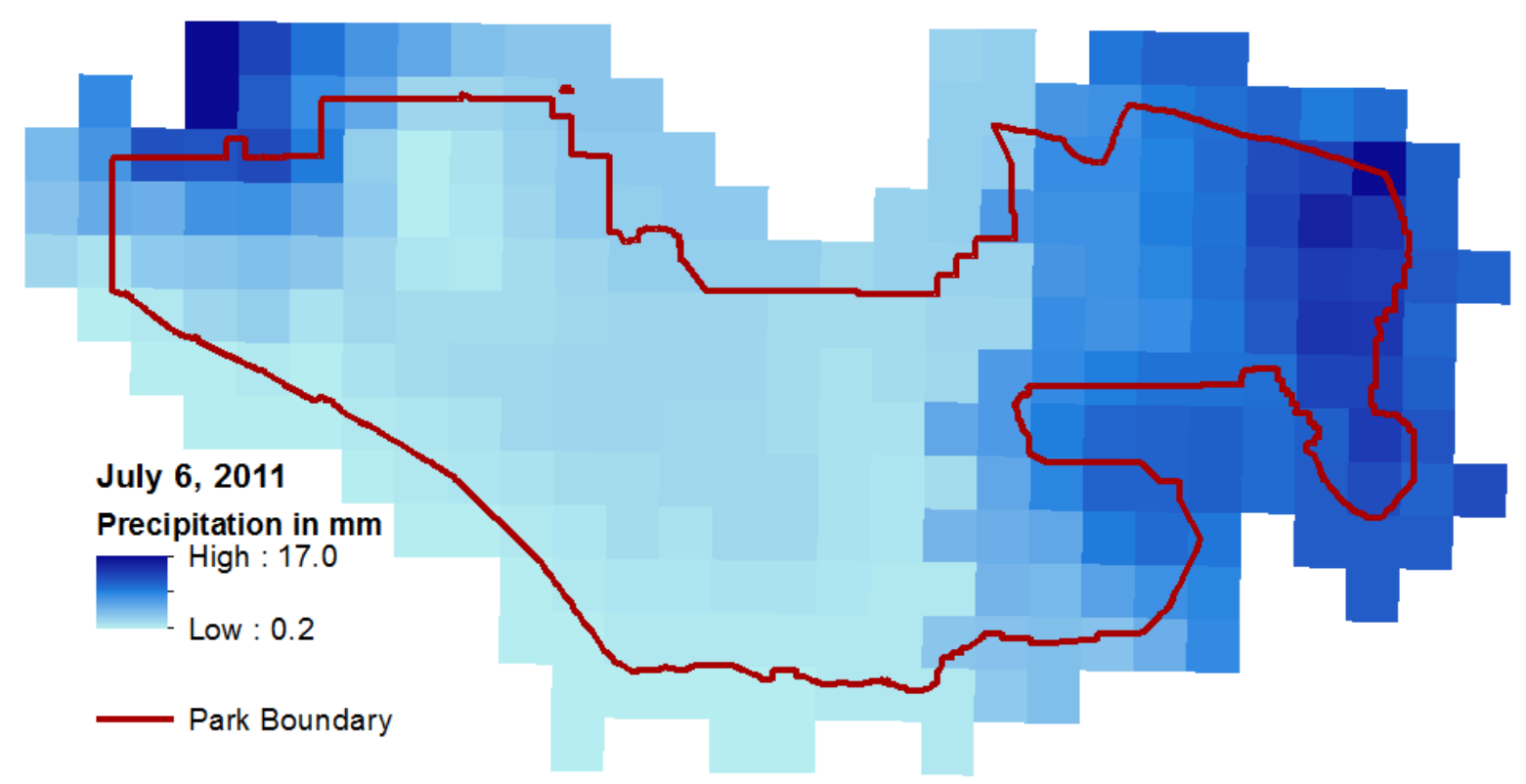

Figure 5.5: Example output product from the NWS Precipitation tool

\subsection{Runoff-Water Infiltration Tool}

After the NEXRAD Level II Conversion tool or the NWS Precipitation tool has been run, runoff and water infiltration maps can be generated from the output of either process. 
Runoff can be calculated using the Soil Conservation Service (SCS) Curve Number (CN) method. This employs the $\mathrm{CN}$ grid derived from land cover and soil data, as described in Chapter 4. An estimation of water losses and infiltration within the soil can also be derived from this method. It should be noted that the estimated runoff from this method approximates the maximum potential runoff possible, and the estimated water infiltration represents the maximum possible infiltration. This processing workflow is shown in Figure 5.6. 


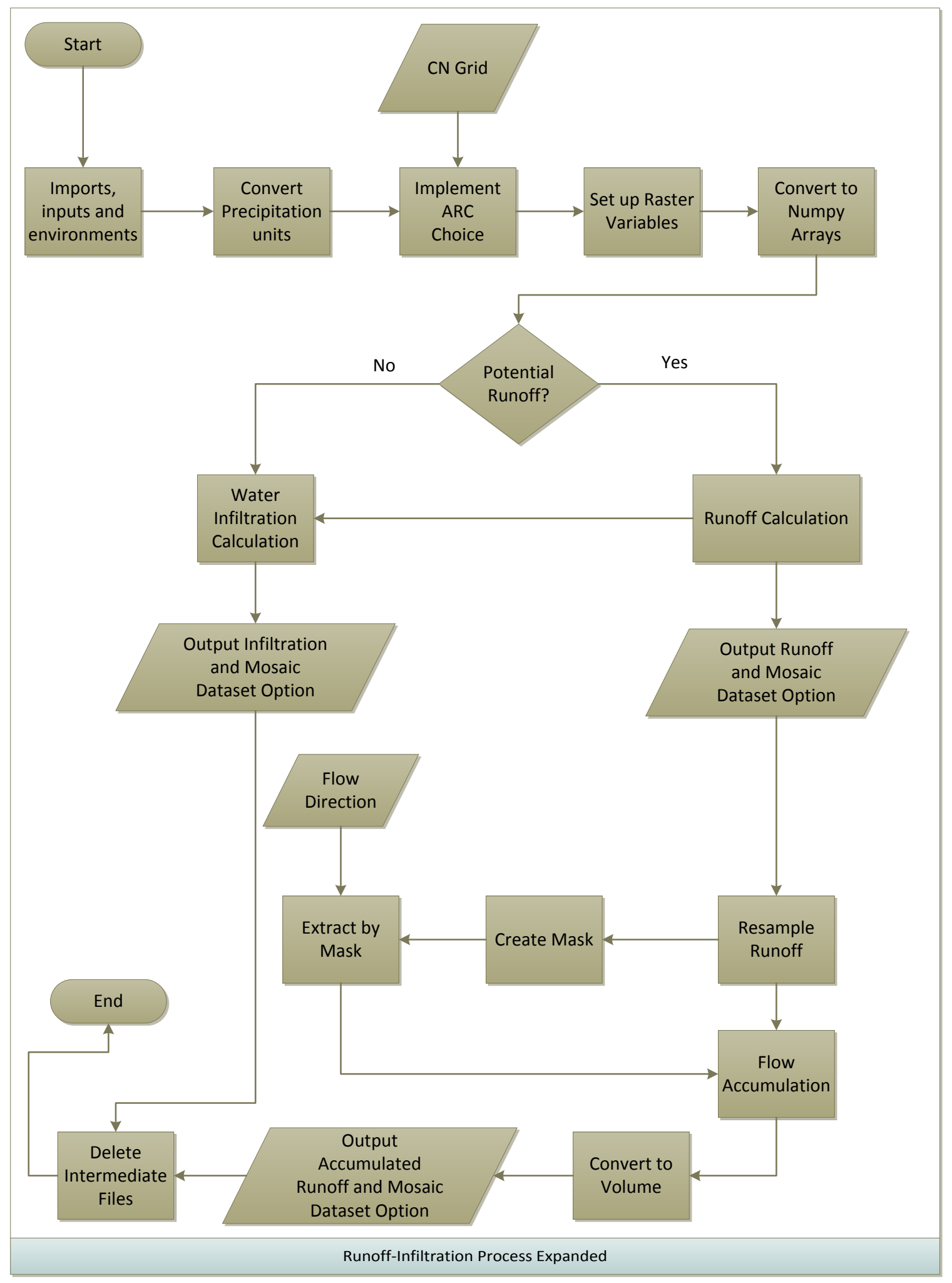

Figure 5.6: Runoff and Infiltration process workflow 
The runoff and infiltration script imports the Arcpy and numpy modules, and specifically, the Spatial Analyst module from Arcpy. The script then sets up variables for the user-defined parameters, which specify the location and name of the precipitation image to be used, the $\mathrm{CN}$ grid to be used, the flow direction grid to be used, and the output runoff, water infiltration, and accumulated runoff locations and names. The first operation is to activate the Spatial Analyst extension. Even if the license is installed in the local environment, the Spatial Analyst functions are not available for use within a script unless this command is run. This extension is also released at the end of the script. The use of the Spatial Analyst module allows calculations to be performed on rasters. The precipitation data are converted into units of inches, which is required for the SCS runoff calculation, and the $\mathrm{CN}$ grid choice is implemented to calculate maximum retention. If runoff is a possibility, the runoff equation is applied. The amount of water retained is calculated each raster. If the evaluation for runoff produces a value less than or equal to zero, the runoff calculation is skipped and the total precipitation for that cell is translated to water infiltrated into the soil.

Since it is quite possible that a storm event may not generate any runoff, an internal check looks at the overall results from the runoff calculation. If sum of the runoff is zero, a message is sent to the user stating that no runoff was produced for that event and the final runoff image is not produced. Figure 5.7 shows an example runoff map from the September 13, 2011 storm event. 


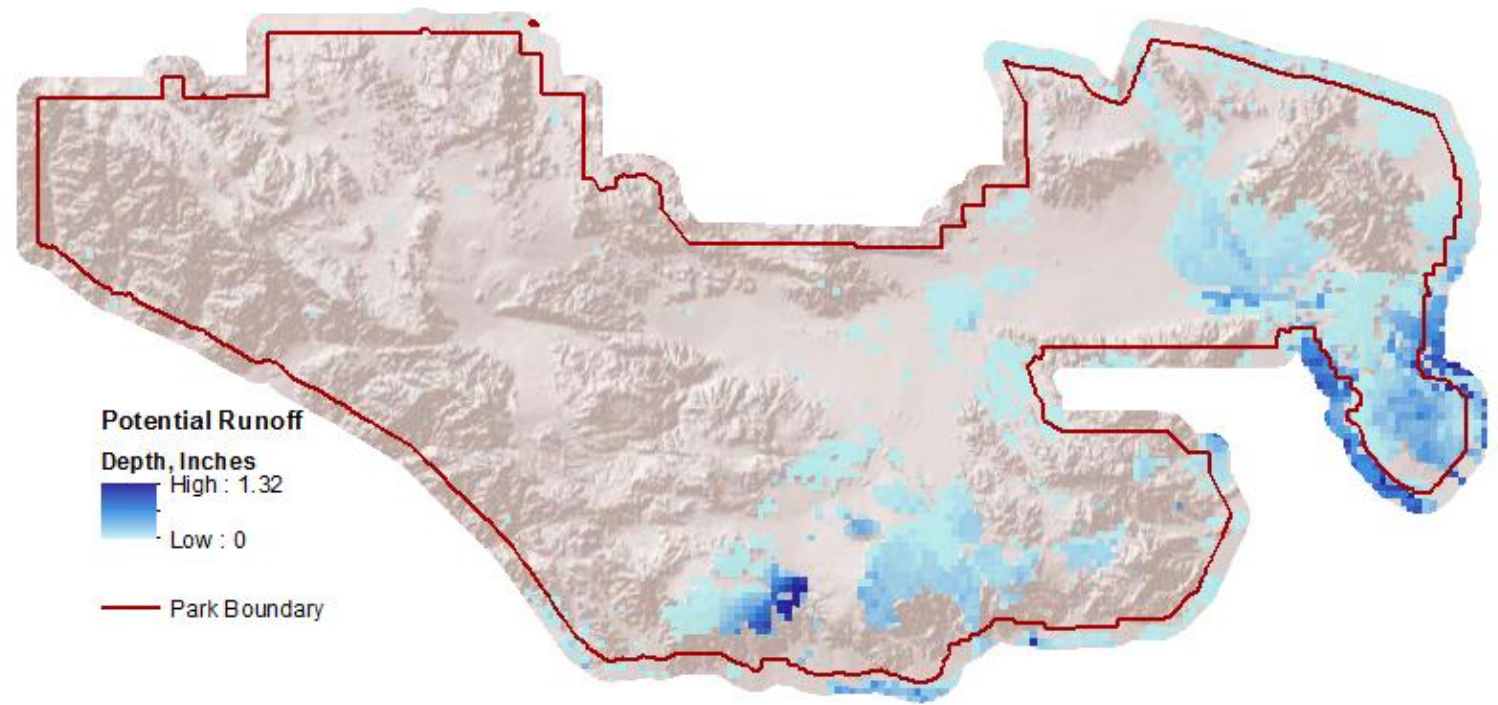

Figure 5.7: Potential runoff generated from NEXRAD Level II data for the September 13, 2011 storm event

Figure 5.8 shows the potential water infiltration from the same event. It is important to note that the values represented here indicate the maximum possible runoff and the maximum possible infiltration. Evaporation and groundwater recharge are not directly modeled; rather these variables are included in the infiltration result. 


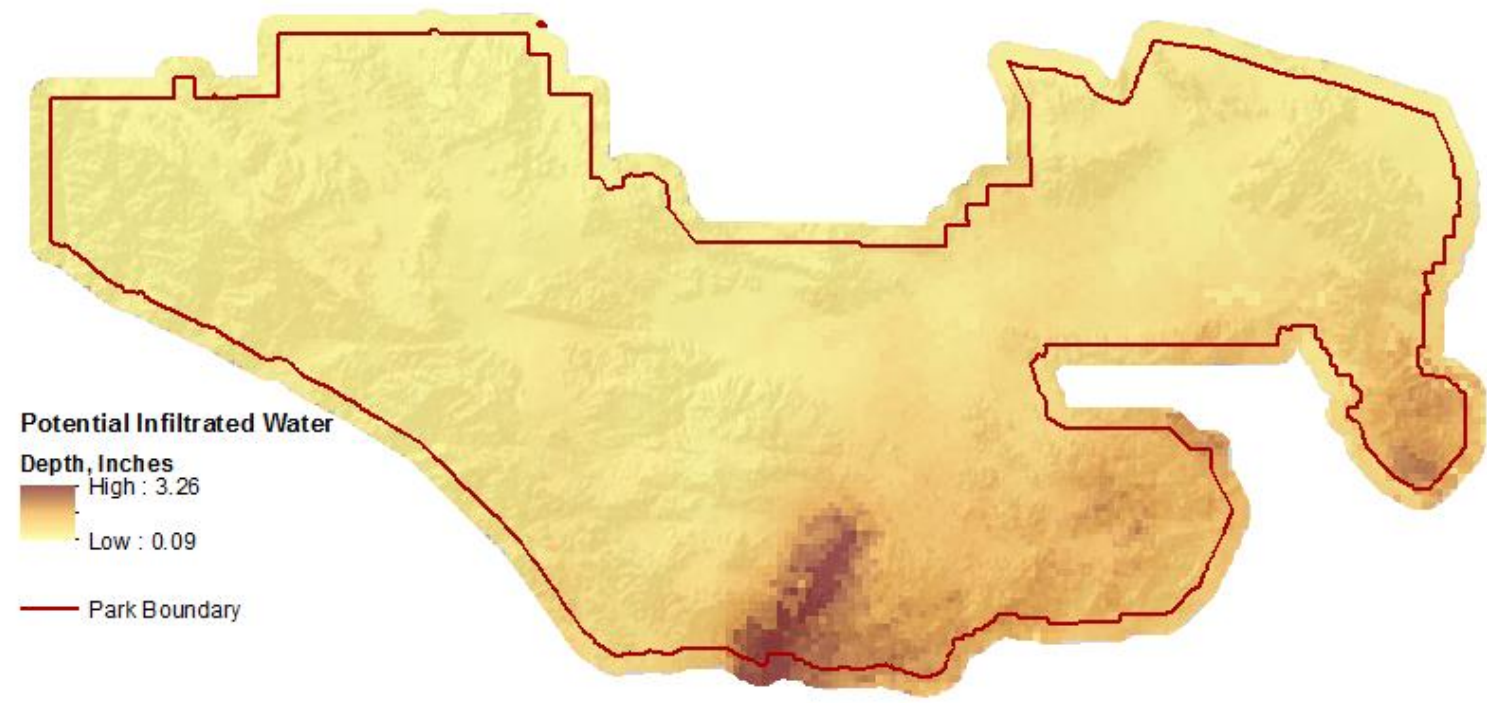

\section{Figure 5.8: Infiltrated water from NEXRAD Level II precipitation data for the September 13, 2011 storm event}

If a valid runoff product is generated, an accompanying accumulated runoff map is also generated. This initiates a set of raster calculations that generate a raster of runoff drainages and their accumulated volume in cubic feet. The accumulated runoff process uses the flow direction raster that was created previously, as described in Chapter 4. This grid is used to resample the runoff raster to the spatial resolution of the flow direction grid, which is 5 by 5 meters. The purpose of this is to generate a more accurate representation of the runoff drainages. The model does not currently consider how far the runoff will travel beyond the impacted areas, as this would require additional information about the timeline and intensity of the storm, as well as travelling time for the surface water. Therefore a mask using the resampled runoff was used to generate a subset of impacted areas. This mask extracts the flow direction grid for the impacted areas. The flow accumulation tool is then used with two inputs: the resampled runoff as a weighted grid and the flow direction grid. The flow accumulation tool generally sums up the 
number of cells that would flow into a specific cell. By adding the runoff grid, the runoff for each cell is added, generating an accumulated runoff map that delineates the drainages. The process limits the volume of accumulated runoff shown to 0.1 cubic feet or more. This allows the drainages generated from runoff to be clearly defined. An example output from this process is shown in Figure 5.9. The rasters are saved to TIFF images in the user defined location. The mosaic dataset condition is checked and new layers in the corresponding mosaic datasets are made. At this point, the intermediate files are deleted and the program is exited. 

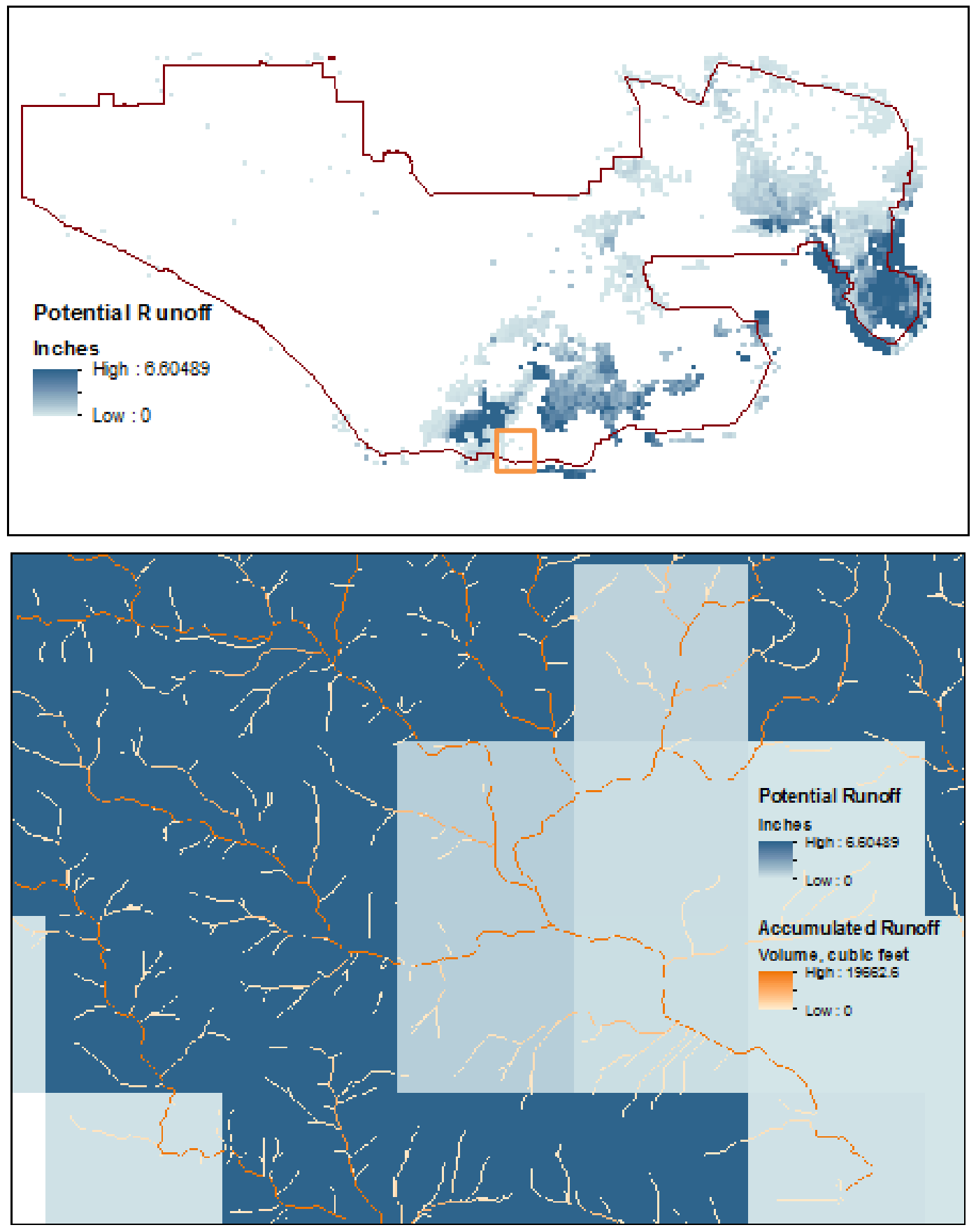

Figure 5.9: Top: runoff map, as a locator map. Bottom: accumulated runoff showing the runoff drainages and potential water volume in cubic feet 


\subsection{Summary}

This chapter reviewed the implementation of the tools built for this project, both as how they were used during testing and how they should be used in the future. While this chapter has focused on how the tools were built and their proper use, Chapter 6 will focus on the output products from these processes and how they can be used for analysis, as well as discuss the analysis that went into certain parameters of each tool and how the final parameters were derived. 


\section{Chapter 6 - Results and Analysis}

One of the primary motivations for this project was to develop a tool to generate precipitation maps for Joshua Tree National Park (JTNP). The script tools developed for this purpose were described in Chapter 5; this chapter will discuss the analysis, results, and potential utility of the script tools.

The rain gauge data provided by the park served as ground truth and was therefore used as the basis of comparison to the precipitation data. The rain gauge observations will be reviewed in Section 6.1. Section 6.2 describes one of the original data sources considered for this project the National Weather Service (NWS) precipitation data and compares it to the rain gauge observations. Section 6.3 discusses the decision to use NEXRAD Level II data to estimate precipitation. Section 6.4 discusses the derived regional Z-R relationship for the JTNP and its comparison to the rain gauge observations, as well as other regional Z-R relationships. The prospect of using local Z-Rs for each rain gauge area is also discussed. Finally, the tools and final outputs are discussed in Section 6.5.

\subsection{Rain Gauge Observations}

Figure 6.1 shows the area of the park and the location of the three weather stations within the park. These stations are labeled as Black Rock (Br), Cottonwood Canyon $(\mathrm{Cw})$, and Pinto Wells $(\mathrm{Pw})$. $\mathrm{Br}$ and $\mathrm{Cw}$ are fairly accessible given that roads are located nearby. Station $\mathrm{Pw}$ is located in a remote area within the park and, as a result, data are retrieved infrequently. The data from these weather stations were used as ground truth for the 
derivations of the various Z-R relationships. The data extend from late summer 2008 to late summer 2012 and contain hourly rain totals.

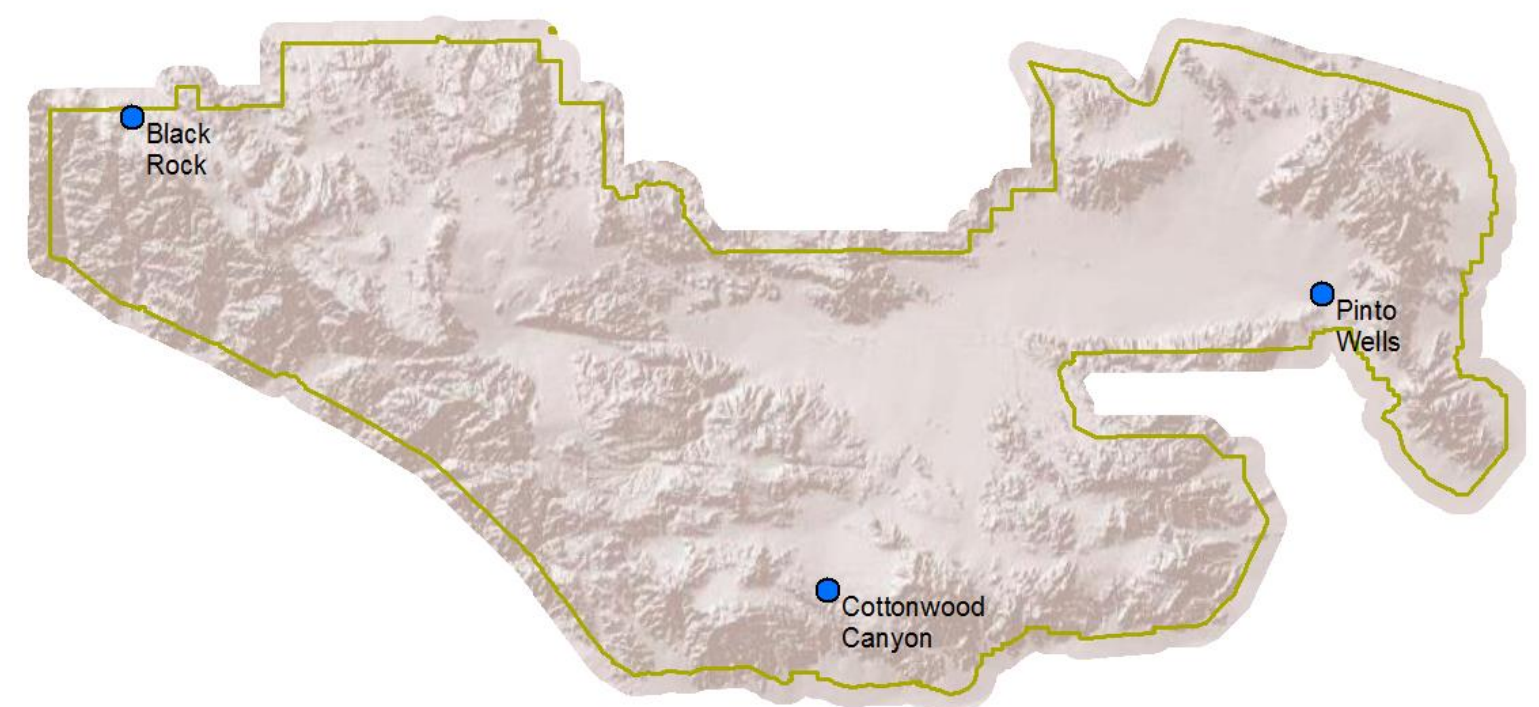

\section{Figure 6.1: Park area and weather station locations}

Hourly rain gauge measurements for every event (including winter events) were condensed from the original Excel spreadsheets made available by the park. From this, hourly observations were summed to produce an event total rainfall corresponding to each of the 31 monsoon events that occurred over the time period from Summer 2008 to Summer 2012. The rainfall total for each event is listed in Appendix B. A subset of the data is listed in Table 6.1. This subset of events will be used to compare the precipitation data throughout this chapter. 
Table 6.1: Example monsoon event rain gauge totals for each weather station in millimeters.

\begin{tabular}{|l|r|r|r|}
\hline Event Date & \multicolumn{1}{|l|}{$\begin{array}{l}\text { Pw } \\
\text { (mm) }\end{array}$} & \multicolumn{1}{l|}{$\begin{array}{l}\text { Cw } \\
\text { (mm) }\end{array}$} & \multicolumn{1}{l|}{$\begin{array}{l}\text { Br } \\
\text { (mm) }\end{array}$} \\
\hline August 22, 2009 & 1.0 & 0.8 & 0.7 \\
\hline July 15, 2010 & & & 4.7 \\
\hline August 26, 2010 & 6.8 & & \\
\hline October 3, 2010 & 12.3 & 5.7 & \\
\hline July 6, 2011 & 1.5 & 0.1 & 3.3 \\
\hline September 13, 2011 & 27.1 & 75.4 & 1.2 \\
\hline July 13, 2012 & 0.9 & 2.9 & 6.0 \\
\hline August 17, 2012 & & & 16.0 \\
\hline
\end{tabular}

\subsection{National Weather Service Precipitation Data}

There are several precipitation datasets available; however, two datasets were examined closely from the beginning of this project. These were the NEXRAD Level II dataset and the National Weather Service (NWS) Precipitation dataset. The NWS dataset was originally derived from NEXRAD data. This NWS dataset has several advantages: readily available in a shapefile format, quicker to download, available more quickly after an event has occurred, and post-processed and calibrated with other data sources. There were some disadvantages as well. Primary among these was that the resolution was averaged and downsampled to $4 \times 4 \mathrm{~km}$. Its temporal resolution of one day was also low compared to the NEXRAD data temporal resolution of five minutes.

A comparison between the rain gauge observations and the NWS precipitation data was done in order to determine if this dataset should be the primary one used for this project. A complete table comparing rain gauge observations to the NWS precipitation 
dataset is included in Appendix B. A subset of these events is shown in Table 6.2 to demostrate how this dataset compares to the rain gauge measurements.

Table 6.2: Example NWS precipitation data compared to rain gauge observations

\begin{tabular}{|c|c|c|c|c|}
\hline Event Date & Measurement Type & Pw & Cw & $\mathrm{Br}$ \\
\hline \multirow[t]{2}{*}{ August 22, 2009} & Rain Gauge & 1 & 0.8 & 0.7 \\
\hline & NWS Precipitation & noData & noData & 0.762 \\
\hline \multirow[t]{2}{*}{ July 15, 2010} & Rain Gauge & & & 4.7 \\
\hline & NWS Precipitation & & & 0.51 \\
\hline \multirow[t]{2}{*}{ August 25, 2010} & Rain Gauge & & & \multirow[t]{2}{*}{6.2} \\
\hline & NWS Precipitation & & & \\
\hline \multirow[t]{2}{*}{ August 26, 2010} & Rain Gauge & 6.8 & & \multirow{2}{*}{3.5} \\
\hline & NWS Precipitation & 1 & & \\
\hline \multirow[t]{2}{*}{ October 3, 2010} & Rain Gauge & 12.3 & 5.7 & \\
\hline & NWS Precipitation & noData & 0.76 & \\
\hline \multirow[t]{2}{*}{ July 6, 2011} & Rain Gauge & 1.5 & 0.1 & 3.3 \\
\hline & NWS Precipitation & 10.9 & 1.78 & 11.17 \\
\hline \multirow[t]{2}{*}{ September 13, 2011} & Rain Gauge & 27.1 & 75.4 & 1.2 \\
\hline & NWS Precipitation & 15.49 & 8.38 & 4.38 \\
\hline \multirow[t]{2}{*}{ July 13, 2012} & Rain Gauge & & \multirow[t]{2}{*}{2.5} & 6 \\
\hline & NWS Precipitation & & & 5.84 \\
\hline \multirow[t]{2}{*}{ July 14, 2012} & Rain Gauge & 0.9 & \multirow{2}{*}{$\begin{array}{l}1.3 \\
4.5\end{array}$} & 3 \\
\hline & NWS Precipitation & 5.33 & & 1.27 \\
\hline \multirow[t]{2}{*}{ August 17, 2012} & Rain Gauge & & & 16 \\
\hline & NWS Precipitation & & & 0.76 \\
\hline
\end{tabular}

It was noted that this dataset did not record all summer monsoon events, nor did it record data over all of the rain gauges where rain gauge observations were made. This is reflected in Table 6.2 by the "noData" label in several fields. The NWS dataset was produced considering $1200 \mathrm{GMT}$ as the beginning of the day, rather than 0 GMT. This put several events on different calendar days, and also occasionally combined two events into one. This is reflected by several merged fields in Table 6.2. This consequently 
reduced the temporal resolution of this dataset. Overall, the standard deviation of the differences between the rain gauge observations and the NWS data was $12.7 \mathrm{~mm}$. This is very high, considering that the average monsoon event for the years between 2008 and 2012 was about $6 \mathrm{~mm}$.

Figures 6.2 provides a closer look at the recorded rainfall distribution for one of the monsoon storms. A concern regarding the NWS precipitation dataset was that some of the monsoon storms, which are small and discrete by nature, would not be represented due to the lower spatial and temporal resolution. It was also noted that often the local rainfall distributions within the storm were not apparent. This dataset can also severely underestimate the magnitude of rainfall compared to other precipitation data as shown in Figure 6.2. 


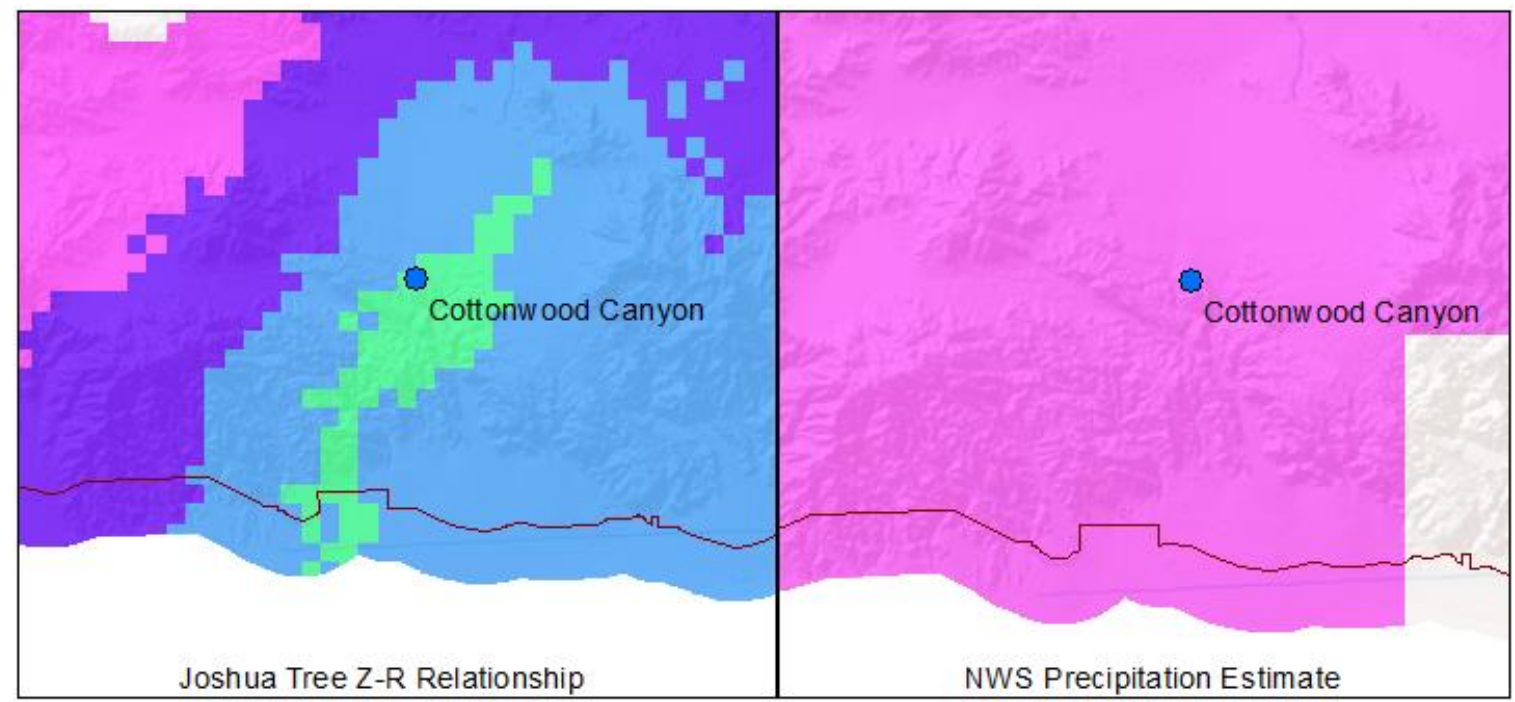

Septem ber 13, 2011

Precipitation in $\mathrm{mm}$

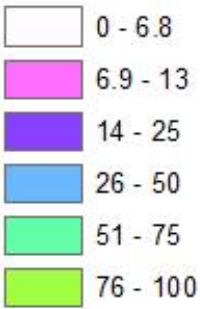

Figure 6.2: Comparison between precipitation data from the NEXRAD Level II data and the NWS data

Discrepancies in the NWS Precipitation dataset have been previously noted by researchers. The general solution is to apply a calibration to the data. There are several techniques used in the literature, including a Kriging method and a simple bias adjustment method. Because of the discrepancies noted in the dataset for this project, a bias adjustment technique was tested for the monsoon events. This bias adjustment is a scale factor calculated as the ratio between the sum of the rain gauge estimates and the total of the NWS rainfall estimates:

$$
\text { bias }=\frac{\sum R g}{\sum R r}
$$


The bias adjustment for the NWS precipitation data was 2.49. Unfortunately, this bias adjustment did not improve the overall precision of the NWS data. The conclusion was that despite the great accessibility of this dataset, the quality and accuracy were not sufficient for studying monsoon events other than for rapid assessment.

\subsection{Z-R Relationship}

Using the analysis described in the previous section, it was determined that using the NWS precipitation data as the primary data source would not be sufficient for studying monsoon events. The highest resolution data available are the NEXRAD Level II data, which record radar reflectivity from precipitation particles. To calculate precipitation, the standard method is to use a Z-R relationship to transform the reflectivity data to precipitation data. Equation 9 describes the Z-R relation with constants of $\mathrm{a}$ and $\mathrm{b}$ to be derived using rain gauge data and radar observations:

$$
z=a R^{b}
$$

Several Z-R relationships have been published in the literature. Because Z-R relationships are empirically derived and do not describe a particular physical process, the Z-R relationship that best describes the ground conditions may change depending on the environment, time of year, and storm and precipitation type. While this situation seemed challenging, it presented an opportunity to derive a Z-R relationship for the area. A Z-R relationship was calculated for Joshua Tree National Park (JTNP) using rain gauge data. This section presents the calculation of the Z-R relationships for three available rain gauges together and for each rain gauge individually. 


\subsubsection{Z-R Relationship Derivation}

NEXRAD Level II radar data were downloaded for each monsoon event from the National Climatic Data Center http://www.ncdc.noaa.gov/nexradinv/. The reported rain gauge times were converted to Greenwhich Mean Time (GMT) in order to find the matching radar data. For each hour of rain recorded, there were 12-14 NEXRAD files recorded in intervals of four to five minutes. All files for each hour were converted to TIFF format. The locations of the three rain gauges were used in a script to extract the corresponding reflectivity values. The $\mathrm{Z}$ values were logged in a text file and arranged based on the timestamp to match the hourly rain gauge measurement.

A separate script used this text file to calculate the constants for the Z-R relationship. The Z-R relationship is a nonlinear function of $a$ and $b$, thus the nonlinear least-square method was used to calculate the values for $a$ and $b$.

\subsubsection{Regional Z-R Relationship for Joshua Tree National Park}

An overall Z-R relationship was derived based on the combination of data for the three rain gauges for the summer monsoon events over Joshua Tree National Park. For the 31 events, 154 hours of usable data were collected with NEXRAD radar that corresponded to rain gauge measurements. It was noted that there were occasions where the radar was not functioning or was in "maintenance mode" or "clear air" mode, in which case the temporal duration between samples was increased for a portion of the hour. Data for these events were excluded from the calculation. For the 154 hours of usable data, 77 observations were used to calculate the Z-R relationship, and the remainder served as a control with their Root Mean Square Error (RMSE). During the calculation, data with 
deviations larger than three times the standard deviation were considered blunders and were excluded from the final Z-R relationship calculation. The final Z-R relationship was:

$$
z=365.2 R^{1.82}
$$

Using this relationship, rain totals were estimated for each event using the script and methodology described in Chapter 5. The rain total was then extracted for each rain gauge location. These totals, along with the corresponding rain gauge totals, are presented in Appendix B. A smaller subset of the data is presented in Table 6.3. Table 6.3: Rain gauge observations and estimates using the derived Z-R relationship

\begin{tabular}{|l|l|r|r|r|}
\hline Event Date & $\begin{array}{l}\text { Measurement } \\
\text { Type }\end{array}$ & & & \multicolumn{1}{l|}{ lw } \\
\hline August 22, 2009 & Rain Gauge & 1.0 & 0.8 & 0.7 \\
\hline & JTNP ZR & 3.28 & 1.05 & 0.62 \\
\hline July 15, 2010 & Rain Gauge & & & 4.7 \\
\hline & JTNP ZR & & & 3.66 \\
\hline August 26, 2010 & Rain Gauge & 6.8 & & \\
\hline & JTNP ZR & 18.9 & & \\
\hline October 3, 2010 & Rain Gauge & 12.3 & 5.7 & \\
\hline & JTNP ZR & 7.74 & 3.28 & \\
\hline July 6, 2011 & Rain Gauge & 1.5 & 0.1 & 3.3 \\
\hline & JTNP ZR & 2.22 & 0.21 & 2.04 \\
\hline September 13, 2011 & Rain Gauge & 27.1 & 75.4 & 1.2 \\
\hline & JTNP ZR & 19.7 & 71.2 & 3.02 \\
\hline July 13, 2012 & Rain Gauge & 0.9 & 2.9 & 6.0 \\
\hline & JTNP ZR & 1.69 & 2.96 & 5.17 \\
\hline August 17, 2012 & Rain Gauge & & & 16.0 \\
\hline & JTNP ZR & & & 29.4 \\
\hline
\end{tabular}

The results for all events are presented in Figure 6.3, which graphs the original reflectivity values to the rain gauge values, with the Z-R relationship graphed for comparison. 


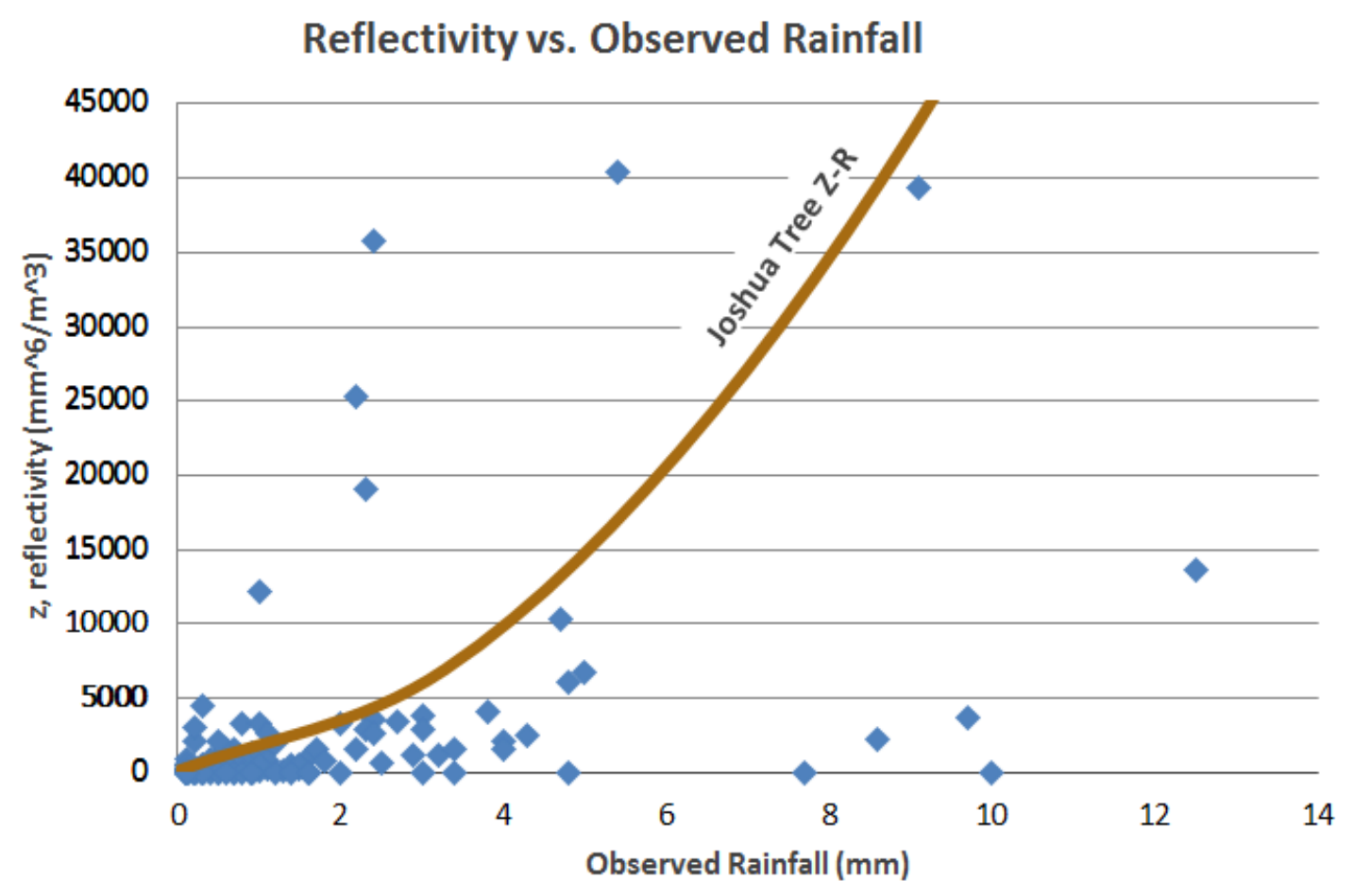

Figure 6.3: Fitting NEXRAD Level II reflectivity data to rain gauge data

\subsubsection{Regional Z-R Comparisons}

This section takes a closer look at how the derived Z-R relationships compare to two regional relationships published in the literature. These are the Z-R relationship derived for the Arizona monsoon season (Morin et al., 2009), and the Z-R relationship used by the NWS for convective storms.

Rain totals for each of the Z-R relationships considered were generated for each monsoon event, and the rain totals were extracted for each of the three rain gauge location. These data are presented in Appendix B. A subset is listed in Table 6.4. 
Table 6.4: Rain gauge observations and estimates from regional $Z-R$ relationships

\begin{tabular}{|c|c|c|c|c|}
\hline Event Date & Measurement Type & Pw & Cw & $\mathrm{Br}$ \\
\hline \multirow[t]{4}{*}{ August 22, 2009} & Rain Gauge & 1 & 0.8 & 0.7 \\
\hline & JTNP ZR & 3.28 & 1.05 & 0.62 \\
\hline & Arizona ZR & 2.43 & 0.69 & 0.41 \\
\hline & NWS ZR & 4.25 & 1.22 & 0.72 \\
\hline \multirow[t]{4}{*}{ July 15, 2010} & \multicolumn{2}{|l|}{ Rain Gauge } & & 4.7 \\
\hline & JTNP ZR & & & 3.66 \\
\hline & \multicolumn{2}{|l|}{ Arizona ZR } & & 5.15 \\
\hline & NWS ZR & & & 9 \\
\hline \multirow[t]{4}{*}{ August 26, 2010} & Rain Gauge & 6.8 & & \\
\hline & JTNP ZR & 18.9 & & \\
\hline & Arizona ZR & 32.19 & & \\
\hline & NWS ZR & 53.23 & & \\
\hline \multirow[t]{4}{*}{ October 3, 2010} & Rain Gauge & 12.3 & 5.7 & \\
\hline & JTNP ZR & 7.74 & 3.28 & \\
\hline & Arizona ZR & 8.7 & 3.58 & \\
\hline & NWS ZR & 15.19 & 6.24 & \\
\hline \multirow[t]{4}{*}{ July 6, 2011} & Rain Gauge & 1.5 & 0.1 & 3.3 \\
\hline & JTNP ZR & 2.22 & 0.21 & 2.04 \\
\hline & Arizona ZR & 1.63 & 0.12 & 1.55 \\
\hline & NWS ZR & 2.85 & 0.22 & 2.72 \\
\hline \multirow[t]{4}{*}{ September 13, 2011} & Rain Gauge & 27.1 & 75.4 & 1.2 \\
\hline & JTNP ZR & 19.7 & 71.2 & 3.02 \\
\hline & Arizona ZR & 22.71 & 145.1 & 2.03 \\
\hline & NWS ZR & 39.66 & 253.46 & 3.54 \\
\hline \multirow[t]{4}{*}{ July 13, 2012} & Rain Gauge & 0.9 & 2.9 & 6 \\
\hline & JTNP ZR & 1.69 & 2.96 & 5.17 \\
\hline & Arizona ZR & 1.37 & 3.13 & 6.74 \\
\hline & NWS ZR & 2.38 & 5.47 & 11.77 \\
\hline \multirow[t]{4}{*}{ August 17, 2012} & \multicolumn{2}{|l|}{ Rain Gauge } & & 16 \\
\hline & JTNP ZR & & & 29.4 \\
\hline & \multicolumn{2}{|l|}{ Arizona ZR } & & 55.96 \\
\hline & NWS ZR & & & 97.7 \\
\hline
\end{tabular}

Table 6.5 summarizes the results by looking at the calculated RMSE and standard deviation for each Z-R relationship. 
Table 6.5: Statistics of the Z-R relationships

\begin{tabular}{|c|c|c|c|}
\hline Comparison Measure & $\begin{array}{l}\text { Joshua Tree Z-R } \\
Z=365.2 R^{1.82}\end{array}$ & $\begin{array}{c}\text { Arizona Z-R } \\
z=655 R^{1.4}\end{array}$ & $\begin{array}{l}\text { NWS Convective Z-R } \\
\quad z=300 R^{1.4}\end{array}$ \\
\hline RMSE & $1.59 \mathrm{~mm}$ & $2.25 \mathrm{~mm}$ & $4.28 \mathrm{~mm}$ \\
\hline
\end{tabular}

From the summary table, it can be shown that the Joshua Tree Z-R has the lowest RMSE compared to the other two regional Z-R relationships. Based on the comparison of individual storm events with low to moderate rainfall, the Joshua Tree Z-R and the Arizona Z-R are similar. This observation differs for extreme rainfall. Figure 6.4 compares the rainfall estimations for the three regional Z-R relationships for the September 13, 2011, event, a heavy rainfall event that caused damage to park infrastructure. The three estimations vary greatly, but the Joshua Tree Z-R does match the observed rainfall more closely, as was shown in Table 6.4. 

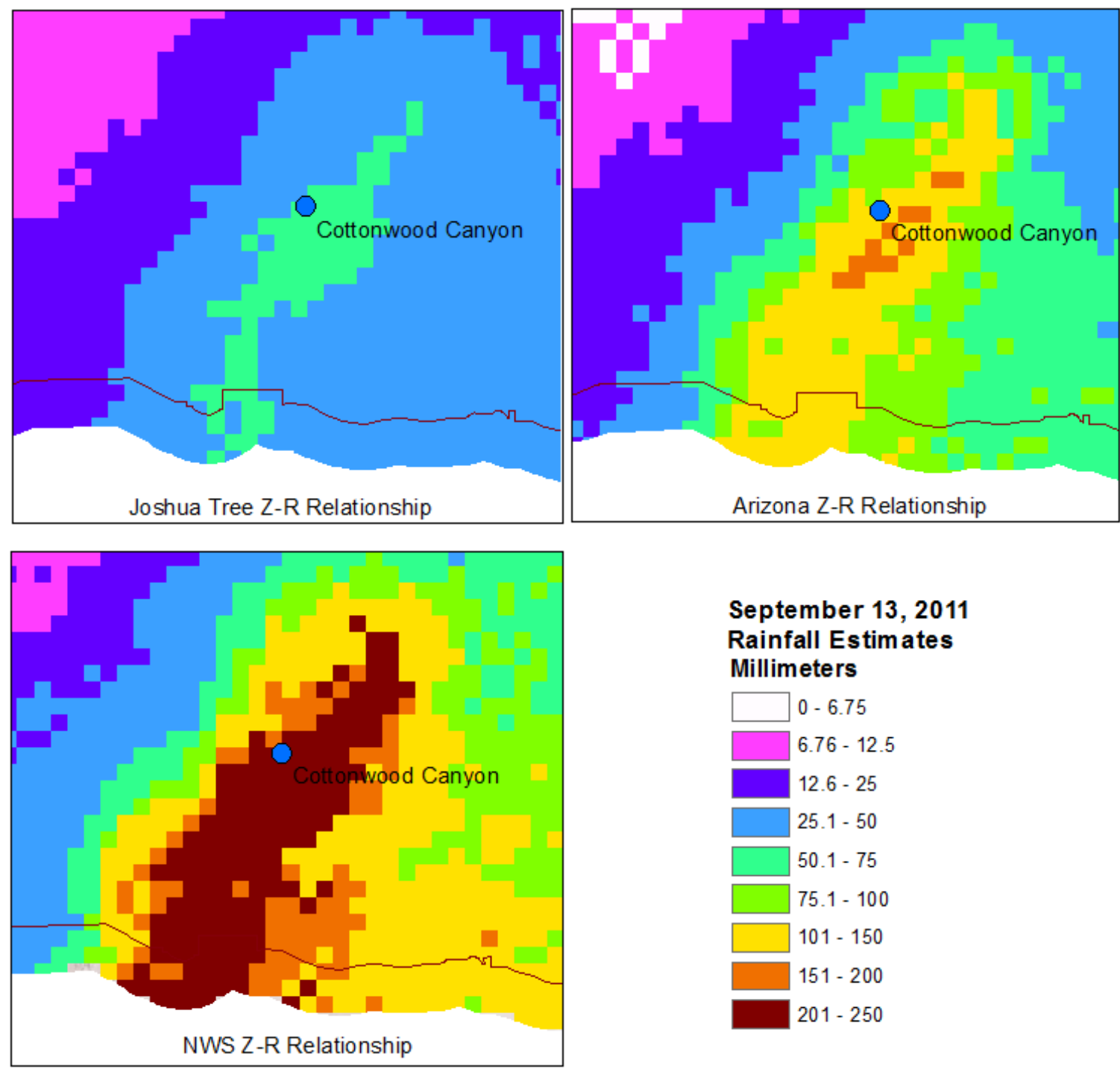

September 13, 2011

Rainfall Estimates

Millimeters

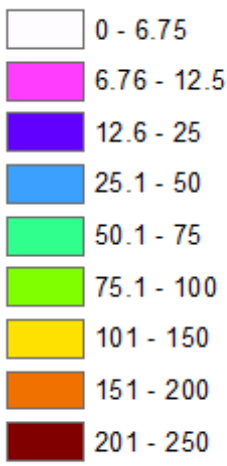

Figure 6.4: Comparison of the Joshua Tree Z-R, Arizona Z-R, and NWS convective $\mathrm{Z}$-R estimates over the Cottonwood Canyon rain gauge

Overall, there were many events that could be compared and various factors to consider. It was apparent that no one Z-R relationship could accurately estimate the rainfall for every event. Overall, the Joshua Tree Z-R relationship had the lowest RMSE and was the best compromise between estimating low, moderate and heavy rainfall 
events. Therefore, this Z-R relationship was used in the final script tool delivered to the client.

\subsubsection{Individual Z-R Relationships}

A current theme of study in the literature is to use Z-R relationships for local geographic areas and even each storm if enough real-time information is available. While implementing a solution like this is currently not practical for Joshua Tree, individual Z$\mathrm{R}$ relationships were derived for each station using the rain gauge data available. This was done in order to see if errors could be reduced, as well as to explore how different the station Z-R relationships were. Differences may indicate variations in the role of topography or local environment, or even differences in the returned energy to the radar from each local area.

Due to the limited number of observations available for individual stations, no check data were allocated for accuracy analysis of individual Z-R relationships. The statistics were calculated based on the data used to derive the Z-R relationships, which fit the errors. The derived Z-R relationships for each station are shown in Table 6.6.

Table 6.6: Individual station $\mathrm{Z}-\mathrm{R}$ relationships

\begin{tabular}{|c|c|c|}
\hline Station & Number of Observations & Z-R Relationship \\
\hline Black Rock & 35 & $z=195.9 R^{2.13}$ \\
\hline Cottonwood & 54 & $z=949.1 R^{1.06}$ \\
\hline Pinto Wells & 59 & $z=261.9 R^{1.74}$ \\
\hline
\end{tabular}


The three Z-R relationships derived for each station differ from one another.

Table 6.7 compares these relationships to each other and to the regional Joshua Tree Z-R relationship with regard to their standard deviations.

Table 6.7: Comparing park-wide Z-R relationships to local relationships

\begin{tabular}{|c|c|c|c|c|}
\hline Comparison Measure & JTNP & PW & CW & BR \\
\hline $\begin{array}{c}\text { Standard Deviation to } \\
\text { Pinto Wells } \\
\text { observations }\end{array}$ & 1.67 & 1.63 & & \\
\hline $\begin{array}{c}\text { Standard Deviation to } \\
\text { Cottonwood } \\
\text { observations }\end{array}$ & 1.38 & & 0.75 & 1.17 \\
\hline $\begin{array}{c}\text { Standard Deviation to } \\
\text { Black Rock } \\
\text { observations }\end{array}$ & 1.36 & & & \\
\hline
\end{tabular}

From this analysis it can be argued that individual Z-R relationships for each rain gauge area do perform better and would likely produce more accurate results for each storm over that given area.

\subsubsection{Winter Z-R Relationships}

It is generally true that the Z-R relationship varies by location, as evidenced by the comparison above, as well as by season and storm type. While the summer monsoon events were the focus and motivation for this project, a Z-R relationship was also calculated for winter storms for the convenience of JTNP. Data from winter storms were scrutinized and used to calculate the Z-R relationship.

The final winter Z-R relationship derived was:

$$
z=23.8 R^{3.17}
$$


Within the script tool interface, a choice between the summer and winter season needs to be made by the user. Choosing summer means that the Z-R relationship for monsoon data is used while choosing winter uses the winter Z-R relationship.

\subsection{Script Tool User Interface and Outputs}

This section describes the interface of the developed tools and presents some results using the tools.

\subsubsection{Script Tool User Interface}

The primary tool produced for this project was the NEXRAD Level II Conversion tool. The user interface for this tool is shown in Figure 6.5. The parameters needed from the user are the input directory where the raw Level II files were stored, the desired output directory, the desired output file name, the season as either winter or summer, the file location of the clipping feature to extract the area of the park, and the mosaic dataset option. The input directory should contain those files downloaded for a single event only, as the script does not make an attempt to parse the file names to determine whether or not there are any extraneous files located in the directory. The clipping feature used during development was the Hydrologic Unit Code boundary because this provides a margin around the park, but the clipping feature is an option for the user. Once the parameters are given, the tool runs in the manner described in Chapter 5. The output is stored in the output directory. The user can choose to add the event to the mosaic dataset within the geodatabase. 


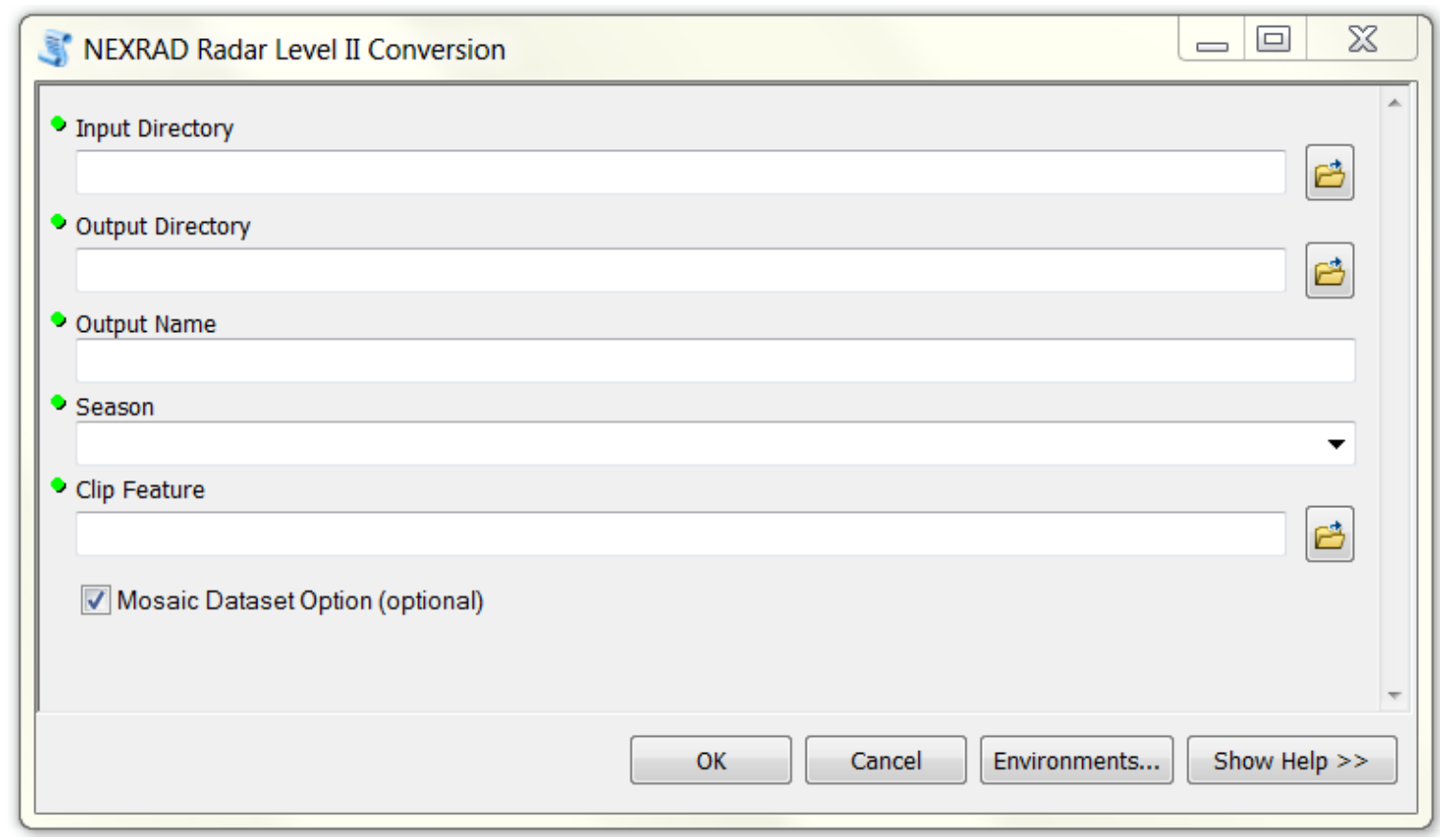

Figure 6.5: NEXRAD Level II conversion tool graphical user interface

The second tool was the NWS Precipitation Conversion tool. Even though the analysis discussed in this chapter revealed that this data source was not the most accurate, particularly for summer monsoon events, these data can be easily downloaded and are ready to use. This dataset is also available more quickly than the NEXRAD Level II data. The tool can be used to convert the data into a GIS format to provide a quick look at an event from any season. The parameters are input file directory and output file location. The graphical user interface (GUI) is shown in Figure 6.6. This script was designed to process either a single file or multiple files, therefore an output name was not required. Instead, a default file name for each input file was created within the script. The input directory should contain only the files that will be processed, as the script will try to process any raster type file. The clip feature is left as an option, but it is the expanded 
boundary feature class is recommended in the tool help in order to capture all of the precipitation information along the boundary of the park.

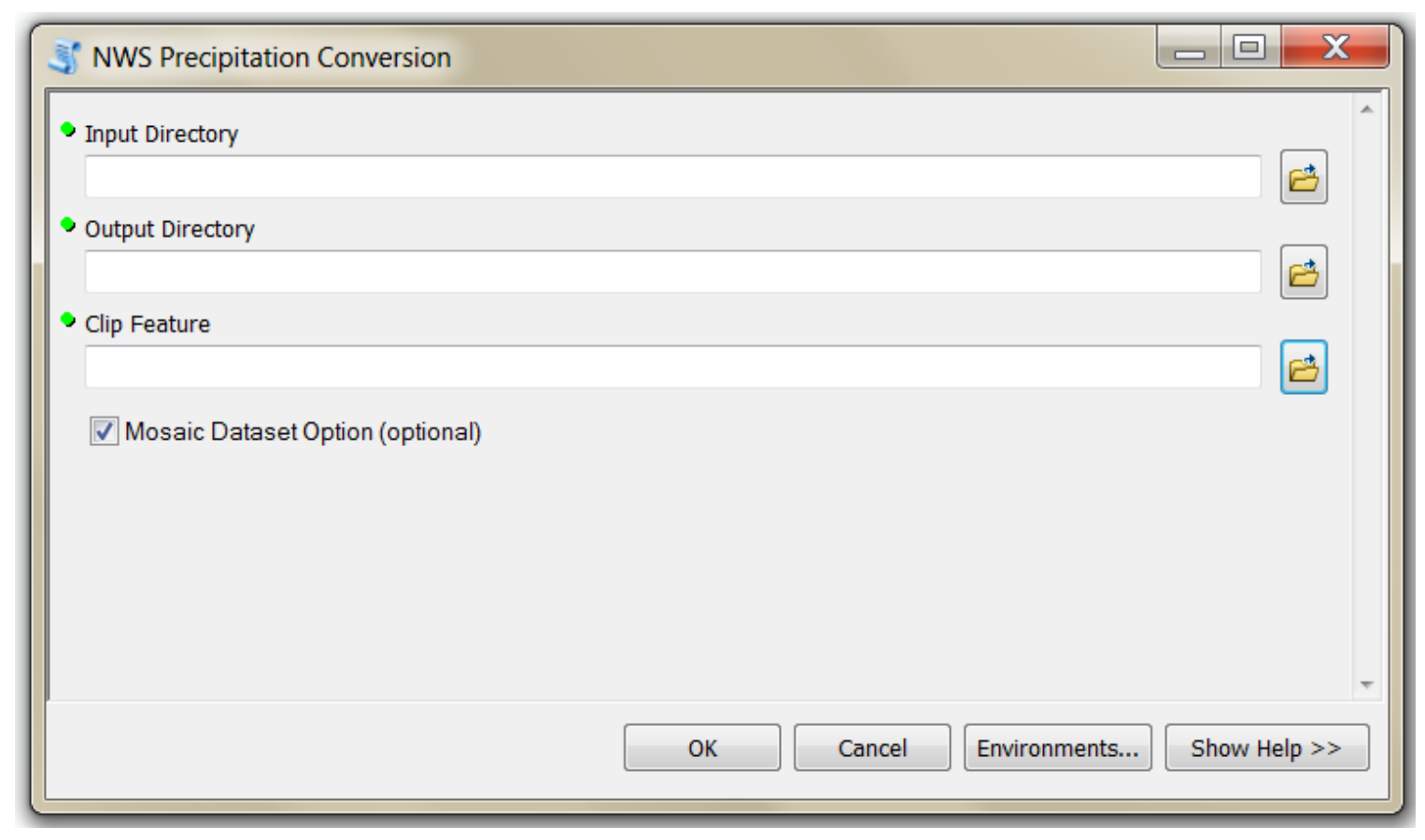

Figure 6.6: NWS Precipitation Conversion tool graphical user interface

The third tool built for this project was the Runoff and Infiltration Calculation tool. This script required several user defined parameters, as shown in Figure 6.8. The precipitation data file is the first input. The next three parameters define the output workspace and the output names for the runoff and infiltration products. The next input is the Curve Number (CN) grid, which gives the user three choices. As discussed in Chapter 4, the soil curve number depends on the environmental conditions prior to the event, described as the antecedent rainfall condition, or ARC. All three CN grids calculated from the three ARC conditions were stored in the project's geodatabase. With some knowledge of the conditions prior to a rainfall event, the proper $\mathrm{CN}$ grid can be 
used to estimate more accurate runoff and infiltration values. For summer monsoon events, the $\mathrm{CN}$ grid derived from ARC I conditions may be more appropriate, as rainfall events are infrequent. In the winter, there have been occasions where storms occurred on subsequent days or lasted for long periods of time. In these cases, the ARC III CN values may be more appropriate. After the $\mathrm{CN}$ Grid, the clipping feature and the Flow Direction grid for the accumulated runoff product were required. The output name for the accumulated runoff parameter is the last required field. The final user parameter was the option for adding layers to the respective mosaic datasets. The GUI is shown in Figure 6.7.

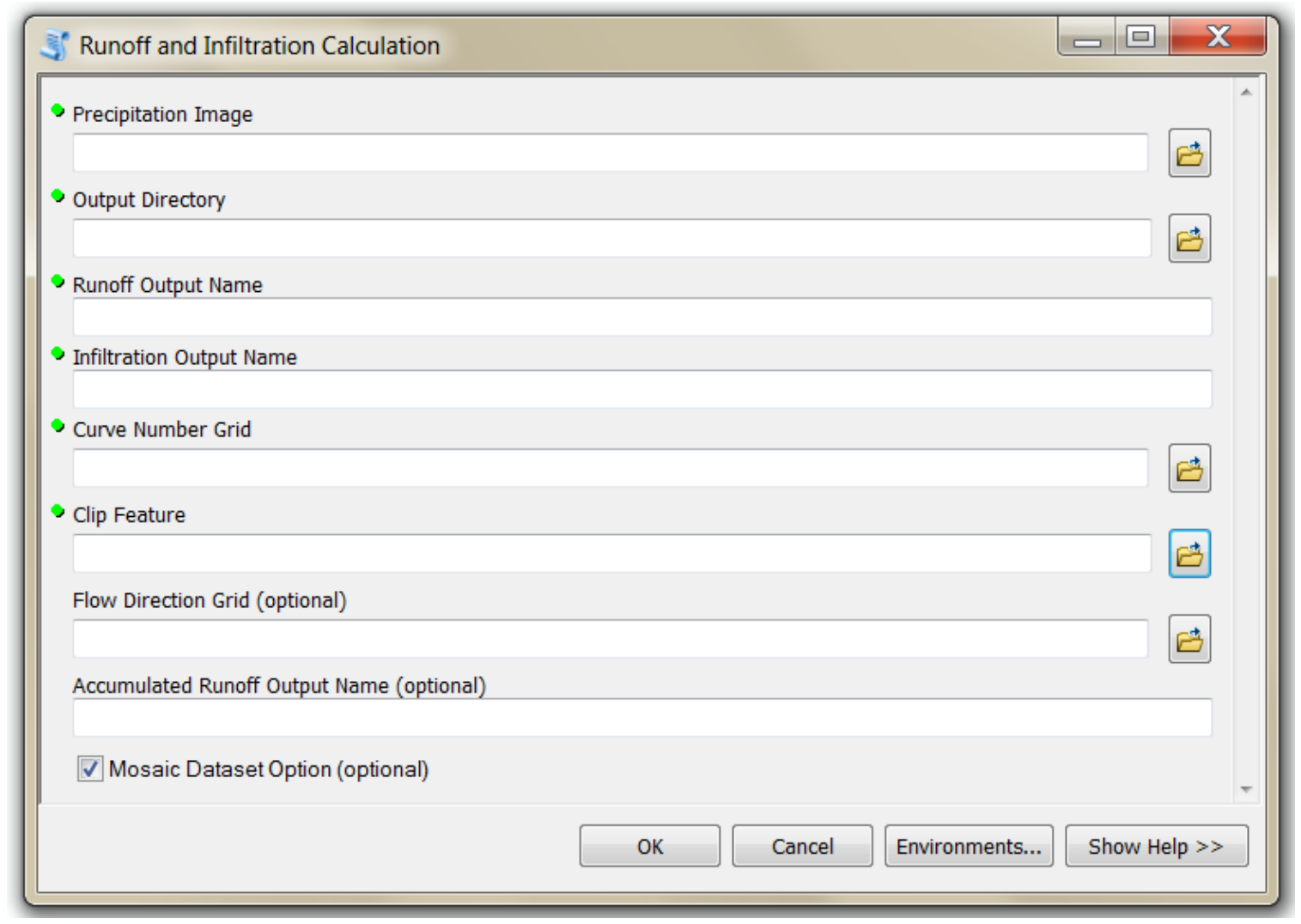

Figure 6.7: Graphical user interface for the runoff and infiltration calculation tool. 


\subsubsection{Precipitation Map Output}

The precipitation maps generated by the tools provide information in the form of rainfall estimates over the entire area of the park. The results proved the enhanced monitoring capability of precipitation shown by several discrete storms that were not recorded at a rain gauge station. Two examples of this are shown to demonstrate the output product's potential. The first example, shown in Figure 6.8, is the August 17, 2012 event, which was recorded only at the Black Rock station. The precipitation map shows several smaller, discrete storms for that day. A small storm to the north was centered over several main park roads, totaling in about $33 \mathrm{~mm}$ of rainfall. Another small storm was located just south of the Cottonwood rain gauge, which did not record any rainfall. The maximum rainfall in this location was over $25 \mathrm{~mm}$.

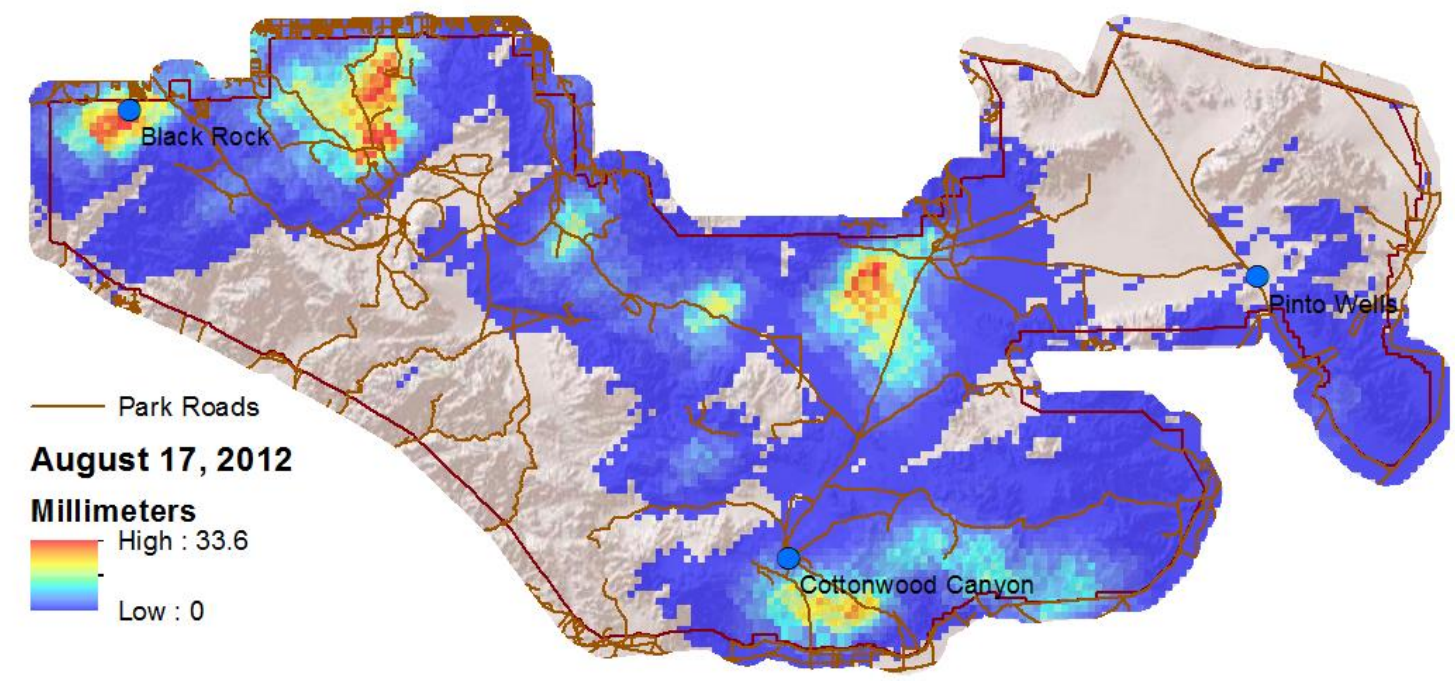

Figure 6.8: August 17, 2012 event precipitation map showing several small storms that were not recorded by rain gauge observations 
The second example was recorded by the Pinto Well station on August 26, 2010. The rainfall was concentrated more on the eastern side of the park; however there were two localized areas of high rainfall that totaled over $25 \mathrm{~mm}$. This example is shown in Figure 6.9 .

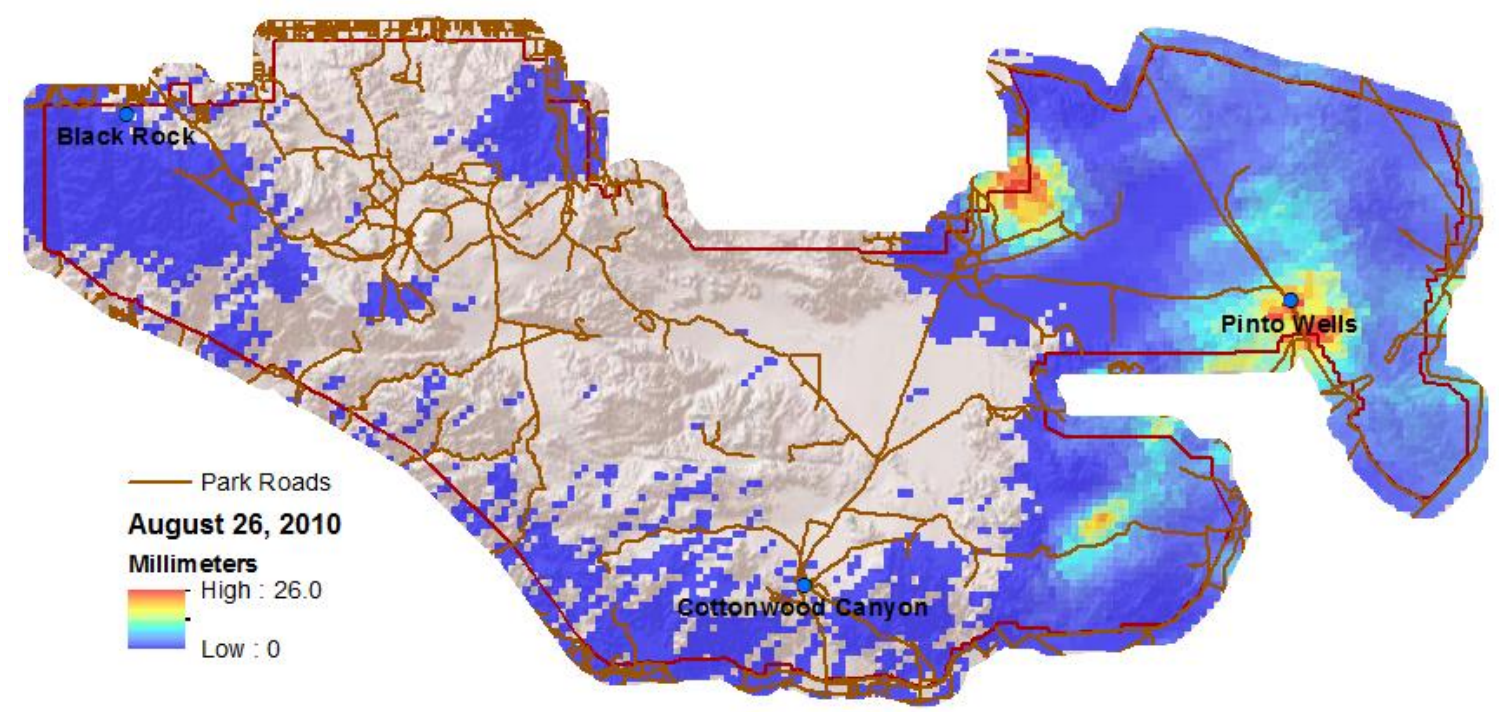

Figure 6.9: August 26, 2010 event showing several small storms that were not recorded by rain gauge observations

These examples provide answers to the questions of where, how much, and how extensive the impact of each event was. From these outputs alone, park officials can gain an understanding of what infrastructure may be affected and what vegetation and environment may be affected and can plan accordingly. Over time, park officials can also gain an understanding of where these events occur or if a particular area receives more rainfall than others in the course of a season. These insights could help target areas for ecological study or identify infrastructure that may be more vulnerable to potential damage. 


\subsubsection{Hydrology Analysis}

Figure 6.10 shows an example of the potential water infiltration product. Using the Soil Conservation Service (SCS) Curve Number method, runoff can be calculated along with the amount of water that potentially remains in situ and is available for plant life and wild life. This also represents the maximum amount of rainfall available for ground water recharge, though some amount will be used by plants or evaporate. This product depends on the soil characteristics and land cover. It indicates that the area with the most rain does not necessarily have the most rainfall available for the environment. The amount of water that infiltrates the ground also depends on the moisture content of the soil prior to the event. The maximum water infiltration product takes the soil, land cover, and precedent water conditions into consideration to model which areas received the most usable water after a rainfall event.

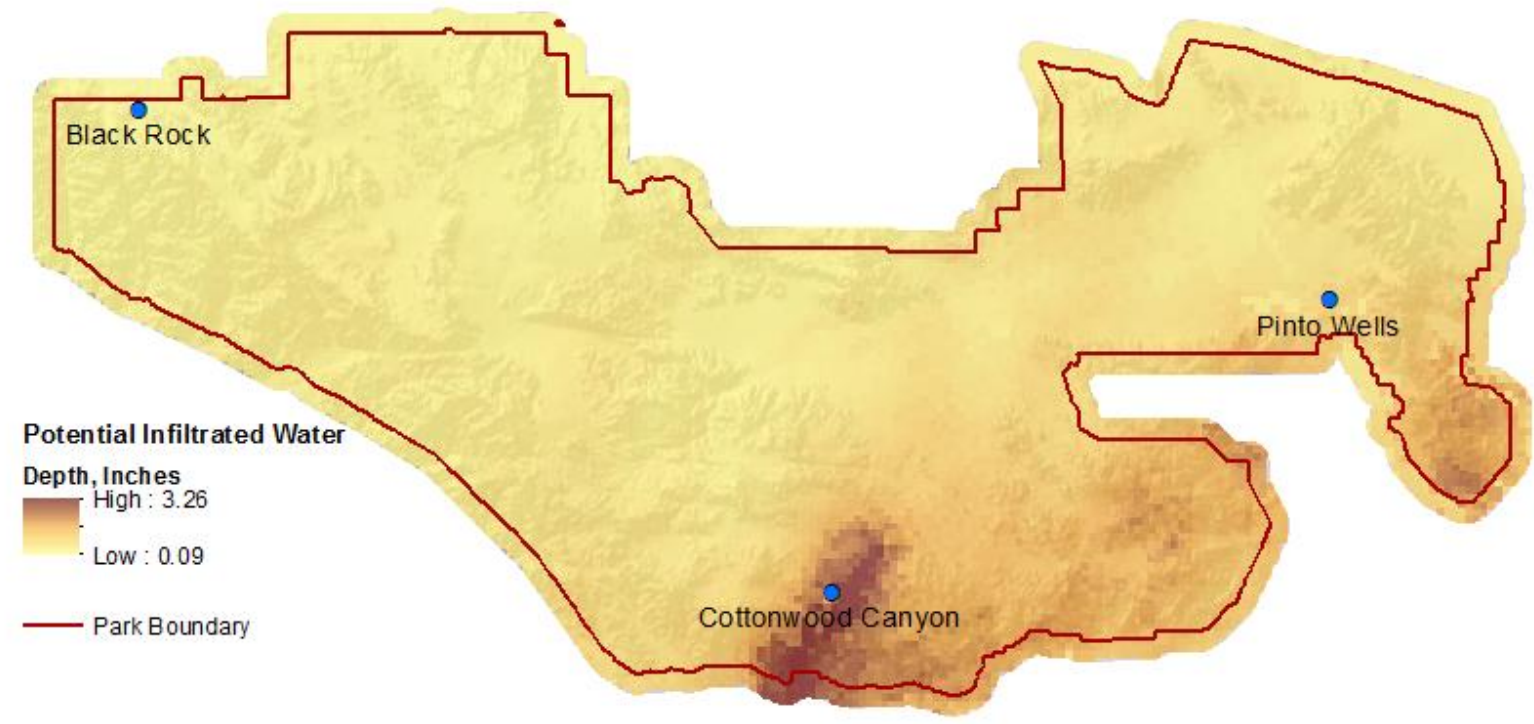

Figure 6.10: Maximum potential water infiltration for the September 13, 2011 monsoon event 
Runoff also depends on the soil characteristics and the land cover, as well as overcoming a minimum threshold depth before runoff begins. Figure 6.11 shows runoff generated from the September 13, 2011 event. Even though it rained throughout the park during that event, in many places it did not rain enough to generate runoff. Knowing where runoff was generated allows park officials to understand where more water could be present than expected, and what environments and infrastructure this excess water may interact with.

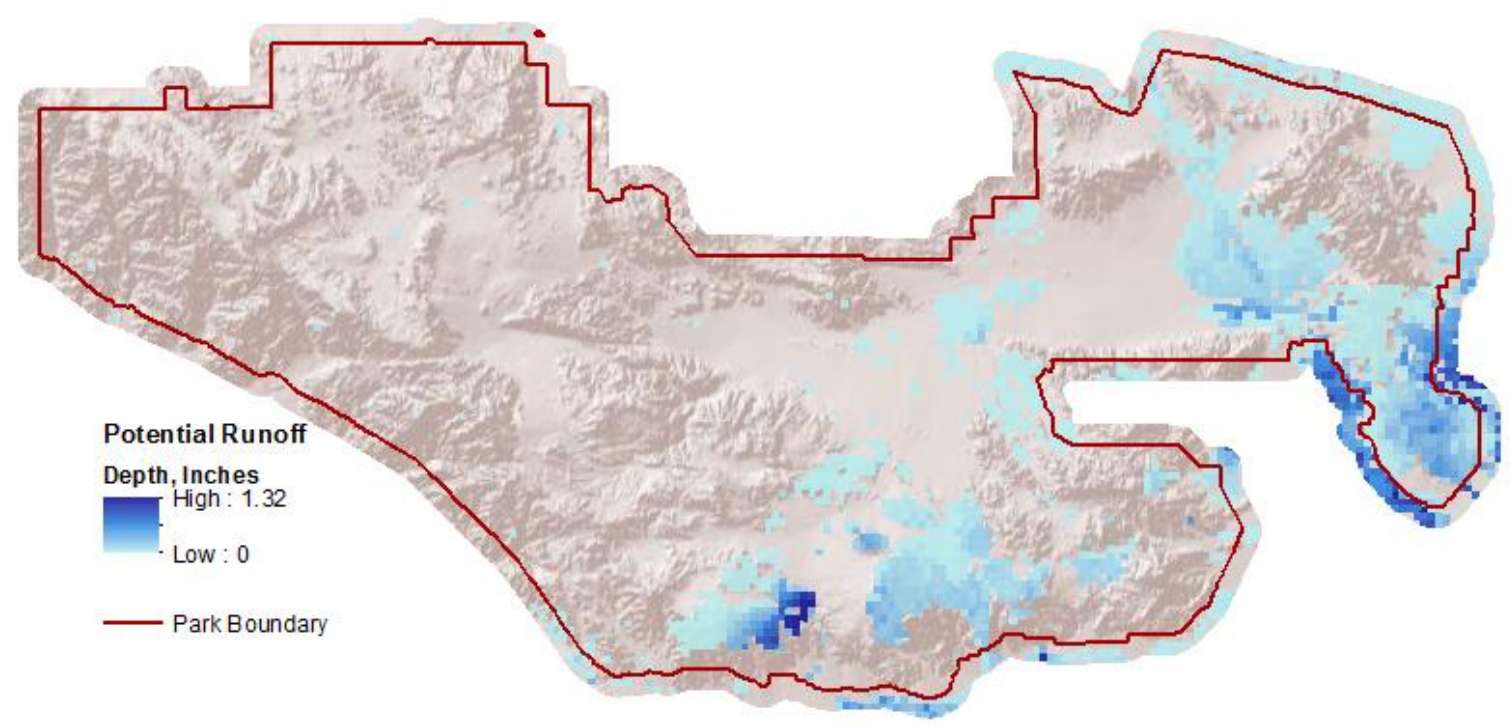

Figure 6.11: Calculated runoff using the SCS Curve Number method for the September 13, 2011 event

For the outputs generated from the runoff and potential water infiltration process, a margin around the park was included to capture the conditions immediately surrounding the park and to ensure that any edge effects produced during processing did not impact the boundaries. In certain areas around the park, however, this meant that the State 
Survey Geographic Database (STATSGO) had to be used for soil information rather than the more temporally current Soil Survey Geographic Database (SSURGO), which included voids in those areas. The difference in the resulting runoff is apparent on the eastern boundary in Figure 6.11. Figure 6.12 focuses on the eastern boundary of the park to show the juxtaposition of the two soil datasets. In some cases, the soil classification is different across the boundary of the park. This effect reflects a current limitation in the SSURGO dataset. If the SSURGO dataset is updated in the future, the soil dataset used in this process should be refined.

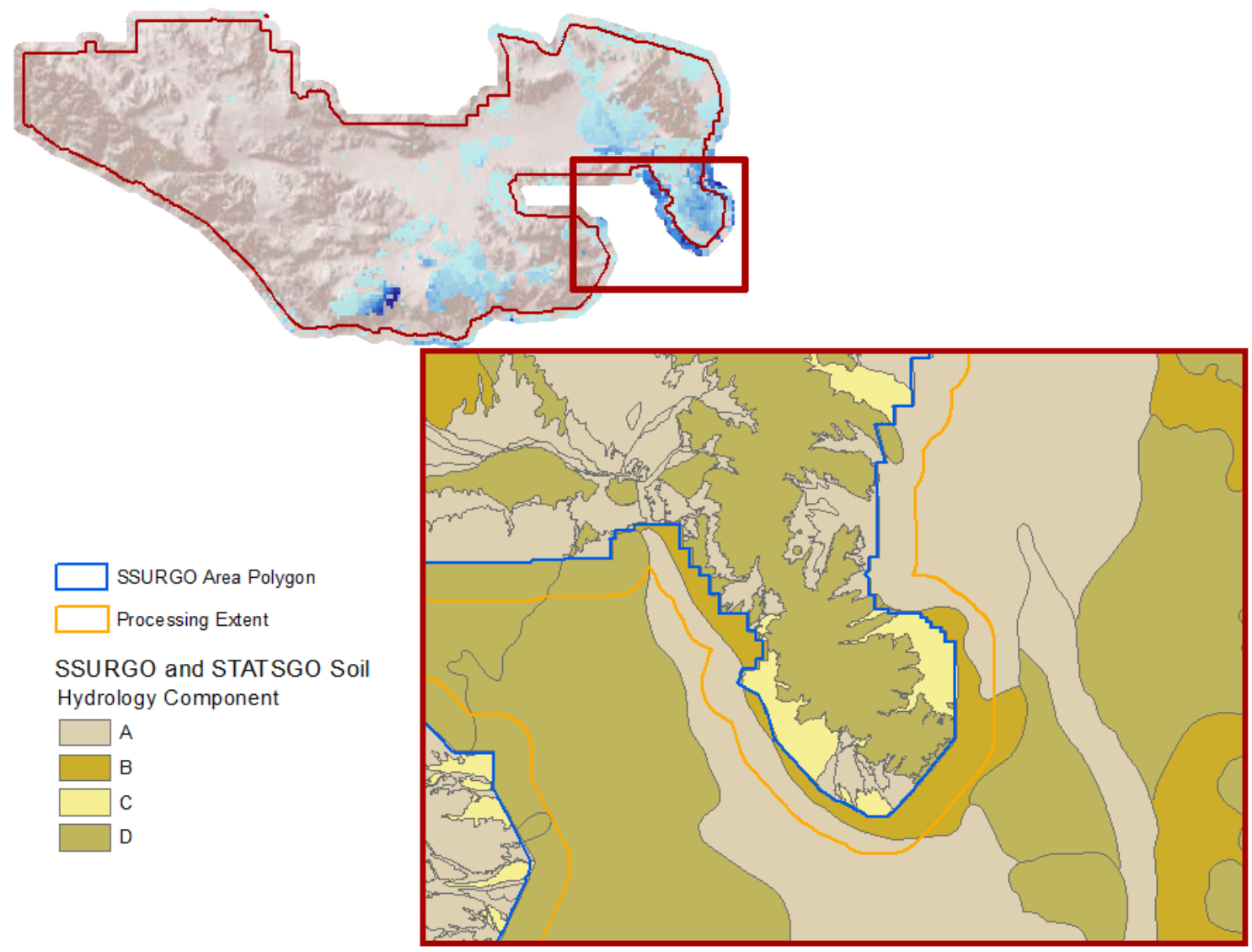

Figure 6.12: Runoff discrepancies between the boundaries of the two soil datasets. 
One of the biggest potential impacts from a monsoon event is flash flooding. An immediate concern after an event occurs is if there is any damage to roads, infrastructure, trails, or areas where visitors may be located. The event that occurred on September 13, 2011 was the largest in the past four years and caused both road and structural damage near the Cottonwood Canyon Visitor Center. A park official provided two shape files containing damage locations after this event, along with several images. The damaged locations are shown in Figure 6.13, along with the major park roads and the precipitation recorded that day.

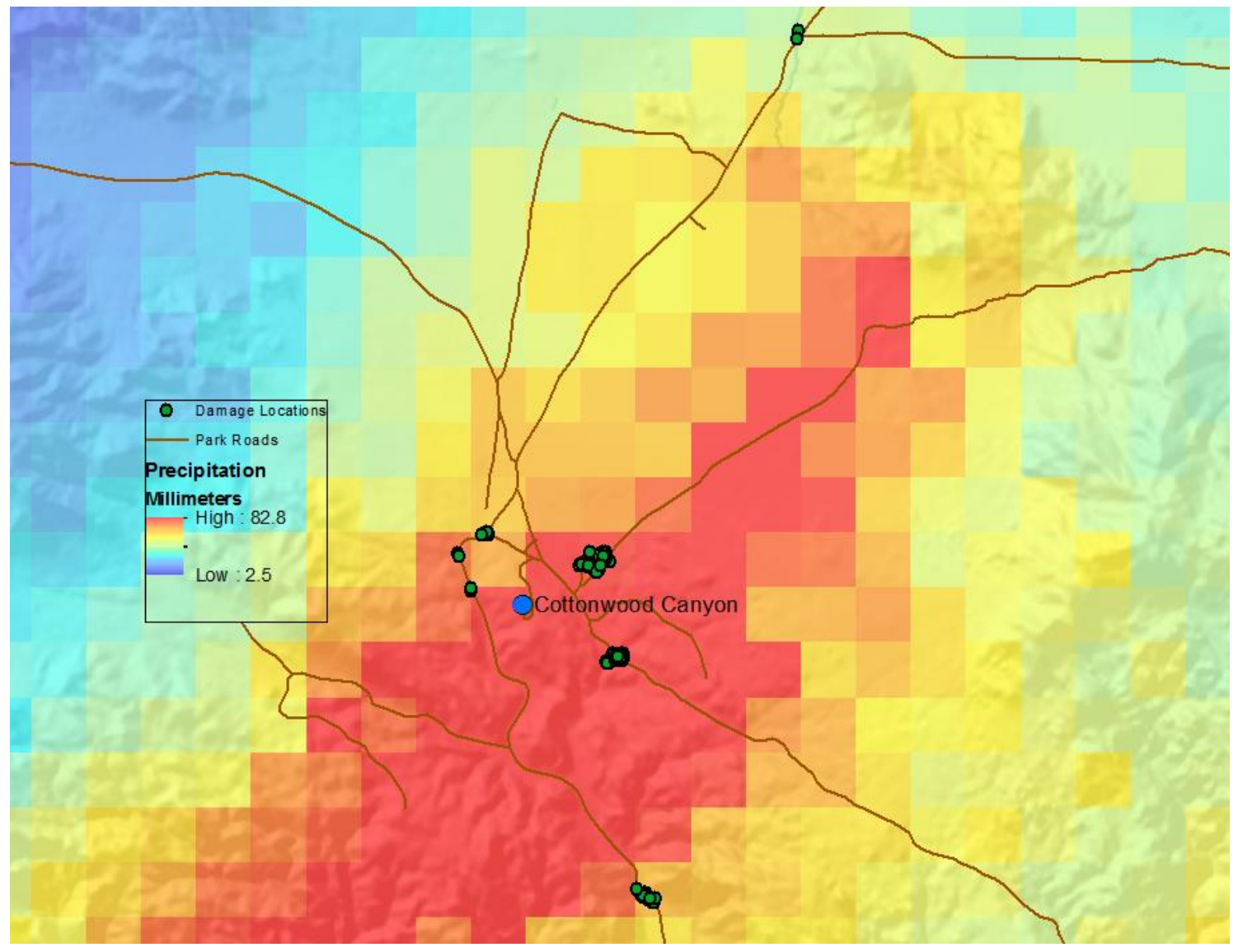

Figure 6.13: Precipitation map for September 13, 2011 event with the locations of documented damage from this event. 
Most of the damage occurred in and around the area that received the heaviest rainfall. The most northern damaged locations occurred just beyond this area, but were affected by a large amount of accumulated runoff. The runoff fractured the road and made it impassable. An image of this damage, provided by the client, is shown in Figure 6.14.

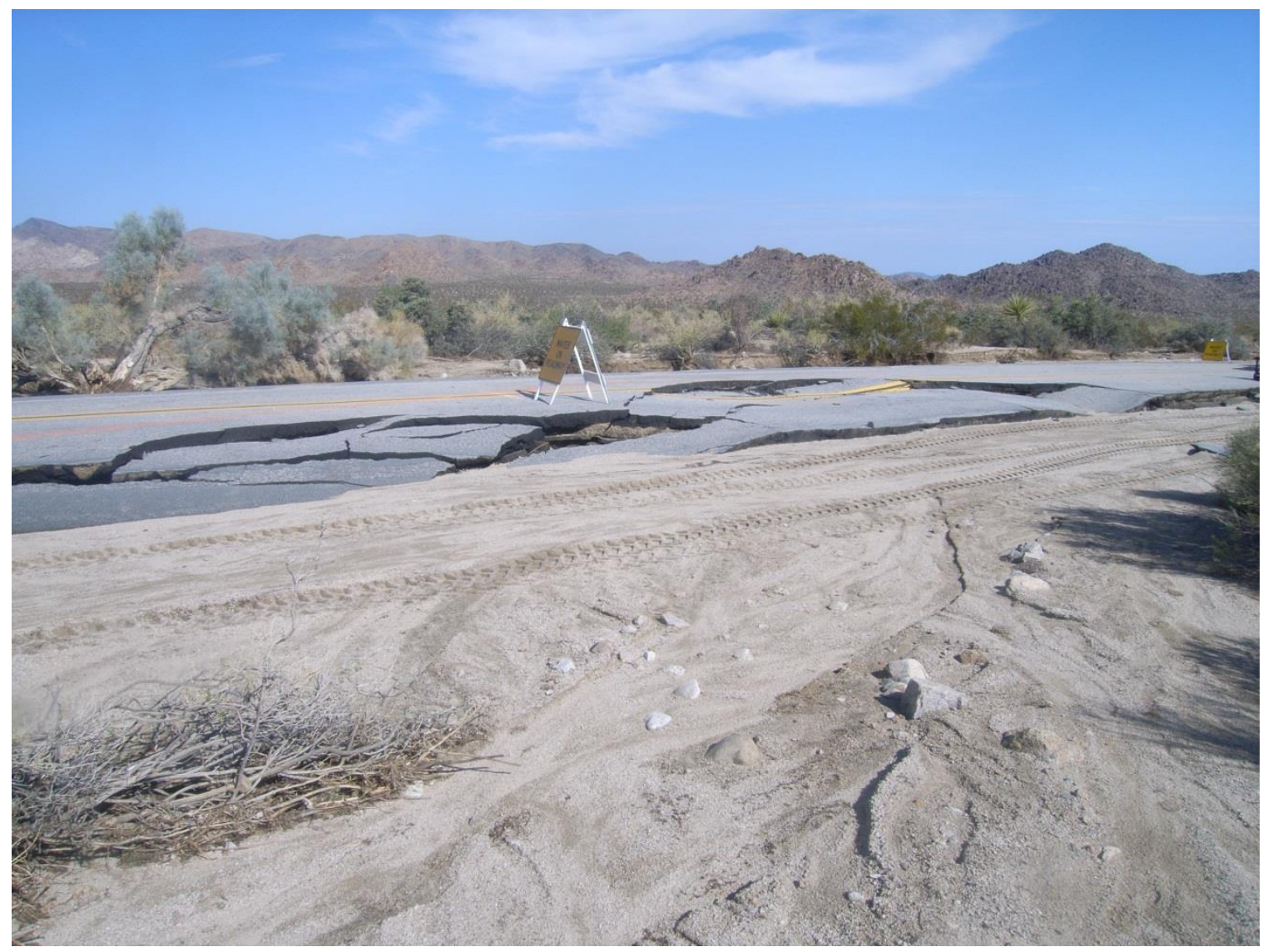

Figure 6.14: Northern road damage resulting from runoff on September 13, 2011. Courtesy the National Park Service.

Another example of damage is shown in Figure 6.15. This image was taken at the most southern area of damaged locations shown in Figure 6.13. Here the road remained intact, but a large area adjacent to the road was scoured away by the accumulated runoff. 


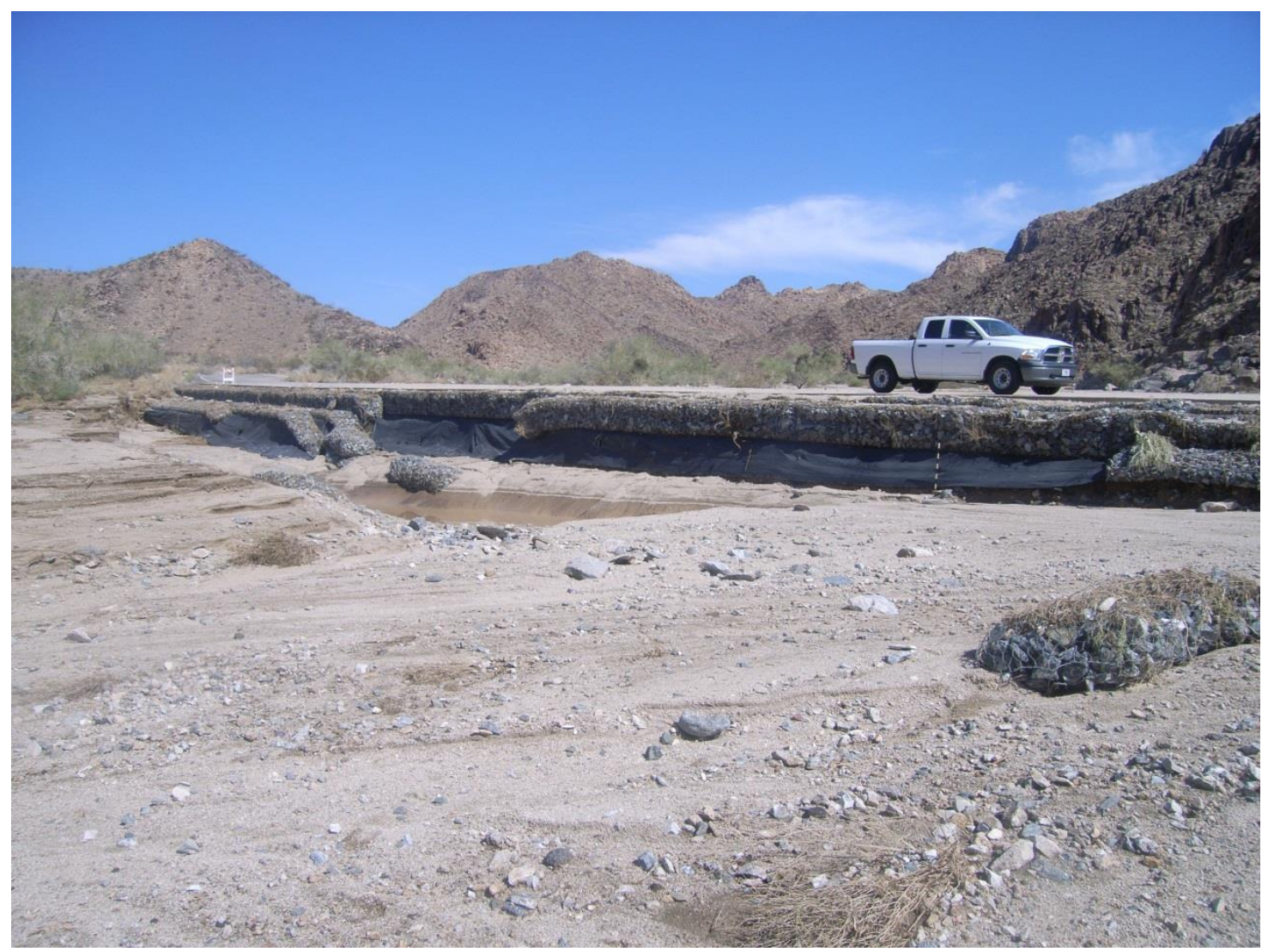

Figure 6.15: Southern road damage location. The area adjacent to the road was scoured out by the runoff during the September 13, 2011 event. Courtesy the National Park Service.

The accumulated volume of water was calculated using the developed tool. This output shows how much water potentially traveled along streams and drainages during the event. Focusing on the southern damage location, Figure 6.16 shows the accumulated runoff result, as well as the estimated water volume that would have been generated. Where the runoff crosses the road, over 4000 cubic feet of runoff was estimated. From the distribution of damage, it appears that the runoff did not travel along a well-defined drainage, but more likely spread out to flow adjacent to the road. For a future event, examining the accumulated water volume output could alert park officials to areas of road may be impacted. 


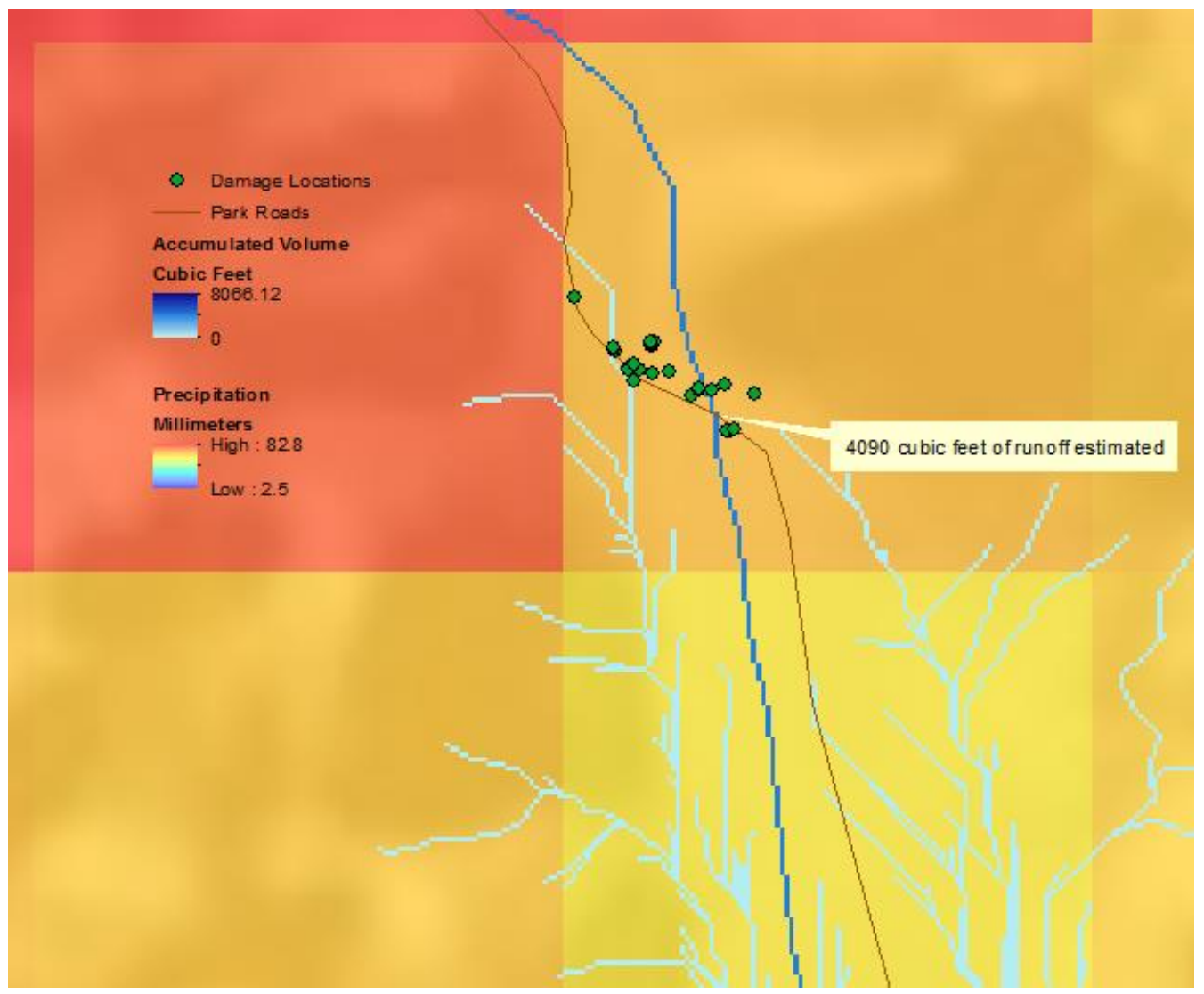

Figure 6.16: September 13, 2011 precipitation map overlaid with accumulated runoff, with the damage locations near the southernmost main road

Currently, the accumulated runoff volume output only generates estimates for areas where runoff is known to occur. In reality, the accumulated runoff may travel further, depending on the duration of the storm, topography, and environmental conditions. However, these hydrology outputs from the developed tool can give an overall assessment of the magnitude of a storm event, as well as an idea of the potential impact and location. They can also help with future planning and mitigation efforts by knowing what areas are more likely to receive runoff and where drainages are most likely to interact with infrastructure. 


\subsection{Summary}

This chapter reviewed several aspects of the results of this project. The Joshua Tree Z-R relationship derived during this project was the most accurate for estimating rainfall over the park. Several examples were presented to demonstrate the capability of using NEXRAD II data to capture small monsoon events and estimate accurate precipitation.

The hydrology tools were also discussed to show their potential for providing useful information about possible impacts from monsoon events. 



\section{Chapter 7 - Conclusions and Future Work}

\subsection{Project Summary and Conclusions}

The purpose of this project was to develop tools to generate precipitation maps for Joshua Tree National Park. These precipitation maps would address the specific challenges of summer monsoon events and deliver information about short lived and sporadic storms. The products developed from this project would also address questions about the ecological effects of the rainfall events, as well as the impacts on infrastructure.

Through the work and analysis done for this project, it has been shown that NEXRAD Level II data can adequately detect and track monsoon events, and produce viable precipitation maps for Joshua Tree National Park. This solution was made possible by decoding the NEXRAD Level II data using third party software, which was seamlessly incorporated into the Python script from this project. An ArcGIS script tool incorporated these solutions and provided an easy-to-use graphical user interface to produce the precipitation maps. A second tool allowed the National Weather Service (NWS) Precipitation data to be utilized within a GIS environment.

An additional tool was developed to focus on potential impacts of precipitation events. Together with the NEXRAD Level II conversion tool or the NWS Precipitation tool, a general understanding of the potential runoff depth, accumulated volume, and potential maximum water infiltration can be gained for each event. These products, along with the precipitation maps, should help Joshua Tree National Park answer questions about the location of rainfall events, where potential flooding may occur, and where the 
most water available for vegetation is located. By analyzing past and current events, park officials can also gain an understanding of what areas of the park may receive more rainfall, what infrastructure may be vulnerable after an event, and what mitigation strategies can be taken in the future.

\subsection{Future Work}

This project developed a viable solution for generating precipitation maps that estimate rainfall over Joshua Tree National Park. This project focused on the summer monsoon events which are harder to capture in rainfall data, and used methods to provide estimates that are as accurate as possible. In addition to this, this project provided a preliminary tool to address the basic hydrological impacts from rainfall events. This work goes a long way to answering the questions park officials have about rainfall events within the Joshua Tree National Park, but extensions to this project could be considered in the future and enhance the utility.

An example of this would be to expand on the hydrology model for the park area. Due to the scope of this project, the hydrology model was a simplified version. An extension of this project could focus fully on the hydrological impacts and consider factors such as the scale and timeline of the rainfall events and develop a more robust hydrology model for Joshua Tree National Park. A more consistent soil dataset could be derived to resolve discrepancies between the SSURGO and STATSGO data, which could improve the runoff and water infiltration products. Beyond this, the stream vector dataset currently used by the park could be revised as it currently includes the Colorado Aqueduct, which may not model surface flow accurately. Work could also be done to 
further model evaporation processes during and after monsoon events, as well as the factors influencing ground water recharge.

Another possible extension would be to use localized Z-R relationships that could be applied to the local area of each rain gauge. Localized Z-R relationships were investigated for this project, but not implemented as a solution due to the lack of sufficient high quality rain gauge data. More study on how the local environment and terrain affect rainfall amounts would also be helpful in order to determine the extent of each relationship's influence. The effects of the topography and environment and how they interact with precipitation is not well known for the park area, but if this were to change in the future, a localized solution could be applied.

Now that the precipitation map tools are in place, a project that focused on a method to automatically download near-real time NEXRAD Level II data could be undertaken. Outside vendors do offer NEXRAD Level II data in real-time, which could be downloaded through a paid service given the proper infrastructure and software. Another solution that approaches this utility would be to take advantage of the National Weather Services' RIDGE images, available at http://radar.weather.gov/ridge/GIS.html. These images are in Graphics Interchange Format (GIF) that are updated in near real-time and available via an ftp site. These images could be automatically downloaded and stored on a server, or even tested against the park's boundaries to determine whether or not rainfall has occurred over the park. Even though the original data would still need to be downloaded, a solution like this would still be a helpful addition to this project, as it would alert park officials of the timeframe of potential rainfall events over the park. 



\section{Works Cited}

Abdella, Y., \& Alfredsen, K. (2010). A GIS toolset for automated processing and analysis of radar precipitation data. Computers \& Geosciences, 422-429.

Adams, D. K., \& Comrie, A. C. (1997). The North American Monsoon. Bulletin of the American Meteorological Society, 2197-2213.

Alfieri, L., Claps, P., \& Laio, F. (2010). Time-Dependent Z-R Relationships for Estimating Rainfall Fields from Radar Measurements. Natural Hazards and Earth System Sciences, 149-158.

Ali, K., \& Said, M. (2009). Determination of Radar Z-R Relationship For Libya - Tripoli City. Proceedings of the World Congress on Engineering.

Ansari, S., Hutchins, C., Del Greco, S., Stroumentova, N., \& Phillips, M. (2009). The Weather and Climate Toolkit. 25th Conference on International Interactive Information and Processing Systems (IIPS) for Meteorology, Oceanography, and Hydrology.

Bhadra, A., Bandyopadhyay, A., Singh, R., \& Raghuwanshi, N. (2010). Rainfall-Runoff Modeling: Comparison of Two Approaches with Different Data Requirements. Water Resources Management, 37-62.

Crum, T. D., \& Alberty, R. L. (1993). The WSR-88D and the WSR-88D Operational Support Facility. Bulletin of the American Meteorological Society, 1669-1687.

Fournier, J.D. (1999) Reflectivity-Rainfall Rate Relationships in Operational Meteorology. Retrieved August 4, 2013 from http://www.srh.noaa.gov/tae/?n=research-zrpaper 
Fulton, R. A., Briedenback, D.-J. S., Miller, D. A., \& O'Bannon, T. (1998). The WSR 88D Rainfall Algorithm. Weather and Forcasting, 377-395.

Gad, M., \& Tsanis, I. (2003). A GIS Methodology for the Analysis of Weather Radar Precipitation Data. Journal of Hydroinformatics, 113-126.

Hammouri, N., \& El-Naqa, A. (2007). Hydrological Modeling of Unguaged Wadis in Arid Environments using GIS: A Case Study of Wadi Madoneh in Jordan. Revista Mexicana de Ciencias Geologicas, 185-196.

Hardegree, S., Van Vactor, S., \& Levinson, D. W. (2008). Evaluation of NEXRAD Radar Precipitiation Products for Natural Resources Applications. Rangeland Ecology and Management, 346-353.

HEC (Hydrologic Engineering Center). (2000). Geospatial Hydrologic Modeling Extension HEC-GeoHMS User's Manual, Version 1.0, CPD-77. Davis, California: U.S. Army Corps of Engineers Hydrologic Engineering Center.

Hunter, S. (2009). WSR-88D Radar Rainfall Estimation: Capabilities, Limitations and Potential Improvements. Retrieved April 28, 2013, from National Weather Service Weather Forecast Office: http://www.srh.noaa.gov/mrx/research/precip/precip.php

Klazura, G. \& Imy, A. (1993). A Description fo the Initial Set of Analysis Products Available from the NEXRAD WSR-88D System. Bulletin of the American Meteorological Society, 1293-1311.

Klazura, G., Thomale, J., Kelly, D. S., \& Jendrowski, P. (1999). A Comparison of NEXRAD WSR-88D Radar Estimates of Rain Accumulation with Gauge 
Measurments for High- and Low-Reflectivity Horizontal Gradient Precipitation Events. American Meterological Society, 1842-1850.

Knebl, M., Yang, Z., Hutchinson, K., \& Maidment, D. (2005). Regional scale flood modeling using NEXRAD rainfall, GIS, and HEC-HMS/RAS: a case study for the San Antonio River Basin Summer 2002 Storm event. Journal of Environmental Management, 325-336.

Martin, P., LeBoeuf, E., Dobbins, J., Daniel, E., \& Abkowitz, M. (2005). Interfacing GIS with Water Resource Models: A State-of-the-Art Review. Journal of the American Water Resources Association, 1471-1486.

McGee, J. (2009). Calculating Pervious Curve Numbers. ArcUser, 54-57.

Morin, E., Krajewski, W. F., Goodrich, D. C., Gao, X., \& Sorooshian, S. (2003).

Estimating Rainfall Intensities from Weather Radar Data: The Scale-Dependency Problem. Journal of Hydrometeorology, 782-797.

Morin, E., Maddox, R. A., Goodrich, D. C., \& Sorooshian, S. (2005). Radar Z-R Relationship for Summer Monsoon Storms in Arizona. Weather and Forcasting, $672-679$.

Muller, B. (n.d.). Radar Equation. Retrieved April 1, 2013, from http://wx.db.erau.edu/faculty/mullerb/Wx365/Radar_equation/radar_equation.pdf

Neary, V., Habib, H., \& Fleming, M. (2004). Hydrologic Modeling with NEXRAD Precipitation in Middle Tennessee. Journal of Hydrologic Engineering, 339-349.

Pennsylvania State University (2009, May 21). Using Soils Data. Retrieved June 4, 2013, from Geospatial Technology Program: http://lal.cas.psu.edu/software/tutorials/soils/st_diff.asp 
Smith, J., \& Krajewski, W. (1993). A Modeling Study of Rainfall Rate-Reflectivity Relationships. Water Resources Research, 2505-2514.

Tubbs, A. (1972). Summer thunderstorms over southern California. Monthly Weather Review, 799-807.

Vivoni, E. R., \& Sheehan, D. D. (2001, January 1). Using NEXRAD Rainfall Data in an ArcView-based Hydrology Model as an Education Tool. Retrieved from Using NEXRAD Rainfall Data in an ArcView-based Hydrology Model as an Education Tool:

http://proceedings.esri.com/library/userconf/proc01/professional/papers/pap374/p 374.htm

Xie, H., Zhou, X., Vivoni, E. R., Hendrickx, J. M., \& Small, E. E. (2005). GIS-based NEXRAD Stage III precipitation database: automated approaches for data processing and visualization. Computers \& Geosciences, 65-76.

Xie, H., Zhou, X., Vivoni, E., Guan, H., Tian, Y., Small, E., et al. (2006). Evaluation of NEXRAD Stage III Precipitation Data Over a Semiarid Region. Journal of the American Water Resources Association, 237-256.

Zhang, X., \& Srinivasan, R. (2010). GIS-based spatial precipitatioin estimation using next generation radar and raingauge data. Environmental Modelling \& Software, $1-8$. 


\section{Appendix A. Geodatabase Schema}

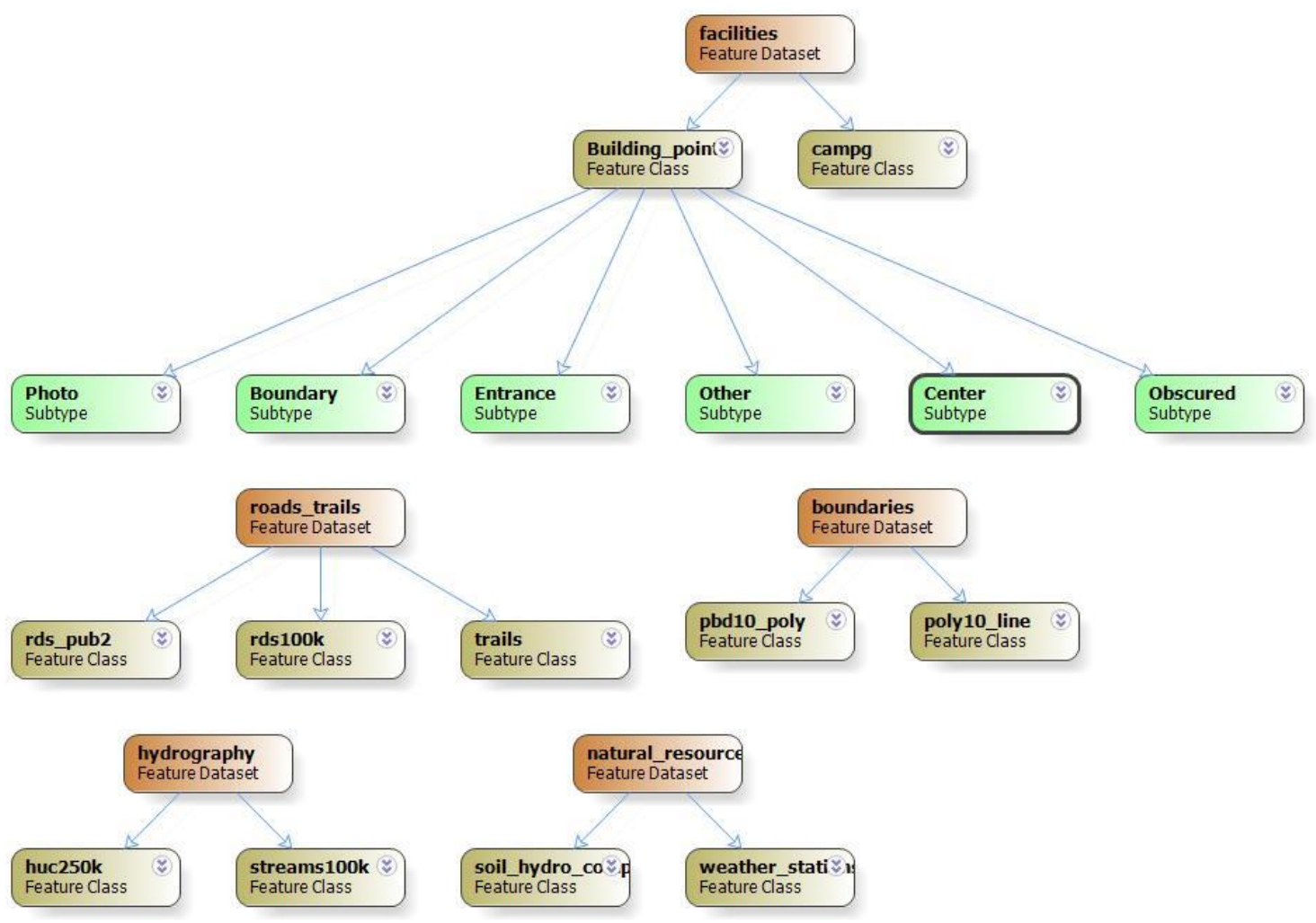

Figure A-1: Geodatabase schema showing included feature classes 


\section{Appendix B. Rainfall Comparison Tables}

Table A-1: Rain Gauge Observations

\begin{tabular}{|l|r|r|r|}
\hline Event Date & \multicolumn{1}{l|}{ Pw } & \multicolumn{1}{l|}{ Cw } & Br \\
\hline August 30, 2008 event a & 13.7 & & \\
\hline August 30, 2008 event b & 0.2 & & \\
\hline September 11, 2008 & 2.4 & & \\
\hline July 1, 2009 & & & 0.2 \\
\hline August 22, 2009 & 1 & 0.8 & 0.7 \\
\hline August 24, 2009 & & 0.1 & \\
\hline July 11, 2010 & & & 0.2 \\
\hline July 15, 2010 & & & 4.7 \\
\hline August 25, 2010 & 6.8 & & 6.2 \\
\hline August 26, 2010 & & & 2.5 \\
\hline September 29, 2010 & 1.5 & & 0.7 \\
\hline September 30, 2010 & 1.7 & 12.2 & \\
\hline October 2, 2010 event a & 12.3 & 5.8 & \\
\hline October 2, 2010 event b & 6.6 & 0.9 & \\
\hline October 3, 2010 & 1.5 & 0.1 & 3.3 \\
\hline July 4, 2011 & 1.6 & 0.3 & \\
\hline July 6, 2011 & 2.4 & 15.7 & 2.8 \\
\hline July 30, 2011 & 0.6 & 3.6 & 0.5 \\
\hline July 31, 2011 & 0.6 & 4.1 & \\
\hline September 5, 2011 & & & 1.6 \\
\hline September 6, 2011 & & & \\
\hline September 13, 2011 & & & \\
\hline October 5, 2011 & & & \\
\hline July 4, 2012 & & & \\
\hline July 13, 2012 & & & \\
\hline July 14, 2012 & & & \\
\hline July 30, 2012 & & & \\
\hline July 13, 2012 & & & \\
\hline August 11, 2012 & & & \\
\hline August 17, 2012 & & & \\
\hline August 22, 2012 & & & \\
\hline
\end{tabular}


Table A-2: Rain gauge observations compared to Regional Z-R relationship

\begin{tabular}{|c|c|c|c|c|}
\hline Event Date & Measurement Type & Pw & Cw & $\mathrm{Br}$ \\
\hline \multirow[t]{2}{*}{ August 30, 2008 event a } & Rain Gauge & 13.7 & & \\
\hline & JTNP ZR & 26.2 & & \\
\hline \multirow[t]{2}{*}{ August 30, 2008 event b } & Rain Gauge & 0.2 & & \\
\hline & JTNP ZR & 0.18 & & \\
\hline \multirow[t]{2}{*}{ September 11, 2008} & Rain Gauge & 2.4 & & \\
\hline & JTNP ZR & 4.46 & & \\
\hline \multirow[t]{2}{*}{ July 1, 2009} & Rain Gauge & & & 0.2 \\
\hline & JTNP ZR & & & 1.59 \\
\hline \multirow[t]{2}{*}{ August 22, 2009} & Rain Gauge & 1 & 0.8 & 0.7 \\
\hline & JTNP ZR & 3.28 & 1.7 & 1.05 \\
\hline \multirow[t]{2}{*}{ August 24, 2009} & Rain Gauge & & 0.1 & \\
\hline & JTNP ZR & & 0 & \\
\hline \multirow[t]{2}{*}{ July 11, 2010} & Rain Gauge & & & 0.2 \\
\hline & JTNP ZR & & & 0.5 \\
\hline \multirow[t]{2}{*}{ July 15, 2010} & Rain Gauge & & & 4.7 \\
\hline & JTNP ZR & & & 3.66 \\
\hline \multirow[t]{2}{*}{ August 25, 2010} & Rain Gauge & & & 6.2 \\
\hline & JTNP ZR & & & 9.1 \\
\hline \multirow[t]{2}{*}{ August 26, 2010} & Rain Gauge & 6.8 & & \\
\hline & JTNP ZR & 18.9 & & \\
\hline \multirow[t]{2}{*}{ September 29, 2010} & Rain Gauge & & & 2.5 \\
\hline & JTNP ZR & & & 2.6 \\
\hline \multirow[t]{2}{*}{ September 30, 2010} & Rain Gauge & & & 0.7 \\
\hline & JTNP ZR & & & 2.24 \\
\hline \multirow[t]{2}{*}{ October 2, 2010 event a } & Rain Gauge & 1.5 & & 1.1 \\
\hline & JTNP ZR & 1.55 & & 0.75 \\
\hline \multirow[t]{2}{*}{ October 2,2010 event $b$} & Rain Gauge & 1.7 & 12.2 & \\
\hline & JTNP ZR & 6 & 9.35 & \\
\hline \multirow[t]{2}{*}{ October 3, 2010} & Rain Gauge & 12.3 & 5.8 & \\
\hline & JTNP ZR & 6.74 & 3.28 & \\
\hline \multirow[t]{2}{*}{ July 4, 2011} & Rain Gauge & 6.6 & 0.9 & \\
\hline & JTNP ZR & 6.69 & 1.66 & \\
\hline
\end{tabular}


Table A-2: Continued

\begin{tabular}{|c|c|c|c|c|}
\hline Event Date & Measurement Type & Pw & Cw & $\mathrm{Br}$ \\
\hline \multirow[t]{2}{*}{ July 6, 2011} & Rain Gauge & 1.5 & 0.1 & 3.3 \\
\hline & JTNP ZR & 2.22 & 0.21 & 2.04 \\
\hline \multirow[t]{2}{*}{ July 30, 2011} & Rain Gauge & 1.6 & 0.3 & \\
\hline & JTNP ZR & 1.45 & 0.86 & \\
\hline \multirow[t]{2}{*}{ July 31, 2011} & Rain Gauge & 2.4 & 15.7 & 2.8 \\
\hline & JTNP ZR & 3.16 & 4.96 & 1.77 \\
\hline \multirow[t]{2}{*}{ September 5, 2011} & Rain Gauge & 0.6 & 3.6 & 0.5 \\
\hline & JTNP ZR & 1.25 & 7.61 & 0.19 \\
\hline \multirow[t]{2}{*}{ September 6, 2011} & Rain Gauge & 0.6 & 4.1 & \\
\hline & JTNP ZR & 1.25 & 6.7 & \\
\hline \multirow[t]{2}{*}{ September 13, 2011} & Rain Gauge & 27.1 & 75.4 & 1.2 \\
\hline & JTNP ZR & 19.71 & 71.17 & 3.02 \\
\hline \multirow[t]{2}{*}{ October 5, 2011} & Rain Gauge & & & 6.9 \\
\hline & JTNP ZR & & & 0 \\
\hline \multirow[t]{2}{*}{ July 4, 2012} & Rain Gauge & & 4 & \\
\hline & JTNP ZR & & 4.53 & \\
\hline \multirow[t]{2}{*}{ July 13, 2012} & Rain Gauge & 0.9 & 2.9 & 6 \\
\hline & JTNP ZR & 3.15 & 3.23 & 5.17 \\
\hline \multirow[t]{2}{*}{ July 14, 2012} & Rain Gauge & & 0.9 & 3 \\
\hline & JTNP ZR & & 2.96 & 1.4 \\
\hline \multirow[t]{2}{*}{ July 30, 2012} & Rain Gauge & & 0.1 & \\
\hline & JTNP ZR & & 0.44 & \\
\hline \multirow[t]{2}{*}{ July 31, 2012} & Rain Gauge & 37.9 & & \\
\hline & JTNP ZR & 12.7 & & \\
\hline \multirow[t]{2}{*}{ August 11, 2012} & Rain Gauge & & & 2 \\
\hline & JTNP ZR & & & 1.98 \\
\hline \multirow[t]{2}{*}{ August 17, 2012} & Rain Gauge & & & 16 \\
\hline & JTNP ZR & & & 29.4 \\
\hline \multirow[t]{2}{*}{ August 22, 2012} & Rain Gauge & 0.3 & & 1.6 \\
\hline & JTNP ZR & 3.28 & & 0.05 \\
\hline
\end{tabular}


Table A-3: Rain Gauge observations compared to precipitation estimates from regional Z-R relationships

\begin{tabular}{|c|c|c|c|c|}
\hline Event Date & Measurement Type & Pw & Cw & $\mathrm{Br}$ \\
\hline \multirow[t]{4}{*}{ August 30, 2008 event a } & Rain Gauge & 13.7 & & \\
\hline & JTNP ZR & 26.2 & & \\
\hline & Arizona ZR & 40.68 & & \\
\hline & NWS ZR & 71.06 & & \\
\hline \multirow[t]{4}{*}{ August 30,2008 event b } & Rain Gauge & 0.2 & & \\
\hline & JTNP ZR & 0.18 & & \\
\hline & Arizona ZR & 0.07 & & \\
\hline & NWS ZR & 0.13 & & \\
\hline \multirow[t]{4}{*}{ September 11, 2008} & Rain Gauge & 2.4 & & \\
\hline & JTNP ZR & 4.46 & & \\
\hline & Arizona ZR & 6.95 & & \\
\hline & NWS ZR & 12.13 & & \\
\hline \multirow[t]{4}{*}{ July 1, 2009} & Rain Gauge & & & 0.2 \\
\hline & JTNP ZR & & & 1.59 \\
\hline & Arizona ZR & & & 1.16 \\
\hline & NWS ZR & & & 2.02 \\
\hline \multirow[t]{4}{*}{ August 22, 2009} & Rain Gauge & 1 & 0.8 & 0.7 \\
\hline & JTNP ZR & 3.28 & 1.7 & 1.05 \\
\hline & Arizona ZR & 2.43 & 0.69 & 0.41 \\
\hline & NWS ZR & 4.25 & 1.22 & 0.72 \\
\hline \multirow[t]{4}{*}{ August 24, 2009} & Rain Gauge & & 0.1 & \\
\hline & JTNP ZR & & 0 & \\
\hline & Arizona ZR & & 0 & \\
\hline & NWS ZR & & 0 & \\
\hline
\end{tabular}


Table A-3: Continued

\begin{tabular}{|c|c|c|c|c|}
\hline Event Date & Measurement Type & Pw & Cw & $\mathrm{Br}$ \\
\hline \multirow[t]{4}{*}{ July 11, 2010} & Rain Gauge & & & 0.2 \\
\hline & JTNP ZR & & & 0.5 \\
\hline & Arizona ZR & & & 0.35 \\
\hline & NWS ZR & & & 0.62 \\
\hline \multirow[t]{4}{*}{ July 15, 2010} & Rain Gauge & & & 4.7 \\
\hline & JTNP ZR & & & 3.66 \\
\hline & Arizona ZR & & & 5.15 \\
\hline & NWS ZR & & & 9 \\
\hline \multirow[t]{4}{*}{ August 25, 2010} & Rain Gauge & & & 6.2 \\
\hline & JTNP ZR & & & 9.1 \\
\hline & Arizona ZR & & & 14.08 \\
\hline & NWS ZR & & & 24.59 \\
\hline \multirow[t]{4}{*}{ August 26, 2010} & Rain Gauge & 6.8 & & \\
\hline & JTNP ZR & 18.9 & & \\
\hline & Arizona ZR & 32.19 & & \\
\hline & NWS ZR & 53.23 & & \\
\hline \multirow[t]{4}{*}{ September 29, 2010} & Rain Gauge & & & 2.5 \\
\hline & JTNP ZR & & & 2.6 \\
\hline & Arizona ZR & & & 2.55 \\
\hline & NWS ZR & & & 4.46 \\
\hline \multirow[t]{4}{*}{ September 30, 2010} & Rain Gauge & & & 0.7 \\
\hline & JTNP ZR & & & 2.24 \\
\hline & Arizona ZR & & & 1.79 \\
\hline & NWS ZR & & & 3.13 \\
\hline \multirow[t]{4}{*}{ October 2,2010 event a } & Rain Gauge & 1.5 & & 1.1 \\
\hline & JTNP ZR & 1.55 & & 0.75 \\
\hline & Arizona ZR & 1.36 & & 0.51 \\
\hline & NWS ZR & 2.38 & & 0.89 \\
\hline \multirow[t]{4}{*}{ October 2,2010 event b } & Rain Gauge & 1.7 & 12.2 & \\
\hline & JTNP ZR & 6 & 9.35 & \\
\hline & Arizona ZR & 6.4 & 11.43 & \\
\hline & NWS ZR & 11.18 & 19.96 & \\
\hline
\end{tabular}


Table A-4: Continued

\begin{tabular}{|c|c|c|c|c|}
\hline Event Date & Measurement Type & Pw & Cw & $\mathrm{Br}$ \\
\hline \multirow[t]{4}{*}{ October 3, 2010} & Rain Gauge & 12.3 & 5.8 & \\
\hline & JTNP ZR & 6.74 & 3.28 & \\
\hline & Arizona ZR & 8.7 & 3.58 & \\
\hline & NWS ZR & 15.19 & 6.24 & \\
\hline \multirow[t]{4}{*}{ July 4, 2011} & Rain Gauge & 6.6 & 0.9 & \\
\hline & JTNP ZR & 6.69 & 1.66 & \\
\hline & Arizona ZR & 8.15 & 1.37 & \\
\hline & NWS ZR & 14.24 & 2.4 & \\
\hline \multirow[t]{4}{*}{ July 6, 2011} & Rain Gauge & 1.5 & 0.1 & 3.3 \\
\hline & JTNP ZR & 2.22 & 0.21 & 2.04 \\
\hline & Arizona ZR & 1.63 & 0.12 & 1.55 \\
\hline & NWS ZR & 2.85 & 0.22 & 2.72 \\
\hline \multirow[t]{4}{*}{ July 30, 2011} & Rain Gauge & 1.6 & 0.3 & \\
\hline & JTNP ZR & 1.45 & 0.86 & \\
\hline & Arizona ZR & 1.05 & 0.64 & \\
\hline & NWS ZR & 1.83 & 1.13 & \\
\hline \multirow[t]{4}{*}{ July 31, 2011} & Rain Gauge & 2.4 & 15.7 & 2.8 \\
\hline & JTNP ZR & 3.16 & 4.96 & 1.77 \\
\hline & Arizona ZR & 2.53 & 7.27 & 1.33 \\
\hline & NWS ZR & 4.43 & 12.71 & 2.33 \\
\hline \multirow[t]{4}{*}{ September 5, 2011} & Rain Gauge & 0.6 & 3.6 & 0.5 \\
\hline & JTNP ZR & 1.25 & 7.61 & 0.19 \\
\hline & Arizona ZR & 2.04 & 6.6 & 0.77 \\
\hline & NWS ZR & 3.57 & 12.71 & 1.34 \\
\hline \multirow[t]{4}{*}{ September 6, 2011} & Rain Gauge & 0.6 & 4.1 & \\
\hline & JTNP ZR & 1.25 & 6.7 & \\
\hline & Arizona ZR & 1.32 & 4.37 & \\
\hline & NWS ZR & 2.3 & 7.64 & \\
\hline \multirow[t]{4}{*}{ September 13, 2011} & Rain Gauge & 27.7 & 75.4 & 1.2 \\
\hline & JTNP ZR & 19.71 & 71.17 & 3.02 \\
\hline & Arizona ZR & 22.71 & 145.1 & 2.03 \\
\hline & NWS ZR & 39.66 & 253.46 & 3.54 \\
\hline
\end{tabular}


Table A-5: Continued

\begin{tabular}{|c|c|c|c|c|c|}
\hline Event Date & Measurement Type & Pw & Cw & $\mathrm{Br}$ & \\
\hline \multirow[t]{4}{*}{ October 5, 2011} & Rain Gauge & & & 6.9 & \\
\hline & JTNP ZR & & & 0 & \\
\hline & Arizona ZR & & & 0 & \\
\hline & NWS ZR & & & 0 & \\
\hline \multirow[t]{4}{*}{ July 4, 2012} & Rain Gauge & & 4 & & \\
\hline & JTNP ZR & & 4.53 & & \\
\hline & Arizona ZR & & 5.08 & & \\
\hline & NWS ZR & & 8.88 & & \\
\hline \multirow[t]{4}{*}{ July 13, 2012} & Rain Gauge & 0.9 & 2.9 & 6 & \\
\hline & JTNP ZR & 3.15 & 3.23 & 5.17 & \\
\hline & Arizona ZR & 1.37 & 3.13 & 6.74 & \\
\hline & NWS ZR & 2.38 & 5.47 & 11.77 & \\
\hline \multirow[t]{4}{*}{ July 14, 2012} & Rain Gauge & & 0.9 & 3 & \\
\hline & JTNP ZR & & 2.96 & 1.4 & \\
\hline & Arizona ZR & & 1.37 & 0.97 & \\
\hline & NWS ZR & & 2.4 & 1.7 & \\
\hline \multirow[t]{4}{*}{ July 30, 2012} & Rain Gauge & & 0.1 & & \\
\hline & JTNP ZR & & 0.44 & & \\
\hline & Arizona ZR & & 0.04 & & \\
\hline & NWS ZR & & 0.08 & & \\
\hline \multirow[t]{4}{*}{ July 31, 2012} & Rain Gauge & 37.9 & & & \\
\hline & JTNP ZR & 12.7 & & & \\
\hline & Arizona ZR & 11.25 & & & \\
\hline & NWS ZR & 19.66 & & & \\
\hline \multirow[t]{4}{*}{ August 11, 2012} & Rain Gauge & & & 2 & \\
\hline & JTNP ZR & & & 1.98 & \\
\hline & Arizona ZR & & & 2.21 & \\
\hline & NWS ZR & & & 3.86 & \\
\hline \multirow[t]{4}{*}{ August 17, 2012} & Rain Gauge & & & 16 & \\
\hline & JTNP ZR & & & 29.4 & \\
\hline & Arizona ZR & & & 55.96 & \\
\hline & NWS ZR & & & 97.7 & \\
\hline \multirow[t]{4}{*}{ August 22, 2012} & Rain Gauge & 0.3 & & 1.6 & \\
\hline & JTNP ZR & 3.28 & & 1.05 & \\
\hline & Arizona ZR & 0.23 & & 0.73 & \\
\hline & NWS ZR & 0.4 & & 1.28 & \\
\hline
\end{tabular}




\section{Appendix C. Python Scripts}

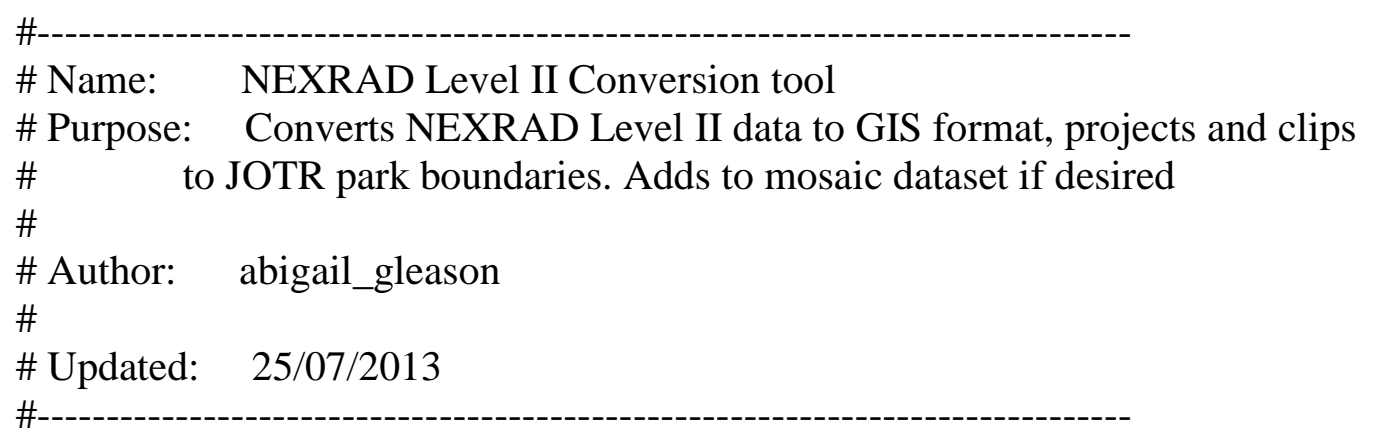

\#\#\#\#\#\#\#\#\#\# import modules/libraries to use

import numpy

import arcpy

from arcpy import env

import sys

import math

import subprocess

\#\#from subprocess import Popen

\#\#import os

\#\#\#\#\#\#\#\#\#\#\#

\#\#\#\#\#\#\#\#\# Get user input for the image to use and other parameters

rainDir $=$ arcpy.GetParameterAsText $(0)$

tiffOutDir $=$ arcpy.GetParameterAsText $(1)$

precipName $=$ arcpy.GetParameterAsText $(2)$

season $=$ arcpy.GetParameterAsText(3)

clip $=$ arcpy.GetParameterAsText(4)

mdOption $=$ arcpy.GetParameterAsText $(5)$

\#set environment workspace to work in that directory

env. workspace $=$ tiffOutDir

\#env.workspace = "in_memory"

arcpy.env.overwriteOutput $=$ True

\#\#\#\#\#\#\#\#\# Calling Weather and Climate Toolkit (WCT) batch decode command line operation.

\#\#\#\#\#\#\#\#\#\# Will work on all images in 'rainDir' and output resulting images in 'rainDir'

print "Converting NEXRAD Level II format. This may take some time."

arcpy.AddMessage("Converting NEXRAD Level II format. This may take some time.") 
subprocess.check_call(r'java -mx850m -Djava.awt.headless=true -jar C:IWCT3.6.6lwct3.6.6 distlwct-3.6.6.jar' + I

" " + rainDir + " " + rainDir + " " + r'tif32 C:IWCT3.6.6lwct-

3.6.6lwctBatchConfig.xml',shell=True)

print "Conversion Complete."

arcpy.AddMessage("Initial conversion complete")

\#\#\#\#\#\#\#\#\#\#

\#\#\#\#\#\#\#\#\# Reading data into memory and displaying properties

print "reading images in directory"

arcpy.AddMessage("Reading images in directory")

\#get a list of all rasters in that directory, should list only .tif images

\# as long as directory on has original files and tif images in there

rasterList $=$ arcpy.ListRasters ()

firstRaster $=$ rasterList $[0]$

\# number of rasters in the directory, to be used later

rasterNum $=$ len(rasterList $)$

rasterDesc $=$ rasterList $[0]$

desc $=$ arcpy.Describe $($ rasterDesc $)$

$\mathrm{sr}=$ desc.spatialReference

print $\mathrm{sr}$

rowNum $=$ desc.height

colNum $=$ desc . width

lowerLeft $=$ desc.Extent.lowerLeft

resX $=$ desc.meanCellWidth

res $\mathrm{Y}=$ desc.meanCellHeight

\#\#print rowNum

\#\#print colNum

\#\#\#\#\#\#\#\#\#\#\#\#\# build empty numpy matrix to hold all rasters as bands

imgImg = numpy.zeros $(($ rasterNum, rowNum, colNum $)$, dtype = numpy.float32 $)$

\#intermediate raster, that can be written out, with precipitation estimates

precipImage $=$ numpy.zeros $(($ rowNum, colNum $)$, dtype $=$ numpy.float 32$)$

\#\#\#\#\#\#\#\#\#\#\#\# Convert dBZ to rainfall rate, build numpy matrix 
print "converting reflectivity dBZ to rainfall rate"

arcpy.AddMessage("Converting reflectivity values to rainfall rate")

\# set up either winter or summer variables

if season $==$ "winter":

$\mathrm{a}=23.8$

$\mathrm{b}=3.17$

$\mathrm{dBa}=10 *($ numpy $\cdot \log 10(\mathrm{a}))$

else:

$$
\begin{aligned}
& \mathrm{a}=365.2 \\
& \mathrm{~b}=1.82 \\
& \mathrm{dBa}=10^{*}(\text { numpy. } \log 10(\mathrm{a}))
\end{aligned}
$$

$\mathrm{i}=0$

for raster in rasterList:

\# convert raster to Numpy array to get at row and col

\# converts background value to 0

\# NOTE: even though I specified "raster in rasterList", rasterList is needed newArray $=$ arcpy.RasterToNumPyArray(rasterList $[\mathrm{i}]$ )

newArray[newArray $<0]=0$

\# loop through rows/colums to evaluate 0 value and calculate new $\mathrm{Rr}$ value \# convert to $\mathrm{dBRr}$ if value is greater than 0 , else keep 0 value for irow in range(rowNum):

for icol in range(colNum):

if newArray[irow,icol] $>0$ :

$\mathrm{dBRr}=($ new Array[irow,icol] $-\mathrm{dBa}) /(\mathrm{b})$

$\mathrm{Rr}=$ numpy.power $(10,(\mathrm{dBRr} / 10))$ else:

$\mathrm{Rr}=0$

\# load values into imgImg matrix

imgImg[i,irow,icol $]=\mathrm{Rr}$

$\mathrm{i}=\mathrm{i}+1$

\# Loop through to get averagae rain estimate over duration of storm for irow in range(rowNum):

for icol in range(colNum):

rateArray = numpy.sum (imgImg[:,irow,icol] $)$

\# NOTE: 13 is the average number of radar images per hour

cellRainTotal $=$ rateArray $/ 13$

\# loading values into PrecipImage array

precipImage $[$ irow, icol $]=$ cellRainTotal 
print "finished calculating rainfall"

arcpy.AddMessage("Finished calculating rainfall")

\#\#\#\#\#\#\#\#\#\#\#\# Convert back to raster from numpy. Project, clip and save

\# convert numpy array back to raster for arcpy operations.

\# These arguments are important - desc.Extent.lowerLeft, resX, resY

precipRaster $=$ arcpy.NumPyArrayToRaster(precipImage, desc.Extent.lowerLeft, resX, resY)

print "converted numpy array to raster"

try:

\# set up file name, define projection and reproject to JOTR standard projection

projName = "in_memory" + "\" + precipName + "_proj"

arcpy.DefineProjection_management(precipRaster, sr)

arcpy.ProjectRaster_management(precipRaster, projName,

arcpy.SpatialReference(26911))

print "project complete"

arcpy.AddMessage("Re-projection complete")

except Exception as e:

arcpy.AddError(e.message)

arcpy.AddError("Projection did not complete")

try:

\# set up clip file name, clip final raster, save as tif

finalName = tiffOutDir + "II" + precipName + ".tif"

clipFeature $=$ clip

arcpy.Clip_management(projName, "\#", finalName, clipFeature, "\#",

"ClippingGeometry")

print "clip complete"

arcpy.AddMessage("Clip complete")

except Exception as e:

arcpy.AddError(e.message)

arcpy.AddError("clip did not complete")

try:

\# add output to mosaic dataset if option has been set to "yes" in user interface

if mdOption == 'true':

arcpy.AddRastersToMosaicDataset_management(r"C:IUserslabigail_gleason.SPATIALVJ

TNP_data\NTP_GDB\JTNP_Precip.gdb\Precip", ।

"Raster Dataset", finalName,"\#","\#","\#","\#","\#","\#","\#","\#","\#", "OVERWRITE_DUPLICATES", "BUILD_PYRAMIDS", । 
"CALCULATE_STATISTICS", "BUILD_THUMBNAILS")

except Exception as e:

arcpy.AddError(e.message)

arcpy.AddError("Could not add to mosaic dataset")

arcpy.Delete_management("in_memory")

print "Finally Finished!!"

arcpy.AddMessage("Finally finished!") 


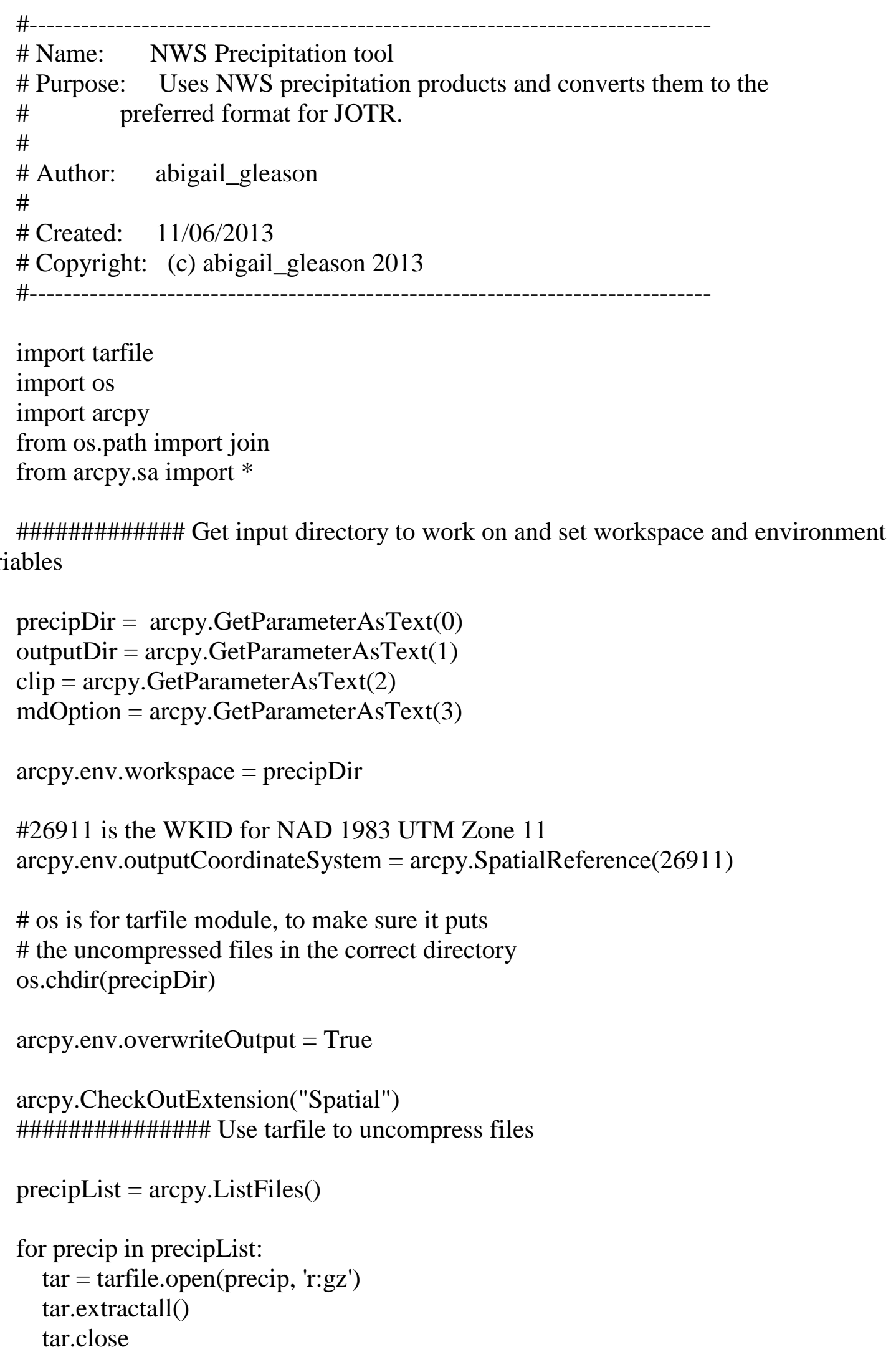

\#\#\#\#\#\#\#\#\#\#\#\# Get input directory to work on and set workspace and environment variables 
\#\#\#\#\#\#\#\#\#\#\#\#\# set up textfile to hold name of datasets without points

file = "NWS_dataset_without_valid_points.txt"

txtPath = join(outputDir, file)

\#\#\#\#\#\#\#\#\#\#\#\#\# Project, clip and convert NWS Precip files to Raster

shpList $=$ arcpy.ListFeatureClasses ()$\quad$ \# should list only. shp files to process

\# clip feature for clip_analysis process

clipFeature $=$ clip

\# set up value field for PointToRaster_conversion process

valueField = "Globvalue"

try:

for shp in shpList:

txtFile = open(txtPath, 'w')

\# set projected output name and reproject

outProj = outputDir + "\" + shp[:-4] + "_proj.shp"

print "projecting dataset"

arcpy.AddMessage("projecting dataset")

arcpy.Project_management(shp, outProj, arcpy.SpatialReference(26911))

\# set clip output name and clip

outClip = outputDir + "\" + shp[:-4] + "_clip.shp"

print "clipping dataset"

arcpy.AddMessage("clipping dataset")

arcpy.Clip_analysis(outProj, clipFeature, outClip)

\# set up new raster name

outRaster $=$ outputDir + "\" + shp[25:-4]

\# check to see if points exist in clip. If so, convert to raster. If not, print message

\# also adds files without valid points to a text file that can be checked

\# later, as well as prints to the screen

numPoints $=$ int(arcpy.GetCount_management(outClip).getOutput(0))

if numPoints $==0$ :

txtFile.write("The dataset " + shp + " does not contain valid points over

JOTR. A rain event may have occured, however. Please check another data source." + 'In')

else:

arcpy.AddMessage("converting rainfall points to raster")

print "converting points to raster"

arcpy.PointToRaster_conversion(outClip, valueField, outRaster, "", "", 4500) 
\# check to make sure new raster exists,

\# convert units from inches to millimeters,

\# set up raster name for tiff conversion

\# then convert output to .tif format

if arcpy.Exists(outRaster):

\# convert units from inches to millimeters

outRaster $=$ arcpy.Raster $($ outRaster $) * 25.4$

outputName = outputDir + "I" + "nws" + shp[25:-4]

outRaster.save(outputName)

\#\# arcpy.Rename_management(outRaster, outputName, "\#")

print "exporting raster to .tif format"

arcpy.RasterToOtherFormat_conversion(outputName, outputDir, "TIFF")

\# add output to mosaic dataset if option has been set to "yes" in user interface

if mdOption == 'true':

print "adding layer to mosaic dataset"

arcpy.AddMessage("adding layer to mosaic dataset")

arcpy.AddRastersToMosaicDataset_management(r"C:IUserslabigail_gleason.SPATIAL J TNP_data\JNTP_GDB\JTNP_Precip.gdb WWSPrecipitation", I

"Raster Dataset", outputName,"\#","\#","\#","\#","\#","\#","\#","\#","\#", "OVERWRITE_DUPLICATES", "BUILD_PYRAMIDS", I

"CALCULATE_STATISTICS", "BUILD_THUMBNAILS")

arcpy.Delete_management(outRaster)

print "deleting intermediate files"

arcpy.Delete_management(outProj)

arcpy.Delete_management(outClip)

except Exception as e:

print e

arcpy.AddError(e.message)

arcpy.AddError("File not converted")

with open("NWS_dataset_without_valid_points.txt", "r") as missing:

data = missing.read().replace('ln', "")

print data

arcpy.AddMessage(data)

txtFile.close()

arcpy.AddMessage("Process complete") 


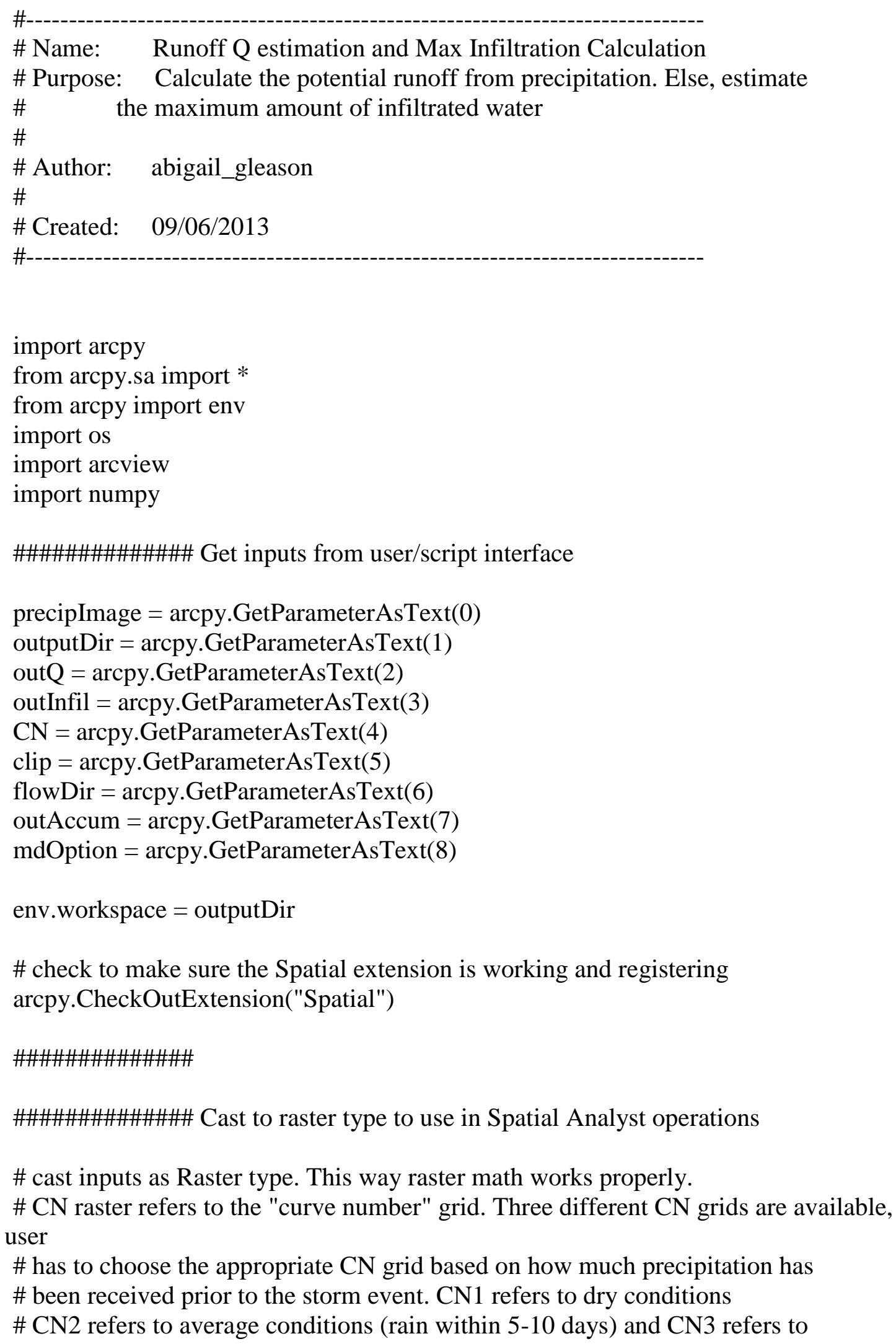


\# wet conditions

precip $=$ arcpy.Raster $($ precipImage $)$

CNraster $=$ arcpy.Raster $(\mathrm{CN})$

print"Rasters ready"

\#\#\#\#\#\#\#\#\#\#\#\#\#\#\#\#\#\#\#\#\#\#\#\#\#\#\#\#\# Initial calculations with rasters

\# convert precipitation to inches using conversion 1 inch $=25.4 \mathrm{~mm}$

\# the method used to convert precipitation to runoff requires inches

precipIn $=$ precip $/ 25.4$

print "precipitation converted to inches"

arcpy.AddMessage("precipitation converted to inches")

\# calculate maximum retention, $\mathrm{S}$, based on $\mathrm{CN}$ grid choice

$\max \operatorname{RetenS}=(1000 /$ CNraster $)-10$

\# calculate precip and Initial Abstraction difference

intermed $=$ precipIn $-(0.2 * \max$ RetenS $)$

intermed $2=$ precipIn $+(0.8 *$ maxRetenS $)$

\#\#\#\#\#\#\#\#\#\#\# raster information to get consisten row/column information

\# Get basic Raster info

rasterDesc $=$ intermed

rasterDescPrecip $=$ precipImage

descIntermed $=$ arcpy.Describe $($ rasterDesc $)$

descPrecip $=$ arcpy.Describe $($ rasterDescPrecip $)$

$\mathrm{sr}=$ descPrecip.spatialReference

rowNum $=$ descIntermed .height

colNum $=$ descIntermed. width

lowerLeft $=$ descIntermed.Extent.lowerLeft

resX $=$ descIntermed.meanCellWidth

resY $=$ descIntermed.meanCellHeight

\#\#\#\#\#\#\#\#\#\# Raster to NumPy arrays.

\# converting rasters to numpy arrays

iArray $=$ arcpy.RasterToNumPyArray(intermed)

i2Array = arcpy.RasterToNumPyArray(intermed2)

precipArray $=$ arcpy.RasterToNumPyArray (precipIn)

print "raster to numpy array complete"

\#\#\#\#\#\#\#\#\#\# Create two new arrays to hold runoff and ground water

$\mathrm{Q}=$ numpy.zeros $($ (rowNum, colNum $)$, dtype=numpy.float32) 
$\mathrm{gWater}=$ numpy.zeros $(($ rowNum, colNum $), \mathrm{dtype}=$ numpy.float32 $)$

\section{\#\#\#\#\#\#\#\#\#\#\#}

print "Calculating runoff and maximum ground water recharge" arcpy.AddMessage("Calculating runoff and maximum water infiltration") \# calculate potential runoff $(\mathrm{Q})$ and potential water infiltration

for irow in range(rowNum):

for icol in range(colNum):

if iArray[irow, icol] $>0$ :

$\mathrm{Q}[$ irow, icol $]=\left((\text { iArray }[\text { irow }, \text { icol }])^{* * 2}\right) /($ i2Array $[$ irow, icol $])$

$\mathrm{gWater}[$ irow, icol] $=$ precipArray[irow, icol $]-\mathrm{Q}[$ irow, icol $]$ else:

$\mathrm{Q}[$ irow, icol $]=0$

$\mathrm{gWater}[\mathrm{irow}, \mathrm{icol}]=$ precipArray[irow, icol $]$

print "Calculation complete"

arcpy.AddMessage("Calculation complete")

\#\#\#\#\#\#\#\#\#\#\#\# convert NumPy arrays into rasters

\# convert numpy array back to raster for arcpy operations. The lowerLeft, \# resX and resY parameters are important

$\mathrm{gWaterRaster}=$ arcpy.NumPyArrayToRaster(gWater, lowerLeft, resX, resY)

$\mathrm{QRaster}=\operatorname{arcpy}$.NumPyArrayToRaster(Q, lowerLeft, resX, resY)

print "converted numpy array to raster"

\#\#\#\#\#\#\#\#\#\#\# for infiltration (gwater), project and clip, write out

try:

\# set up file name, define projection and reproject to JOTR standard projection

projName = "in_memory" + "\" + outInfil + "_proj"

arcpy.DefineProjection_management(gWaterRaster, sr)

arcpy.ProjectRaster_management $(\mathrm{gWaterRaster}$, projName,

arcpy.SpatialReference(26911))

print "project complete"

arcpy.AddMessage("water infiltration projected")

\# set up clip file name, clip final raster, save as tif

clipName = outputDir + "\\" + outInfil + ".tif"

clipFeature $=$ clip

arcpy.Clip_management(projName, "\#", clipName, clipFeature, "\#", "ClippingGeometry") 
print "clip complete"

arcpy.AddMessage("water infiltration clipped")

except Exception as e:

arcpy.AddError(e.message)

arcpy.AddError("water infiltration failed to write out")

arcpy.AddMessage("water infiltration raster complete")

\#\#\#\#\#\#\#\#\#\#\#\# for $\mathrm{Q}$ raster, test valid points, then project, clip, write out

QMax = arcpy.GetRasterProperties_management(QRaster, "MAXIMUM")

QMaxValue = float $($ QMax.getOutput $(0))$

if QMaxValue $==0$ :

arcpy.AddMessage("this precipitation event did not produce runoff") else:

try:

\# set up file name, define projection and reproject to JOTR standard projection

qProjName = "in_memory" + "\" + outQ + "_proj"

arcpy.DefineProjection_management(QRaster, sr)

arcpy.ProjectRaster_management(QRaster, qProjName,

arcpy.SpatialReference(26911))

print "project complete"

arcpy.AddMessage("runoff projected")

\# set up clip file name, clip final raster, save as tif

qClipName = outputDir + "\" + outQ + ".tif"

qClipFeature $=$ clip

arcpy.Clip_management(qProjName, "\#", qClipName, qClipFeature, "\#",

"ClippingGeometry")

print "clip complete"

arcpy.AddMessage("runoff clipped")

except Exception as e:

arcpy.AddError(e.message)

arcpy.AddError("runoff raster failed to write out")

\#\#\#\#\#\#\#\#\#\#\#\#\#\#\#\#\#\# if Q raster has valid points, make accumulation output

\#\#\#\#\#\#\#\#\#\#\#\#\#\#\#\#\#\# Optionally, this block could be commeted out and a model used

try:

print "working on resample"

arcpy.AddMessage("working on resample for accumulation process")

runoffResample =outputDir + "II" + "resamp"

"BILINEAR")

arcpy.Resample_management(qClipName, runoffResample, "5 5",

memCon 1 = Con(runoffResample, runoffResample, "", "VALUE > 0") 
print "extracting flow direction"

arcpy.AddMessage("extracting flow direction")

extractFlowDir = ExtractByMask(flowDir, memCon1)

print "performing flow accumulation"

arcpy.AddMessage("performing flow accumulation")

arcpy.AddMessage("performing flow accumulation")

flowAcc = FlowAccumulation (extractFlowDir, memCon1, "FLOAT")

print "flow accumulation complete"

arcpy.AddMessage("flow accumulation complete")

calc $=$ flowAcc $* 0.0224$

memCon 2 = Con (calc, calc, "0", "VALUE > 0.1")

accumName = outputDir + "\" + outAccum + ".tif"

print "saving output"

arcpy.AddMessage("saving accumulated output")

memCon2.save(accumName)

arcpy.AddMessage("accumulation process complete")

except Exception as e:

arcpy.AddError(e.message)

arcpy.AddError("Accumulated runoff process did not complete")

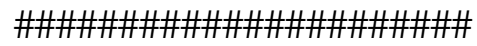

print "adding layers to mosaic datasets"

try:

\# add output to infiltation mosaic dataset if option has been set to "yes" in user interface

if mdOption == "true":

arcpy.AddRastersToMosaicDataset_management(r"C:IUserslabigail_gleason.SPATIAL\J TNP_data\JNTP_GDB\JTNP_Precip.gdb\nfiltrationGrids", ।

"Raster Dataset", clipName,"\#","\#","\#","\#","\#","\#","\#","\#","\#",

"OVERWRITE_DUPLICATES", "BUILD_PYRAMIDS", ।

"CALCULATE_STATISTICS", "BUILD_THUMBNAILS")

except Exception as e:

arcpy.AddError(e.message)

arcpy.AddError("Could not add to water infiltration mosaic dataset")

try:

\# add output to runoff mosaic dataset if option has been set to "yes" in user interface

if mdOption == "true":

arcpy.AddRastersToMosaicDataset_management(r"C:IUserslabigail_gleason.SPATIALVJ

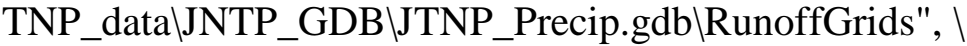


"Raster Dataset", qClipName,"\#","\#","\#","\#","\#","\#","\#","\#","\#", "OVERWRITE_DUPLICATES", "BUILD_PYRAMIDS", ।

"CALCULATE_STATISTICS", "BUILD_THUMBNAILS")

except Exception as e:

arcpy.AddError(e.message)

arcpy.AddError("Could not add to runoff mosaic dataset")

try:

\# add output to accumulated runoff mosaic dataset if option has been set to "yes" in user interface

if mdOption == "true":

arcpy.AddRastersToMosaicDataset_management(r"C:IUserslabigail_gleason.SPATIALIJ TNP_datalJNTP_GDB JTNP_Precip.gdb\AccumulatedRunoff", I

"Raster Dataset", accumName,"\#","\#","\#","\#","\#","\#","\#","\#","\#", "OVERWRITE_DUPLICATES", "BUILD_PYRAMIDS", ।

"CALCULATE_STATISTICS", "BUILD_THUMBNAILS")

except Exception as e:

arcpy.AddError(e.message)

arcpy.AddError("Could not add to accumulated runoff mosaic dataset")

arcpy.Delete_management("in_memory")

arcpy.Delete_management(runoffResample)

arcpy.Delete_management(memCon1)

arcpy.Delete_management(extractFlowDir)

arcpy.Delete_management(flowAcc)

arcpy.Delete_management(calc)

arcpy.Delete_management(precipIn)

arcpy.Delete_management(maxRetenS)

arcpy.Delete_management(intermed)

arcpy.CheckInExtension("Spatial")

print "finished"

arcpy.AddMessage("process complete") 